\title{
Computer-Guided Total Synthesis of Natural Products. Recent Examples and Future Perspectives
}

\author{
Franco Della-Felice, ${ }^{a}$ Ronaldo A. Pilli ${ }^{*, a}$ and Ariel M. Sarotti ${ }^{*, b}$ \\ ${ }^{a}$ Instituto de Química, Universidade de Campinas, CP 6154, 13084-971 Campinas-SP Brazil \\ ${ }^{b}$ Instituto de Química Rosario, Facultad de Ciencias Bioquímicas y Farmacéuticas, \\ Universidad Nacional de Rosario-CONICET, Suipacha 531, S2002LRK, Rosario, Argentina
}

\begin{abstract}
Quantum chemical calculations of nuclear magnetic resonance (NMR) shifts and coupling constants have been extensively employed in recent years mainly to facilitate structural elucidation of organic molecules. When the results of such calculations are used to determine the most likely structure of a natural product in advance, guiding the subsequent synthetic work, the term "computer-guided synthesis" could be coined. This review article describes the most relevant examples from recent literature, highlighting the scope and limitations of this merged computational/experimental approach as well.
\end{abstract} GIAO

Keywords: total synthesis, natural products, NMR calculations, computational chemistry,

\section{Introduction}

The discovery of natural products with challenging structures and promising biological activities has been a pervasive theme of scientific research, substantially impacting different areas of chemistry, biology and medicine. ${ }^{1}$ Much of our current knowledge in spectroscopy, chromatography, and other instrumental analysis techniques are largely the result of development related to the isolation, purification and structural determination of natural products. In addition, the need of novel and efficient strategies to synthesize natural products has allowed modern organic chemistry to cross limits unsuspected a few decades ago.

One of the most critical aspects related to the natural products discovery is the determination of their tridimensional structures, highly correlated with the corresponding chemical and biological properties. Nowadays, structural elucidation of natural products

*e-mail: pilli@iqm.unicamp.br; sarotti@iquir-conicet.gov.ar The authors dedicate this work to Clayton H. Heathcock, emeritus professor at University of California, Berkeley, for his outstanding contributions to the art of total synthesis of natural products. One of the authors (R. A. P.) is particularly grateful for being part of his research group from 1982-84 and share his generosity and commitment in mentoring new generations of synthetic organic chemists.

This paper is part of the PubliSBQ Special Issue "IUPAC-2017" (http://publi.sbq.org.br/). relies heavily on nuclear magnetic resonance (NMR) spectroscopy, and impressive advances have been made in this field. ${ }^{2}$ For instance, apart from the now classical through-bond correlation spectroscopy (COSY), total correlation spectroscopy (TOCSY), heteronuclear singlequantum correlation spectroscopy (HSQC), heteronuclear multiple-bond correlation spectroscopy (HMBC) and through-space nuclear Overhauser effect spectroscopy (NOESY), rotating frame nuclear Overhauser effect spectroscopy (ROESY) correlations, other exciting methods are gaining popularity, including 1,1 and 1,n-ADEQUATE ${ }^{3}$ and Pure-Shift ${ }^{4}$ methodologies. In addition, the possibility to perform NMR experiments in anisotropic media allows the exploration of interesting interactions, such as residual dipolar couplings (RDCs) and residual chemical shift anisotropy (RCSAs), which can be highly valuable for structural determination purposes. ${ }^{5}$ The use of computerassisted structural elucidation (CASE) programs has been significantly helpful to handle information provided by different NMR experiments and transform it into a plausible $2 \mathrm{D}$, or even $3 \mathrm{D}$, structure. ${ }^{6}$

All in all, NMR spectroscopy has advanced to such a stage that nowadays we can routinely run NMR experiments that would have been unthinkable some years ago. Such progress has made the scientific community overconfident of structural assignments made exclusively on the basis of NMR data, forgetting somehow the deductive nature of 
these techniques. That is, indirect evidence is transformed into a tridimensional molecular architecture following a series of deductive reasoning generally made by humans. Therefore, misinterpretation of NMR data can never be completely ruled out, and when coupled with sample impurities, signal ambiguities, high molecular complexity, and other sources of confusion may lead to structural misassignments. ${ }^{7}$ The best proof of this is the large number of natural products that have been incorrectly assigned in the recent past, with sources of errors ranging from subtle (stereochemical) to gross (connectivity). ${ }^{7,8}$ On the other hand, although crystallographic analysis of natural products offers one of the most accurate and irrefutable data for their structural assignment such experiments are not always possible. In addition, while rare, there have been cases of structural misassignments even with X-ray data available. ${ }^{7,9}$

Typically, structural misassignment cases are detected once the synthesis of the originally proposed structure is achieved. Several review articles have been written in this regard during the last decade, highlighting the role of total synthesis to settle structural issues. ${ }^{7}$ Naturally, thinking this beautiful discipline as a mere source of structural integrity is somehow inappropriate, but due to the current state of the art of NMR spectroscopy, it still provides (and will surely do in the near feature) the final proof in structural assignment of natural products.

It is well known that total synthesis of natural products is a complex field, often fraught with difficulties and detours. ${ }^{10}$ Hence, if there is sufficient cause to suspect that a structural misassignment has occurred, having additional certainty on the target structure to be synthesized in the first place would significantly reduce time, money and manpower required to succeed. A similar situation occurs when the originally proposed structure of a natural product is found incorrect by a previous synthetic work (but the real structure remains unknown), or when the isolation team actually recognizes the impossibility to irrefutably determine the structure at certain part of the molecule.

As it is frequently the case that authentic samples of the natural product are unavailable to synthetic chemists for further analysis (more refined NMR techniques, derivatization experiments, etc), quantum chemical calculations of NMR properties emerge as a powerful and simple option to shed light on structural or stereochemical issues. ${ }^{11}$ The high accuracy provided by quantum chemically computed NMR shifts and coupling constants has been extensively employed in recent years to facilitate the determination of the tridimensional structure of a wide variety of organic molecules. Since the seminal reports of Bagno et al. ${ }^{12}$ and Bifulco and co-workers, ${ }^{12}$ the use of NMR calculations in structural organic chemistry have been widely spread. Extensive work by several research teams have been conducted to study different aspects of NMR calculations, ${ }^{13}$ and excellent reviews were published covering the state of the art of this discipline. ${ }^{11}$

Apart from the choice of the level of theory to be employed in NMR calculation procedure, another critical aspect for structural elucidation purposes is the strategy to correlate the results of such calculations with the available experimental data, in order to manage the judgment action (for instance, decide the most likely structure of a given molecule). Naturally, all the different approaches share the same premise that the correct structure is expected to show a better match between experimental and simulated NMR data, but the differences between them arise on how such agreement is computed. For example, simple and easy-tocompute statistical parameters of correlation have been typically used to quantify the goodness of fit between different candidate structures. Among them, correlation coefficient $\left(\mathrm{R}^{2}\right)$ values, mean absolute error (MAE), corrected mean absolute error (CMAE) and maximum errors represent the most common parameters. ${ }^{11}$ More recently, new and sophisticated procedures to correlate experimental and calculated NMR data were introduced to increase the level of confidence and facilitate the structural assignment in different scenarios. For instance, the Goodman's CP3 parameter was thought to assign two sets of experimental NMR data to two plausible structures, ${ }^{14}$ whereas the DP4 probability was created by the same group to determine the most likely structure when only one set of experimental NMR data is available..$^{15}$ This last method, and the updated version DP4+ developed by the Sarotti and co-workers, ${ }^{16}$ are among the most popular strategies to unravel the tridimensional structure of elusive molecules otherwise difficult to assign. The use of artificially-created neural networks to detect structural and/or stereochemical misassignments using pattern recognition analysis from the correlation of only one set of both experimental and calculated data (ANN-PRA method) ${ }^{17}$ completes the set of more elaborate alternatives to facilitate the decision making process. ${ }^{11}$

On the basis of the above said, it is not surprising that quantum chemical calculations of NMR properties have been widely adopted as a simple and powerful alternatives for structural elucidation. ${ }^{18}$ When the results of such calculations are used to determine the most likely structure of a natural product in advance, guiding the subsequent synthetic work, the term "computer-guided synthesis" could be coined. In this review article, the scope and limitations of this merged computational-experimental approach towards the total synthesis of natural products will be assessed with the discussion of recent examples from literature. In this regard, two different scenarios can 
be identified. In one case, the computational simulations are carried out by the same group (or as part of a collaboration) which is actually interested in deducing the most likely structure of a natural product to be synthesized first. On the other hand, the computational work might be done as part of a standard structural elucidation process but with no immediate purposes of validating such predictions experimentally, later conducted by the same or most typically by another research group. Despite in both cases the computational simulations end up guiding the synthetic work, strictly speaking only the former should be termed "computer-guided total synthesis". Nevertheless, both types of studies have been considered and will be discussed in the present review article.

\section{Cernupalhine A}

Cernupalhine A was isolated in 2014 by Zhao and co-workers ${ }^{19}$ from Palhinhaea cernua $\mathrm{L}$. The planar structure $\mathbf{1}$ of this trace Lycopodium alkaloid (Scheme 1), bearing a $\mathrm{C}_{17} \mathrm{~N}$ skeleton and an unusual hydroxydihydrofuranone moiety was determined from high-resolution electrospray ionization mass spectrometry (HRESIMS), ${ }^{1} \mathrm{H}$ NMR,${ }^{13} \mathrm{C}$ NMR, DEPT, COSY and HMBC experiments. Given that lycoflexine (2, a known $\mathrm{C}_{17} \mathrm{~N}$ alkaloid) had been previously isolated from the same source, ${ }^{20}$ the authors hypothesized that $\mathbf{1}$ could biosynthetically arise from $\mathbf{2}$ following the path shown in Scheme 1.
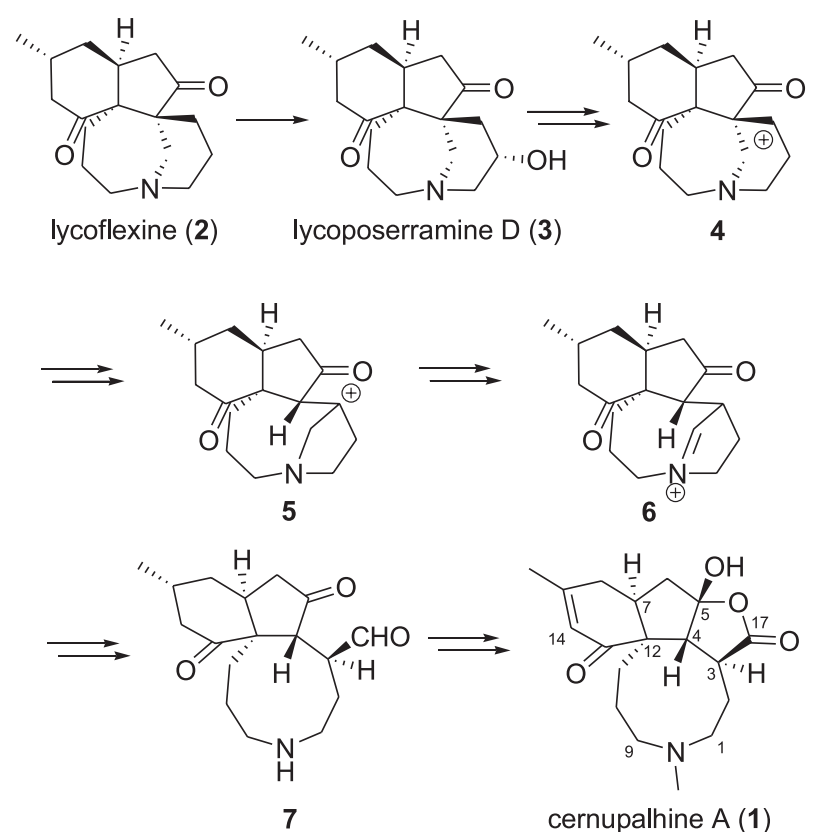

cernupalhine $A(1)$

Scheme 1. Biogenetic pathway proposed for cernupalhine A (1).

From this biosynthetic viewpoint, the relative configurations at C-7 and C-12 should be $7 S^{*}$ and $12 S^{*}$.
Hence, the observation of through-space correlations between $\mathrm{H}-7$ with $\mathrm{H}-3$ or $\mathrm{H}-4$ would provide insightful evidence to settle the configurations at C-3, C-4 and C-5. However, ROESY experiments did not afford the expected results, since the key H-7 signal was partially overlapped with $\mathrm{H}-2 \mathrm{a}, \mathrm{H}-9 \mathrm{a}$ and $\mathrm{H}_{3} \mathrm{C}-18$, and consequently, hampered the configurational analysis discussed above. Moreover, despite H-4 showed ROESY correlation with $\mathrm{H}-2 \mathrm{a}$ (indicating a cofacial relationship between both protons), similar interactions were noticed for $\mathrm{H}-3$ and H-4 with H-1a, H-10b and H-11. Such inconsistencies, coupled with the small amount of isolated sample $(0.7 \mathrm{mg})$ and the impossibility to obtain suitable crystals for X-ray analysis, precluded the unambiguous elucidation of the tridimensional structure of the natural product. ${ }^{19}$

Therefore, the authors decided to settle the real structure of cernupalhine A by asymmetric total synthesis of the natural product. However, given the unassigned stereochemistry of the target, they conducted density functional theory (DFT) calculations of NMR shifts to suggest the most likely structure to be further synthesized. The NMR calculations of all plausible 16 diastereoisomers were carried out at the PCM/mPW1PW91/6-311+G(2d,p)// B3LYP/6-31+G** level of theory, and after correlating the experimental and simulated data using DP4, isomer $\mathbf{1}$ was identified as the most likely candidate in high probability (> 99\%). Interestingly, this structure was totally consistent with the suggested biosynthetic proposal, providing further confidence in the assignment. With these results in hand, the authors next designed and carried out the total synthesis of the computationally-selected isomer starting from advanced intermediate 8 (Scheme 2). Using a stereospecific $\alpha$-epoxidation followed by ring-opening to furnish allyl alcohol 9, and the regio- and stereoselective cyanide ion addition as key synthetic stages, the total synthesis of $\mathbf{1}$ was accomplished. A nice match between the NMR signals of synthetic and isolated samples allowed the final proof to settle the structure of $\mathbf{1}$, in excellent agreement with the computational findings. ${ }^{19}$

\section{Cryptomoscatone E3}

In 2010, Cavalheiro and Yoshida ${ }^{21}$ isolated eleven structurally related 6-[ $\omega$-arylalkenyl]-5,6-dihydro- $\alpha$-pyrones from the branch and steam bark of Cryptocarya moschata, a Brazilian tree, and named them cryptomoscatones D2, E1, E2, E3 and F1, and cryptopyranmoscatones A1, A2, A3, B1, B2 and B4. The structures of all these compounds were established by standard spectroscopic methods. In the particular case of cryptomoscatone E3 (11, Figure 1), the absolute configuration at C-6 was settled as $R$ by a positive 

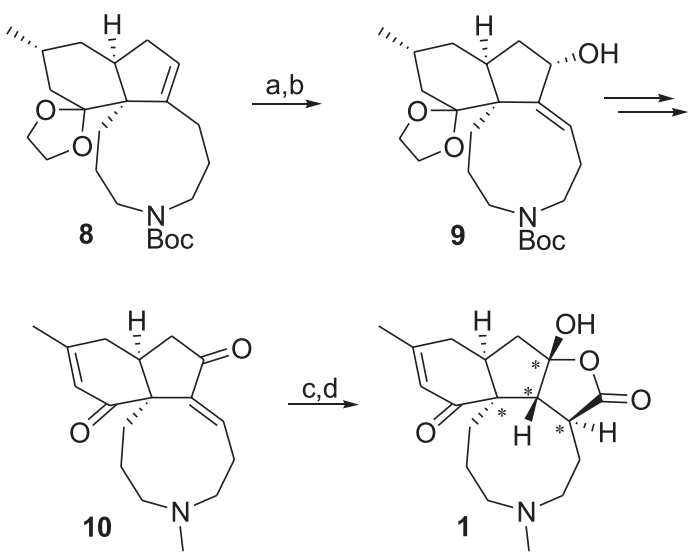

Scheme 2. Total synthesis of cernupalhine A (1). Selected reagents and conditions: (a) 3-chloroperbenzoic acid ( $m$-CPBA), $\mathrm{NaHCO}_{3}$, dichloromethane (DCM) (60\%, dr 10:1); (b) $1 \mathrm{M} \mathrm{HCl}$, THF (85\%); (c) $\mathrm{KCN}, \mathrm{MeCN} / \mathrm{H}_{2} \mathrm{O}(52 \%)$; (d) $6 \mathrm{M} \mathrm{HCl}$, reflux $(80 \%)$. The carbon atoms that were varied to generate the candidate isomers of $\mathbf{1}$ for NMR calculations are marked with an asterisk.

Cotton effect observed in the circular dichroism (CD) spectra, and the relative configuration at the stereotriad at the side chain was suggested as threo/erythro from comparison of the ${ }^{13} \mathrm{C}$ NMR shifts obtained for $\mathbf{1 1}$ with those collected for two analogs. However, in the manuscript a relative $8 S, 10 R, 12 R$ configuration for cryptomoscatone $\mathrm{E} 3$ was shown, which is in contrast to the threo/erythro analysis. In addition to this contradiction, the connection between the two stereoclusters configuration of the molecule (the $\mathrm{C}-8 / \mathrm{C}-12$ stereotriad and C-6 of the lactone) could not be carried out. ${ }^{21}$

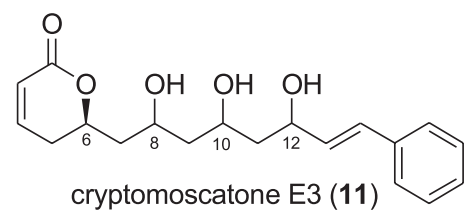

Figure 1. Plane structure of cryptomoscatone E3.

As part of an ongoing interest in the total synthesis and structural elucidation of natural products bearing the 5,6-dihydropyran-2-one motif, ${ }^{22}$ Pilli and co-workers ${ }^{23}$ tackled the cryptomoscatone E3 case. Given the inconsistencies discussed above regarding the structure of the natural product, and in order to avoid the synthesis of all plausible isomers, a computer-guided total synthesis approach was conducted. Hence, in collaboration with Sarotti, the NMR shifts of all possible eight diastereoisomers were computed at the B3LYP/6-31G**// MMFF level of theory (also known as MMFF94), the recommended for DP4 calculations. The combined DP4 probabilities (proton and carbon data) suggested that isomers $6 R, 8 R, 10 R, 12 R(74 \%)$ and $6 R, 8 S, 10 S, 12 S(24 \%)$ were the most likely ones. Interestingly, both compounds featured the same relative configuration at the stereotriad (anti/syn) but with the exact opposite configurations at those centers. Despite the all- $R$ diastereoisomer was identified in higher probability, the NMR calculations were repeated after optimizing all significantly populated conformations at the B3LYP/6-31G* level in order to strengthen the confidence in the computational stereoassignment. With these new theoretical NMR data in hand, the DP4 calculations strongly supported isomer $6 R, 8 R, 10 R, 12 R$ in high confidence (>99\%, Figure 2). ${ }^{23}$

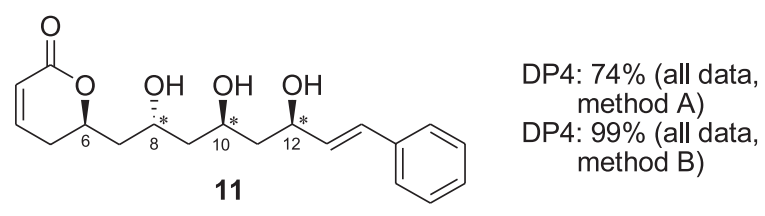

Figure 2. Most likely structure of cryptomoscatone E3 according to NMR calculations. The carbon atoms that were varied to generate the candidate isomers of $\mathbf{1 1}$ are marked with an asterisk. The NMR calculations of the resulting eight diastereoisomers were carried out at the B3LYP/6-31G**// MMFF (method A) and B3LYP/6-31G**//B3LYP/6-31G* (method B) levels of theory.

With these theoretical results, the authors next designed and carried out the total synthesis of the most likely structure of cryptomoscatone E3. After some detours typically encountered in the elaboration of complex molecules, the target was successfully accomplished as summarized in Scheme 3. Asymmetric Keck allylation allowed the transformation of $\mathbf{1 2}$ into 13, which was easily transformed into aldehyde $\mathbf{1 4}$. Next, a key $\mathrm{BF}_{3} \cdot \mathrm{OEt}_{2}$-promoted Mukaiyama aldol reaction with silyl enol ether $\mathbf{1 5}$ furnished the desired anti aldol product 16. Stereoselective 1,3-syn reduction of the ketone group of 16 with $\mathrm{Et}_{2} \mathrm{BOMe}$ and $\mathrm{LiBH}_{4}$ followed by protection of the resulting diol and selective deprotection of the primary alcohol generated acetonide 17. Dess-Martin oxidation and Brown asymmetric allylation introduced the desired $R$ configuration at C-6 (cryptomoscatone E3 numbering) in 18. To elaborate the six-membered lactone, the secondary alcohol 18 reacted with acryloyl chloride and the resulting diene 19 was submitted to a ring-closing metathesis (RCM) reaction to furnish the final product after final deprotection steps. Noteworthy, all spectroscopic data of synthetic cryptomoscatone E3 nicely matched those reported for the natural product, in good agreement with the computational predictions. ${ }^{23}$

\section{Cryptoconcatone $\mathrm{H}$}

The story behind the cryptoconcatone $\mathrm{H}$ case reflects, at the same time, the strengths and limitations of quantum chemical calculations of NMR shifts in 


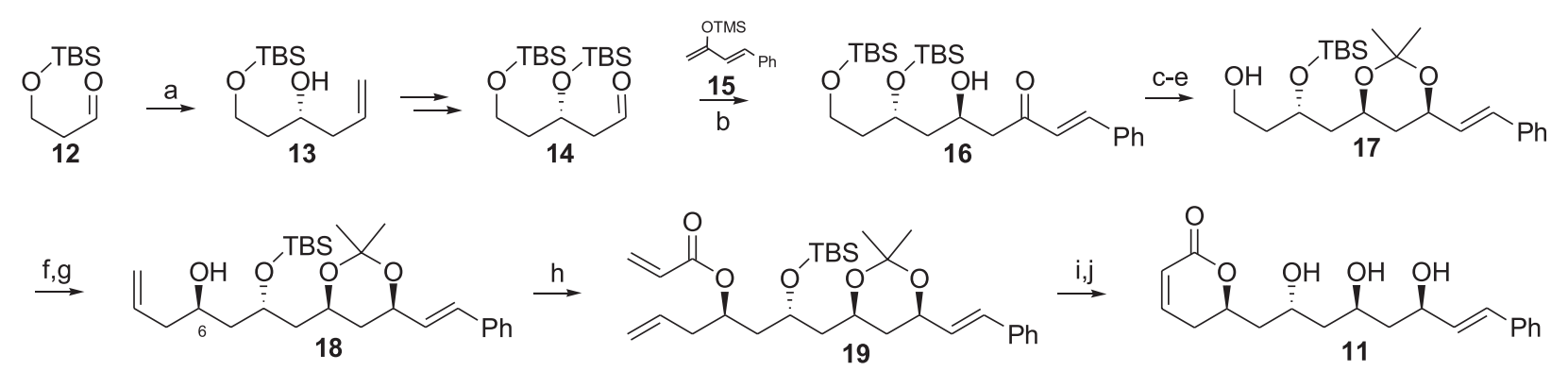

Scheme 3. Total synthesis of cryptomoscatone E3. Selected reagents and conditions: (a) Ti(OiPr) $4(10 \mathrm{~mol} \%),(R)-1,1$ '-bi-2-naphthol (BINOL) (20 mol\%),

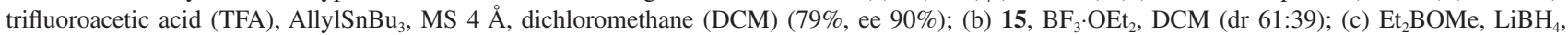
tetrahydrofuran (THF), $\mathrm{MeOH}$ (71\%, two steps); (d) $\mathrm{Me}_{2} \mathrm{C}(\mathrm{OMe})_{2}$, pyridinium $p$-toluene sulfonate (PPTS) (97\%); (e) hydrogen fluoride pyridine (HF-Py), Py, THF (72\%); (f) Dess-Martin periodinane, DCM; (g) (+)-Ipc 2 BAllyl, THF (70\%, two steps; dr > 95:5); (h) acryloyl chloride, $N, N$-diisopropylethylamine (DIPEA), DCM, $0{ }^{\circ} \mathrm{C}(83 \%)$; (i) Grubbs I, DCM (88\%); (j) HCl, THF (90\%).

structural elucidation of complex natural products. In 2016, Luo and co-workers ${ }^{24}$ reported the isolation and structural elucidation of eight $\alpha, \beta$-unsaturated- $\delta$-lactones and two $\alpha, \beta$-unsaturated- $\gamma$-lactones from the leaves and twigs of Cryptocarya concinna. Some of the isolated compounds showed promising anti-inflammatory activity evaluated by NO production (3-8 $\mu \mathrm{M})$. The structures of these compounds were proposed after extensive 1D and 2D NMR experiments, coupled with Riguera and coworkers ${ }^{25}$ chemical derivatization method to determine absolute configuration, and the Snatzke ${ }^{26}$ chirality rule. In particular, for the elucidation of cryptoconcatone $\mathrm{H}$ (Figure 3), the authors suggested the absolute configuration at C-6 as $R$ from a positive Cotton effect at 250-272 nm in the electronic circular dichroism (ECD) spectrum, and C-4' as $S$ from the modified Mosher's method. Next, ROESY correlations between $\mathrm{H}-2^{\prime} / \mathrm{H}-4$ ' and $\mathrm{H}-4^{\prime} / \mathrm{H}-6^{\prime}$ allowed to settle the configurations at the remaining centers (C-2' and C-6'). Noteworthy, the absolute configurations at the tetrahydropyran (THP) ring in $\mathbf{2 0}$ are exactly opposite than those suggested for the side chain in cryptoconcatone D (21), even when both natural products were isolated from the same source and might share the same biosynthetic path.
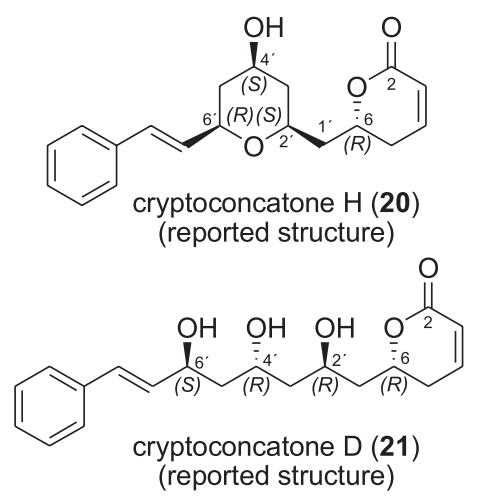

Figure 3. Originally proposed structures 20 and 21 for cryptoconcatones $\mathrm{H}$ and $\mathrm{D}$, respectively.
Intrigued by this observation, and given the restless effort in contributing to the stereochemical assignment of natural products displaying the dihydropyranone scaffold, Pilli and co-workers ${ }^{27}$ became interested in conducting the first total synthesis of cryptoconcatone $\mathrm{H}$ using a computer-guided approach. In collaboration with Sarotti, the NMR shifts of all eight diastereoisomers candidates resulting from the systematic variation of the relative configurations at the THP ring while keeping constant the configuration at C- 6 as $R$ were computed at the PCM/ mPW1PW91/6-31+G**//B3LYP/6-31G* after exhaustive conformational sampling, and were further correlated with the experimental shifts of natural cryptoconcatone $\mathrm{H}$ using DP4+. Interestingly, the calculation results did not include isomer $\mathbf{2 0}$ among the most likely candidates, but instead, it was placed in the seventh position (in other words, the originally proposed structure was the second less probable candidate structure). On the other hand, the isomers bearing the same cis/trans relative stereochemistry at the THP ring (compounds $\mathbf{2 2}$ and $\mathbf{2 3}$, Figure 4) were identified as the most probable structures for the natural product, being the former strongly supported from DP4+ calculations (99.9\%) when using the full NMR dataset. Given the known tendency of DP4 (or DP4+) to overstate the probability rates, and considering that the two stereoclusters of the molecule are separated by a rotating methylene group, the authors recomputed the DP4+ values with only the NMR shifts of the most relevant region of the molecule (THP ring). In this case, the preference towards $\mathbf{2 2}$ considerably narrowed down (53\% for $\mathbf{2 2}, \mathbf{4 7 \%}$ for $\mathbf{2 3}$ ), though the low probability associated to the remaining six candidates remained almost unchanged $(<0.1 \%)$.

Encouraged by this result, Pilli and co-workers ${ }^{27}$ directed the synthetic efforts towards the synthesis of compound 22 (Scheme 4), the most likely one according to the NMR calculations. Starting from mono-protected propanediol 24, two consecutive Krische allylations 
<smiles></smiles>

22

DP4+: $99 \%$ (full NMR data) DP4+: $53 \%$ (partial NMR data)

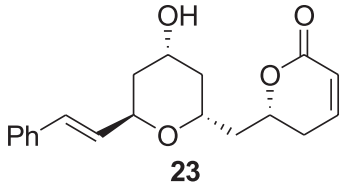

DP4+: $1 \%$ (full NMR data) DP4+: $47 \%$ (partial NMR data)
Figure 4. Most likely structures of cryptoconcatone $\mathrm{H}$ according to the NMR calculations. The carbon atoms that were varied to generate the candidate isomers are marked with an asterisk.

allowed the formation of $\mathbf{2 5},{ }^{28}$ which was further converted to 27 by a cross-metathesis reaction with chiral alkene 26. In order to generate the THP ring, the authors relied on a key $\mathrm{Pd}^{\mathrm{II}}$-catalyzed cyclization, allowing the generation of the THP ring with the desired cis/trans stereochemistry in $\mathbf{2 8}$ after standard manipulation of functional groups. ${ }^{29} \mathrm{~A}$ third Krische allylation introduced the desired $R$ configuration at C-6 (cryptoconcatone H numbering), and the synthesis was culminated by esterification of $\mathbf{2 9}$ with acryloyl chloride, followed by RCM and deprotection steps. ${ }^{27}$

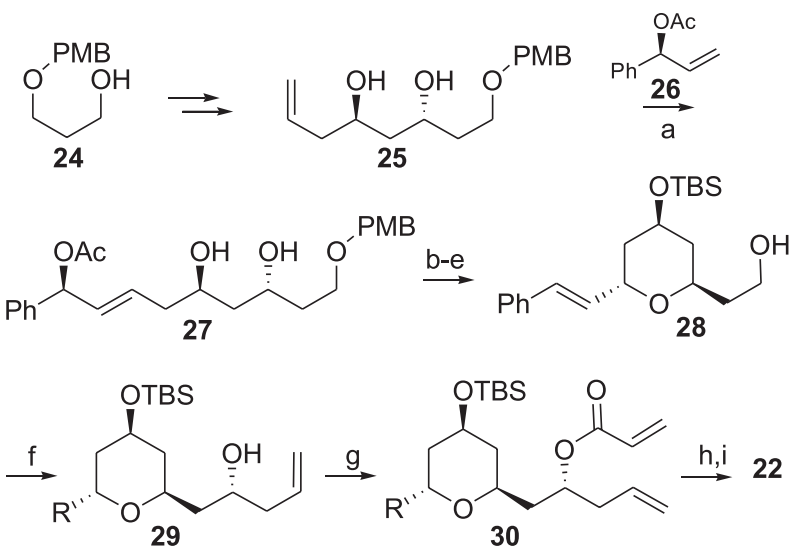

Scheme 4. Total synthesis of the most likely structure of cryptoconcatone $\mathrm{H}(22, \mathrm{R}=(E)-\mathrm{CH}=\mathrm{CH}-\mathrm{Ph})$. Selected reagents and conditions: (a) Grubbs II (3 mol\%), DCM (89\%, E:Z> 20:1); (b) $\mathrm{K}_{2} \mathrm{CO}_{3}, \mathrm{MeOH}$; (c) $\mathrm{PdCl}_{2}(\mathrm{MeCN})_{2}(10 \mathrm{~mol} \%)$, THF $(78 \%$, two steps; dr > 20:1); (d) tert-butyldimethylsilyl chloride (TBSCl), imidazole, DCM; (e) CAN, acetone $/ \mathrm{H}_{2} \mathrm{O}(54 \%$, two steps $)$; (f) $[\operatorname{Ir}(\operatorname{cod}) \mathrm{Cl}]_{2}(2.5 \mathrm{~mol} \%),(R)$-BINAP (5 mol\%), $\mathrm{Cs}_{2} \mathrm{CO}_{3}, 3-\mathrm{Cl}-4-\mathrm{NO}_{2}-\mathrm{BzOH}$, AcOAllyl, THF (59\%, dr > 20:1); (g) acryloyl chloride, Et ${ }_{3} \mathrm{~N}$, DCM (67\%); (h) Grubbs I, DCM; (i) TBAF, AcOH, AcOEt (55\%, two steps).

Once the synthesis of structure $\mathbf{2 2}$ was achieved, the NMR data of synthetic sample did not match perfectly with those of the natural product. However, the differences exhibited by both sets of NMR data were reasonably low ( $\Delta \delta$ values of up to 0.33 and $1.3 \mathrm{ppm}$ for ${ }^{1} \mathrm{H}$ and ${ }^{13} \mathrm{C}$ NMR, respectively) suggesting that the true structure of cryptoconcatone $\mathrm{H}$ might be similar to $\mathbf{2 2}$. Hence, the authors directed their attention to structure $\mathbf{2 3}$ (the second most likely isomer according to the DP4+ analysis), featuring the exact opposite configurations at the THP ring than 22. Interestingly, a closer inspection of the isolation paper indicated that Luo and co-workers ${ }^{24}$ misassigned the analysis of the NMR data collected for the Mosher esters prepared to settle the absolute configuration at C-4'. In particular, the $\Delta \delta_{\mathrm{SR}}$ values found (negative for $\mathrm{H}-5$ ' and H-6', and positive for H-2' and H-3') should have been assigned to a 4' $R$ configuration, according to the model described by Riguera and co-workers ${ }^{25}$ (as in $\mathbf{2 3}$ ), and not to 4' $S$ as proposed. In order to validate this hypothesis, Pilli and co-workers ${ }^{27}$ focused their efforts on the synthesis of ent-23 by using alcohol 28, a common intermediate in the synthesis of 22 (Scheme 5). In this case, Krische protocol was carried out with (S)-BINAP (2,2'-bis(diphenylphosphino)1,1 '-binaphthalene) in order to install the $S$ configuration at C-6 (cryptoconcatone $\mathrm{H}$ numbering). Following the same procedures developed for $\mathbf{2 2}$, esterification with acryloyl chloride, RCM and deprotection furnished the desired ent23, with NMR data now identical (within the experimental errors) to those reported for the natural product. ${ }^{27}$ The publication of these findings represents a fine example of a computer-guided structural revision case that was achieved without synthesizing first the originally proposed structure of the natural product. However, the fact that the real natural product was not the most likely isomer according to DP4+, but the second one, illustrates a fact that should never be forgotten: quantum NMR calculations-based elucidation tools are not infallible, and should always been taken as a rough guide to the experimental work, rather than final proofs of structural identity.

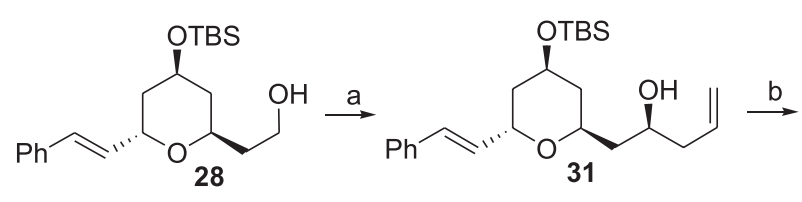<smiles>C=CC[C@@H](CC1CC(O[Sb])C[C@H](/C=C/c2ccccc2)O1)OC(=O)C=C</smiles>

Scheme 5. Total synthesis of the second most likely structure of (+)-cryptoconcatone $\mathrm{H}$ (ent-23). Selected reagents and conditions: (a) $\left[\operatorname{Ir}(\operatorname{cod}) \mathrm{Cl}_{2}(5 \mathrm{~mol} \%),(S)\right.$-BINAP $(10 \mathrm{~mol} \%), \mathrm{Cs}_{2} \mathrm{CO}_{3}$, 3-Cl-4- $\mathrm{NO}_{2}$-BzOH, AcOAllyl, THF (93\%, dr > 20:1); (b) acryloyl chloride, $\mathrm{Et}_{3} \mathrm{~N}, \mathrm{DCM}(70 \%)$; (c) Grubbs I, DCM; (d) tetra- $n$-butylammonium fluoride (TBAF), AcOH, AcOEt (38\%, two steps).

\section{Hemicalide}

Hemicalide (33) is a complex polyketide isolated from the marine sponge Hemimycale sp. collected in deep water near the Torres Islands (Vanatu, South Pacific).$^{30}$ This compound was shown to display high growth inhibitory activity against different human cancer cell lines with picomolar half maximal 
inhibitory concentration $\left(\mathrm{IC}_{50}\right)$ values, possibly acting through a novel tubulin-targeting antimitotic mechanism. Its planar structure, proposed after exhaustive NMR experiments, is characterized by a densely functionalized 46 carbon skeleton, including a polyoxygenated carboxylic acid and three separated olefinic regions and two $\delta$-lactone rings (Figure 5). However, on the basis of the small amount of isolated natural product, and given its high molecular complexity, the configuration of none of the 21 stereocenters could be determined by the isolation team.

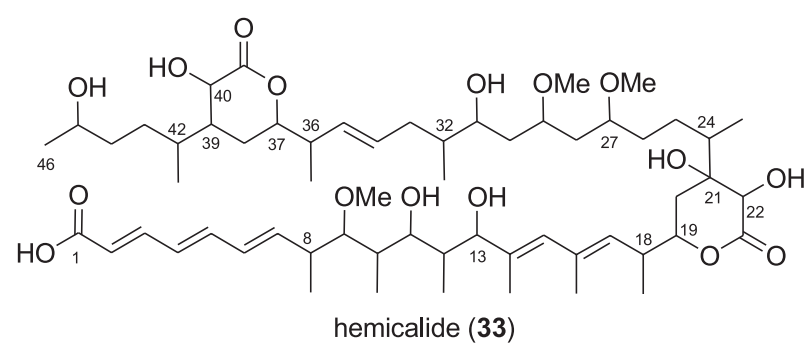

Figure 5. Planar structure of hemicalide.

The impressive biological properties exhibited by hemicalide, coupled with its challenging structure and undetermined stereochemistry, encouraged different research teams to work on the synthesis and elucidation of different fragments of the molecule. The first approach was made by Ardisson and co-workers, ${ }^{31}$ which focused their efforts to tackle the configurations at the $\mathrm{C}-1 / \mathrm{C}-17$ region. Noticeably, this work was published two years in advance of the patent disclosure, therefore no specific mention related to hemicalide was provided. In order to narrow down the number of isomers to be considered (up to 32), the authors took advantage of the shielding exhibited by the methyl group at $\mathrm{C}-12\left(\delta_{\mathrm{C}}=7.6 \mathrm{ppm}\right)$, consistent with a syn-syn stereotriad. Consequently, the C-11/C-13 motif was assigned as syn-syn, leaving 3 options for the C-9/C-11 motif: syn-anti, anti-syn or anti-anti. The six fragment analogues that met these stereochemical requirements were next synthesized, followed by NMR comparison with the natural product. On the basis of the $\Delta \delta$ values experimentally observed, the authors concluded that isomer 34 (Figure 6) represented the most likely relative configuration of hemicalide in that region of the molecule. This finding was later validated by Goodman and co-workers ${ }^{15}$ as part of their original development of the DP4 probability.

Once the configuration of the C-8/C-13 stereohexad was settled, the same Ardisson and co-workers ${ }^{32}$ next moved on to the C-17/C-25 $\delta$-lactone fragment of hemicalide. Having access to authentic NMR data of the natural product, the presence of NOESY correlations between $\mathrm{H}-22$ and $\mathrm{H}-20$ along with a ${ }^{3} J=11.3 \mathrm{~Hz}$

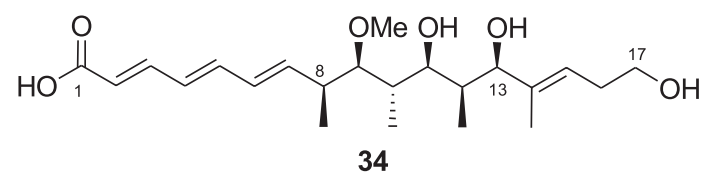

Figure 6. Isomer that showed the best NMR match for the C-1/C-17 region of hemicalide.

coupling between $\mathrm{H}-19 / \mathrm{H}-20$ was consistent with a $\delta$-lactone in its chair conformation with the two hydroxyl groups at C-21 and C-22 in a cis relative orientation and the side chain at $\mathrm{C}-19$ directed to the other face of the molecule. Such arrangement narrowed down to only 4 of 16 possible isomers corresponding to that region, and all these candidates were next synthesized. After comparison of the ${ }^{1} \mathrm{H}$ NMR data, the closest match was noticed for compound 35 (Figure 7), featuring a syn C-19/C-24 and anti $\mathrm{C}-18 / \mathrm{C}-19$ relationships, respectively. On the other hand, the ${ }^{13} \mathrm{C}$ NMR data showed no conclusive results mainly because the $\Delta \delta$ values observed for all isomers were not significant (often less than $1 \mathrm{ppm}$ ).

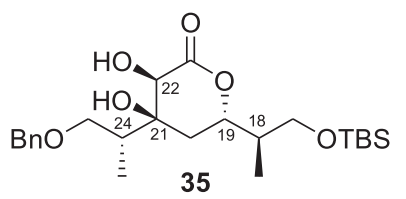

Figure 7. Isomer that showed the best NMR match for the C-17/C-25 region of hemicalide.

With these background results, the same year Ardisson and co-workers ${ }^{33}$ performed the synthesis of one of the two possible isomers of the C-1/C-25 subunit of hemicalide (compound 36, Figure 8). In good agreement with their previous work, a nice match between the ${ }^{1} \mathrm{H}$ and ${ }^{13} \mathrm{C}$ NMR shifts corresponding to the $\mathrm{C}-8 / \mathrm{C}-24$ region of the synthesized compound with those of hemicalide was observed ( $\Delta \delta$ up to 0.12 and $1.2 \mathrm{ppm}$, respectively). ${ }^{33}$

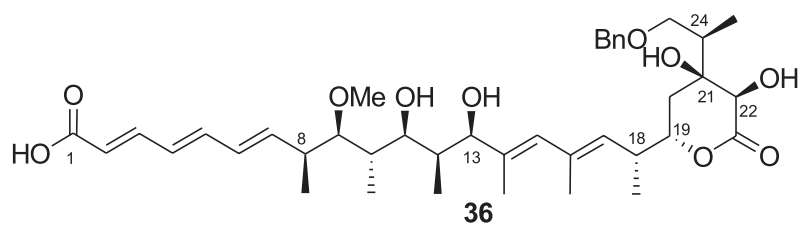

Figure 8. Synthesized structure of one of the possible isomers of the C-1/C-25 subunit of hemicalide.

In the meantime, Cossy and co-workers ${ }^{34}$ decided to study the C-36/C-46 unit. In view of the six stereocenters in that region, up to 32 possible diastereoisomers might be postulated. However, they managed to narrow down this number to 8 using NOESY data obtained from the natural product, which showed a cis relative orientation 
between $\mathrm{H}-37, \mathrm{H}-40$, and the side chain at C-39. On the basis of these findings, the authors prepared five isomers with different configurations at C-45, C-42 and C-36. The epimers at C-45 showed almost identical NMR data, thus preventing the configurational assignment of the remote C-45 center. Further comparison of the NMR shifts and coupling constants of the C-42 and C-36 isomers with the natural product, led the authors to suggest that the relative configuration at the C-36/C-46 unit of hemicalide should be the same as the synthetic fragment isomer 37 (Figure 9).

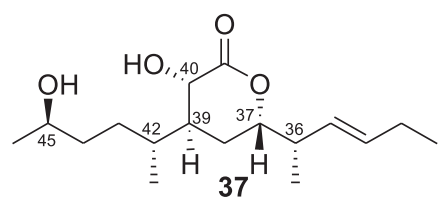

Figure 9. Fragment isomer that showed the best NMR match for the C-36/C-42 region of hemicalide.

After the final reports of Cossy and co-workers, ${ }^{34}$ it seemed that the relative configurations of the three stereoclusters of hemicalide had been determined, remaining pending the final connection between them to achieve the first total synthesis and final structural elucidation.

However, in 2016, Paterson and co-workers ${ }^{35}$ challenged the assignment made by Ardisson and co-workers ${ }^{32}$ on the relative configuration of the C-16/C-25 fragment (Figure 7). In particular, they considered that the ${ }^{1} \mathrm{H}$ NMR splitting pattern and ${ }^{3} \mathrm{~J}$ coupling constants that lead to the proposed $\mathrm{H}-18 / \mathrm{H}-19$ anti relationship, did not represent an incontrovertible proof for that assignment. Analysis of the ${ }^{1} \mathrm{H}$ NMR data of related lactones bearing a syn relationship indicated that such assignment might be also taken into account. ${ }^{35}$

In order to determine the most likely structure of the natural product, the authors undertook a computational study of NMR shifts coupled with DP4 analysis. Since there are several thousands of possible diastereoiosmers, they decided to follow a fragment-based approach that was termed DP4f. Hence, they broke down the structure of hemicalide into more manageable virtual stereocluster fragments.

To analyze the $\alpha, \beta$-hydroxy- $\delta$-lactone region $(\mathrm{C}-13$ to $\mathrm{C}-27)$, the 16 possible diastereoisomers of the virtual fragment 38 were evaluated (Figure 10). Interestingly, the most likely candidate showed a syn relationship between the adjacent methyl and acyloxy groups at C-18 and C-19 $(\mathbf{3 8 A})$, in contrast to the one originally suggested by Ardisson and co-workers ${ }^{32}$ (fragment $\mathbf{3 8 B}$ ). In addition, the calculations suggested a 1,5-syn relationship between C-18 and C-24, opposed to the anti configuration proposed by Ardisson and co-workers. ${ }^{32}$
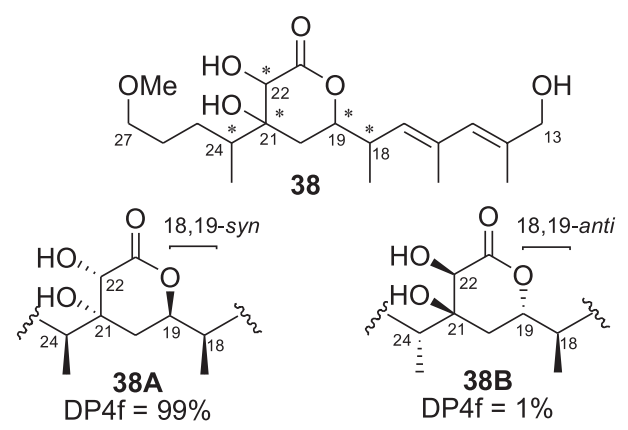

Figure 10. Virtual fragment used to determine the most likely structure of hemicalide at the $\mathrm{C}-13 / \mathrm{C}-27$ region. The carbon atoms that were varied to generate the candidate isomers for DP4f calculations are marked with an asterisk.

In order to unravel this issue, the authors carried out the synthesis of advanced intermediate $\mathbf{4 4}$, summarized in Scheme 6. The synthesis started with the preparation of compound $\mathbf{4 1}$ with the desired 1,4-syn stereochemistry from boron-mediated aldol reaction between 39 and $\mathbf{4 0}$. Next, the $\delta$-lactone was elaborated by a sequence of tertbuthyldimethylsilyl ether (TBS) ether formation and enolate addition to yield $\mathbf{4 2}$. Further cleavage of the TBS ether induced lactonization to afford the corresponding $\delta$-lactone, which upon elimination of the tertiary alcohol furnished intermediate $\mathbf{4 3}$. Finally, compound $\mathbf{4 3}$ was converted to $\mathbf{4 4}$ through dihydroxylation and Stille cross-coupling reaction. Interestingly, after correlating the NMR data of synthetic $\mathbf{4 4}$ with that of the C-13/C-25 region of hemicalide, the authors found an improved correlation (mainly in the ${ }^{1} \mathrm{H}$ NMR

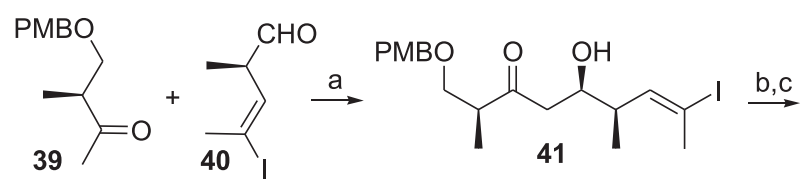

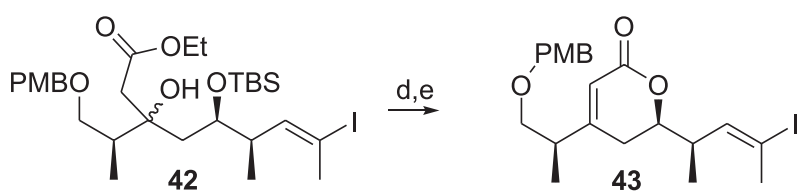

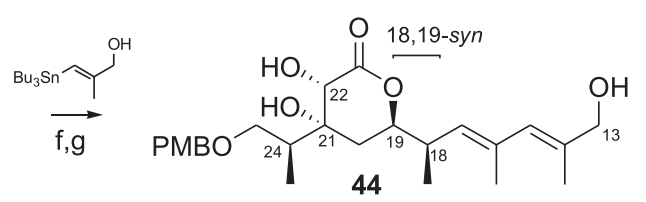

Scheme 6. C-13/C-25 fragment isomer of hemicalide synthesized by Paterson and co-workers ${ }^{35}$ following the DP4f predictions. Selected reagents and conditions: (a) $(-)-\mathrm{Ipc}_{2} \mathrm{BCl}$, triethylamine $\left(\mathrm{NEt}_{3}\right), \mathrm{Et}_{2} \mathrm{O}(70 \%, \mathrm{dr}>20: 1)$; (b) tert-butyldimethylsilyl trifluoromethanesulfonate (TBSOTf), 2,6-lutidine, DCM (95\%); (c) AcOEt, lithium diisopropylamide (LDA), THF (97\%); (d) HF-pyr, THF (85\%); (e) DMAP, $\mathrm{Ac}_{2} \mathrm{O} / \mathrm{pyr} / \mathrm{PhH}$ (83\%); (f) $\mathrm{K}_{2} \mathrm{OsO}_{4} \cdot 2 \mathrm{H}_{2} \mathrm{O}$, $\mathrm{N}$-methylmorpholine- $\mathrm{N}$-oxide (NMO), citric acid, ${ }^{\mathrm{BuOH}} / \mathrm{H}_{2} \mathrm{O} / \mathrm{THF}$ (85\%); (g) $\mathrm{Pd}\left(\mathrm{PPh}_{3}\right)_{4}(20 \mathrm{~mol} \%)$, copper(I)-thiophene-2-carboxylate (CuTC), $\left[\mathrm{Ph}_{2} \mathrm{PO}_{2}\right]\left[\mathrm{NBu}_{4}\right]$, dimethylformamide (DMF) $(74 \%)$. 
region) than that observed by Ardisson and co-workers ${ }^{32}$ for intermediate 35 (Figure 7). Further support to the proposed H-18/H-19 syn stereochemistry was possible by inspection of the resonance assigned to H-19 in $\mathbf{4 4}(\delta 4.41 \mathrm{ppm}$, ddd, $J=11.6,7.7,3.7 \mathrm{~Hz})$, comparable with that found for hemicalide $(\delta 4.42 \mathrm{ppm}$, ddd, $J=11.3,7.5,3.5 \mathrm{~Hz})$.

In the same work, Paterson and co-workers ${ }^{35}$ also evaluated the DP4f approach to settle the most likely configuration at the C-33/C-44 region. Initially, the NMR shifts of all possible 16 isomers of the virtual fragment $\mathbf{4 5}$ were calculated, and the fragment $\mathbf{4 5 \mathbf { A }}$ was identified as the preferred candidate in $84 \%$ probability (Figure 11). Since this assignment challenged the findings of Cossy and co-workers $^{34}$ (compound 37, Figure 9), the computational predictions were revised. In particular, the NOE correlation experimentally observed between $\mathrm{H}-37$ and H-40 clearly confirmed that both protons should be on the same side of the molecule, which was not the case in 45A. On that basis, and considering that the problem might be due to a structural simplicity of the chosen fragment model, the authors next undertook a similar NMR protocol using a more realistic fragment $\mathbf{4 6}$, including the extended sidechain with an hydroxyl group at C-45. To reduce the computational cost, only six fragment isomers were taken into consideration: four with the relative stereochemistry considered by Cossy and co-workers ${ }^{34}$ following NOE constraints, and the two most likely from DP4f calculations on fragment 45. Interestingly, now isomer $\mathbf{4 6 A}$ was the most likely candidate in $99 \%$ probability, a prediction that was in good agreement with the Ardisson, Cossy and coworkers ${ }^{34}$ finding of a 1,4-anti relationship between C-42 and C-45. The authors hypothesized that this change in the DP4f predictions might be due because the hydroxyl group at C-45 might affect the conformational equilibria by introducing additional elements of hydrogen bonding. In addition, the additional uncertainty introduced by the<smiles>C=CC(C)(C)[C@H]1C[C@H](C(C)CC)[C@H](O)C(=O)O1</smiles><smiles>C=CC(C)(C)[C@H]1C[C@H](C(C)C)[C@@H](O)C(=O)O1</smiles><smiles>C=CC(C)[C@H]1CC([C@H](C)CC)[C@H](O)C(=O)O1</smiles>

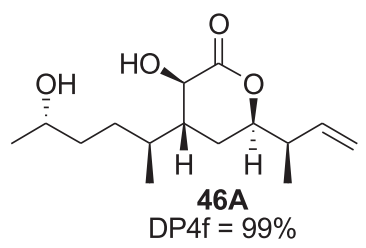

Figure 11. Virtual fragment used to determine the most likely structure of hemicalide at the C-33/C-44 region. The carbon atoms that were varied to generate the candidate isomers for DP4f calculations are marked with an asterisk. fragment approach when employed in conformationally flexible structures was also emphasized.

Eight months later of the reassignment by Paterson and co-workers, ${ }^{35}$ Cossy, Ardisson, Lannou and co-workers ${ }^{33}$ published their own synthetic results on the C-1/C-27 fragment on hemicalide with the revised stereochemistry at the lactone fragment as suggested by the computational findings. To date, the total synthesis and final structural confirmation of hemicalide has not yet been achieved.

\section{Stolonines A-C}

In 2015, Quinn and co-workers ${ }^{36}$ reported the isolation and synthesis of stolonines A-C from the marine tunicate Cnemidocarpa stolonifera. In the case of stolonine A, from the NMR data available, the authors could not unequivocally distinguish between the two candidate possibilities: $\mathbf{4 7}$ and 48 (Figure 12). The lack of HMBC correlations between any proton of the molecule with the carbonyl group at C-8 precluded the assignment. However, a correlation between H-2 and C-3a was noticed after detailed HMBC analysis, suggesting that $\mathbf{4 7}$ (with a three-bond distance between $\mathrm{H}-2$ and C-3a) was more favorable than $\mathbf{4 8}$ (with a four-bond distance between $\mathrm{H}-2$ and C-3a). All in all, the authors decided to run NMR calculations to settle this structural issue at the mPW1PW91/6-31G*//B3LYP/6-31G* level of theory. As expected, a better agreement was found for 47, mainly for carbon data, with $100 \%\left({ }^{13} \mathrm{C}\right.$ NMR $)$ and $85.3 \%$ ( ${ }^{1} \mathrm{H}$ NMR) probabilities values according to DP4 calculations. Finally, the authors undertook the preparation of $\mathbf{4 7}$ from the condensation of 3-indoleglyoxylic acid and taurine, and observed that the NMR data of the synthetic sample perfectly matched those of the natural product. ${ }^{36}$

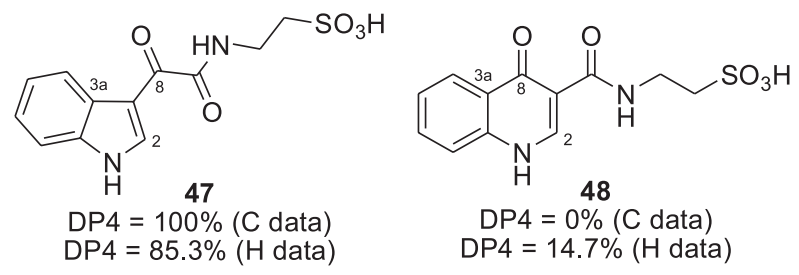

Figure 12. Originally proposed candidates for stolonine A.

\section{Glabramycins B and C}

Glabramycins B (49) and C (50) were first isolated in 2009 from the fungus Neosartorya glabra by Singh and co-workers $^{37}$ (Figure 13). Their planar structures were determined on the basis of standard 1D and 2D NMR experiments, whereas the relative configurations at C-10, $\mathrm{C}-11$ and $\mathrm{C}-15$ were settled on the basis of the magnitude of the scalar couplings. In particular, the H-10 signal of 
49 was observed as a triplet, with $J=9.6 \mathrm{~Hz}$, indicative of a trans-diaxial relationships between $\mathrm{H}-11$ and $\mathrm{H}-15$. However, the coupling constants reported for $\mathrm{H}-10$ of $\mathbf{5 0}$ were different $(10.0$ and $4.5 \mathrm{~Hz})$, though this observation was not discussed by the authors. On the other hand, the relative configuration at $\mathrm{C}-20$ could not be determined by the isolation team, and the structures of the two natural products were published as depicted in Figure $13 .{ }^{37}$ In 2015, Yang $\mathrm{Li}^{38}$ noticed the structural similarity between glabramycins B and $\mathrm{C}$ with another natural product, Sch642305 (51, Figure 13), isolated in 2003 by Chu et al.$^{39}$ from Penicillium verrucosum. A large coupling constant between H-5 and H-6 $(J=11.5 \mathrm{~Hz})$ suggested a trans arrangement of these protons, whereas $\mathrm{H}-4$ and $\mathrm{H}-5$ were assigned as cis from the relatively small coupling observed $(3.7 \mathrm{~Hz})$. The structure of $\mathbf{5 1}$ was validated by X-ray analysis, and further confirmed by total synthesis. ${ }^{40}$

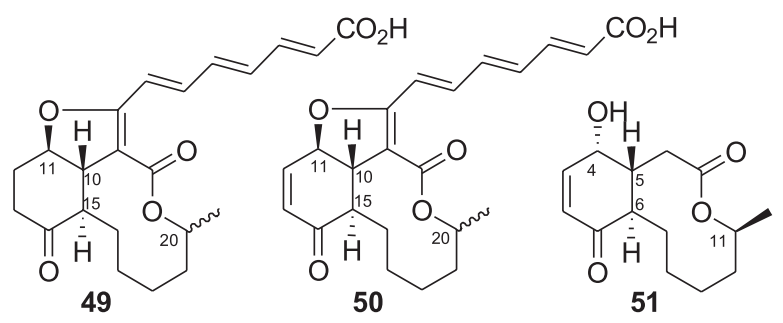

Figure 13. Originally proposed structures 49 and $\mathbf{5 0}$ for glabramycin B and C, respectively, and structure of Sch-642305 (51) verified by X-ray and total synthesis.

On the basis of this background, Yang Li carried out a complete computational study at the mPW1PW91/6-

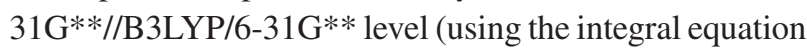
formalism polarizable continuum model (IEF-PCM) solvation model) to challenge the originally proposed stereochemistry at C-11 of $\mathbf{4 9}$ and $\mathbf{5 0}$, as well as to provide their most likely configuration at $\mathrm{C}-20$. In both cases, the $(11 S, 20 S)$ isomers $\mathbf{5 2}$ and $\mathbf{5 3}$ displayed the best agreement with the experimental data, indicating that the originally proposed structures should be revised as shown in Figure 14. The author also conducted ${ }^{3} J$ coupling constants calculations at the B3LYP/6-31G** level of theory, and found consistent results with their hypothesis. ${ }^{38}$

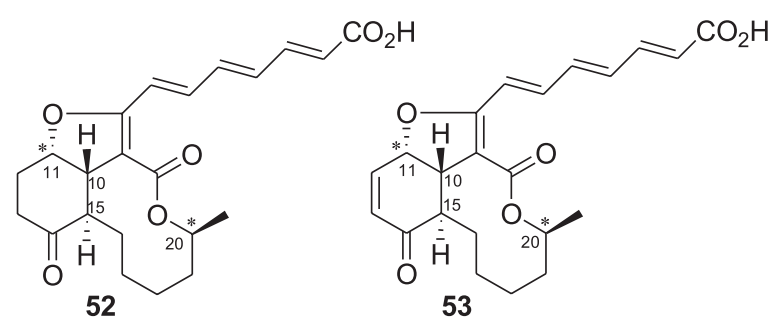

Figure 14. Most likely structures $\mathbf{5 2}$ and $\mathbf{5 3}$ for glabramycin B and C, respectively, according to NMR calculations. The carbon atoms that were varied to generate the candidate isomers are marked with an asterisk.
These computational predictions were finally confirmed by Watanabe and co-workers, ${ }^{41}$ who performed the total synthesis of the revised structure of glabramycin B (52) as summarized in Scheme 7. Starting from known compound $\mathbf{5 4},{ }^{41}$ the advanced intermediate 55 was obtained using standard transformations. Nitrile reduction, selective deprotection and lactol oxidation yielded the desired five-membered lactone $\mathbf{5 6}$, which was further transformed into the acid $\mathbf{5 7}$ by introduction of a methoxycarbonyl group, hydrolysis and deprotection sequence. Lactonization of $\mathbf{5 7}$ yielded tricyclic compound 58, which was next transformed into vinyl triflate 59. Stille cross-coupling reaction and standard functional group manipulation allowed the generation of $\mathbf{6 0}$. Finally, oxidation of the secondary alcohol and deprotection furnished the target compound in good yields. In perfect agreement with the computational findings, synthetic $\mathbf{5 2}$ showed identical NMR data with those of the natural product, ${ }^{42}$ except for some differences reported for the multiplicity of $\mathrm{H}-10$ in the natural and synthetic sample. One interesting fact in structure $\mathbf{5 2}$ is the two large coupling constants observed for $\mathrm{H}-10$, although it bears a cis relationship with $\mathrm{H}-11$.
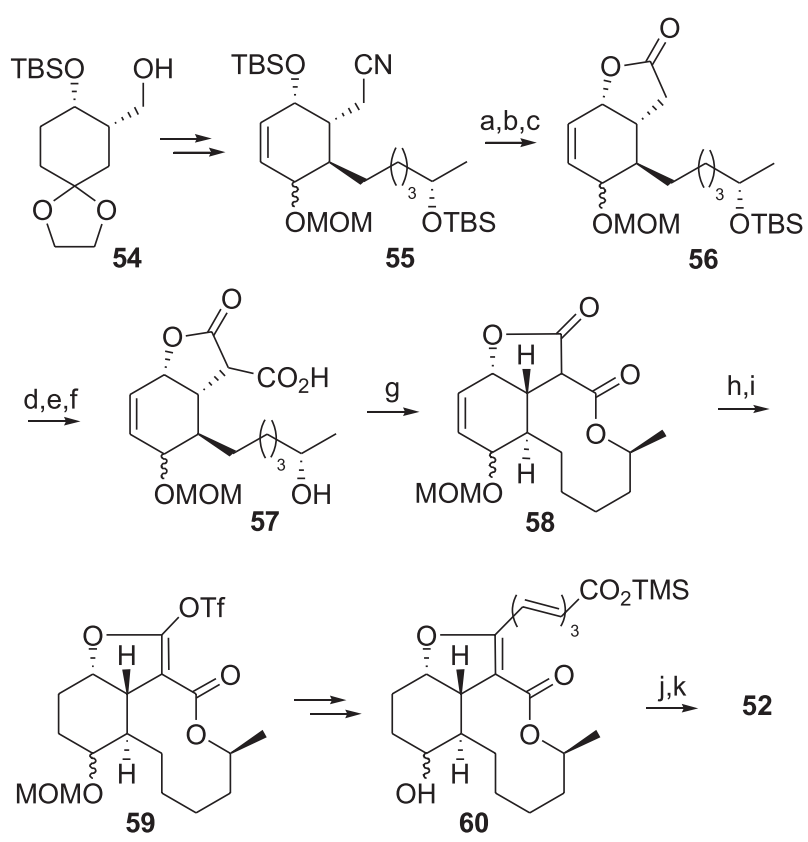

Scheme 7. Total synthesis of the most likely structure $\mathbf{5 2}$ of glabramycin B. Selected reagents and conditions: (a) diisobutylaluminium hydride (DIBAL), DCM; (b) TBAF, THF; (c) $\mathrm{Ag}_{2} \mathrm{CO}_{3}$, Celite, $\mathrm{PhH}, \Delta$ (65\%, three steps); (d) $\mathrm{NCCO}_{2} \mathrm{Me}$, lithium bis(trimethylsilyl)amide (LHMDS), THF (99\%); (e) HF, MeCN (99\%); (f) $\mathrm{LiOH}_{2} \mathrm{H}_{2} \mathrm{O}$, dioxane, $\mathrm{H}_{2} \mathrm{O}$ (99\%); (g) 2-methyl-6-nitrobenzoic anhydride (MNBA), 4-(dimethylamino)pyridine (DMAP), DCM (64\%); (h) $\mathrm{H}_{2}, \mathrm{Rh} \mathrm{Al}_{2} \mathrm{O}_{3}$, AcOEt (99\%); (i) potassium bis(trimethylsilyl)amide (KHMDS), $\mathrm{Tf}_{2} \mathrm{O}, \mathrm{DME} ;(\mathrm{j}) \mathrm{DMP}, \mathrm{NaHCO}_{3}$, DCM; (k) tris(dimethylamino)sulfonium difluorotrimethylsilicate (TAS-F), DMF (69\%, two steps). 


\section{Nobilisitine A}

Nobilisitine A was isolated in 1999 by Evidente et al. ${ }^{43}$ from the crude $\mathrm{CHCl}_{3}$ extract of Clivia nobilis, an ornamental plant cultivated in Egypt. Whereas its planar structure was determined from standard 1D and 2D NMR experiments, the relative configuration proposal relied mainly on the observed coupling constants. In particular, the ${ }^{3} J_{4 \mathrm{a}-5}=9.9 \mathrm{~Hz}$, ${ }^{3} J_{4 \mathrm{~b}-5}=5.0 \mathrm{~Hz}$ and ${ }^{3} J_{5-5 \mathrm{a}}=6.6 \mathrm{~Hz}$ values were interpreted on the basis of an axial and equatorial orientation of H-5 and $\mathrm{H}-5 \mathrm{a}$, respectively. Next, from the coupling constant between $\mathrm{H}-5 \mathrm{a}$ and $\mathrm{H}-11 \mathrm{~b}\left({ }^{3} J_{4 \mathrm{a}-5}=5.0 \mathrm{~Hz}\right)$ the authors suggested that $\mathrm{H}-11 \mathrm{~b}$ should be axial, corresponding to a cis $\mathrm{B} / \mathrm{C}$ ring fusion. Furthermore, $\mathrm{H}-11 \mathrm{c}$ was proposed to have an equatorial orientation from its coupling with $\mathrm{H}-11 \mathrm{~b}\left({ }^{3} J_{11 \mathrm{~b}-1 \mathrm{c}}=5.0 \mathrm{~Hz}\right)$. Finally, the cis $\mathrm{C} / \mathrm{D}$ fusion was proposed considering that $\mathrm{H}-3 \mathrm{a}$ should be axial $\left({ }^{3} J_{3 \mathrm{a}-11 \mathrm{c}}\right.$ $=5.8 \mathrm{~Hz}$ ). However, the originally proposed structure of nobilisitine A (61, Figure 15) was found incorrect by Cade and co-workers ${ }^{44}$ after completing the first total synthesis of ent-61 (verified by X-ray) showing significant deviations in the NMR data with those of the natural product. After thorough comparison of the spectroscopic data of synthetic sample and the natural product, the authors hypothesized that the source of the problem was stereochemical. Under this assumption, Lodewyk and Tantillo ${ }^{45}$ performed a comprehensive computational study to elucidate the most likely structure of nobilisitine A. In order to narrow down the number of diastereoisomers (up to 16), the authors assumed that the cis C/D ring fusion might not have been misassigned, leading to 8 candidate structures. Next, they computed the NMR shifts at the mPW1PW91/6$311+\mathrm{G}(2 \mathrm{~d}, \mathrm{p}) / / \mathrm{B} 3 \mathrm{LYP} / 6-31+\mathrm{G}^{* *}$ level of theory, previously validated in the same work with known analogues. The best match between experimental and calculated NMR data was found for isomer 62 (Figure 15), showing high DP4 probability values $(>99 \%){ }^{45}$
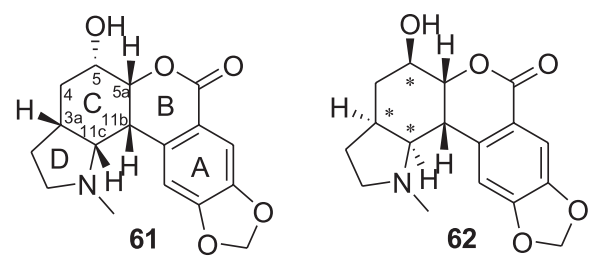

Figure 15. Originally proposed (61) and most likely (62) structures of nobilisitine $\mathrm{A}$. The carbon atoms that were varied to generate the candidate isomers are marked with an asterisk.

From this theoretical prediction, Banwell and coworkers $^{46}$ designed and carried out the synthesis of $\mathbf{6 2}$ using (+)-clividine (63) as starting material. As depicted in Scheme 8,63 is the C-5 epimer of the most likely structure of nobilisitine, but all attempts to invert the configuration using the Mitsunobu reaction met with no success. For that reason, the authors next evaluated the Zard protocol for the inversion of secondary alcohols. ${ }^{47}$ Hence, the starting material was converted into the corresponding propargyl xantathe 64, which was next heated to refluxed in chlorobenzene in the presence of benzoic acid. The desired benzoate $\mathbf{6 5}$, which was obtained in low yields because of the formation of a by-product (not shown), was finally hydrolyzed to furnish the desired compound $\mathbf{6 2}$. Comparison of the ${ }^{13} \mathrm{C}$ and ${ }^{1} \mathrm{H}$ NMR spectra data collected from synthetic sample with those reported for the natural product clearly indicated that $\mathbf{6 2}$ corresponds to the relative configuration of nobilisitine A. However, since the isolation team did not report the specific optical rotation, the absolute configuration could not be irrefutably assessed. In this regard, given that clividine (63) occurs naturally in the form of ent-63, the authors hypothesized that the correct structure of nobilisitine A should be ent-62. ${ }^{46}$
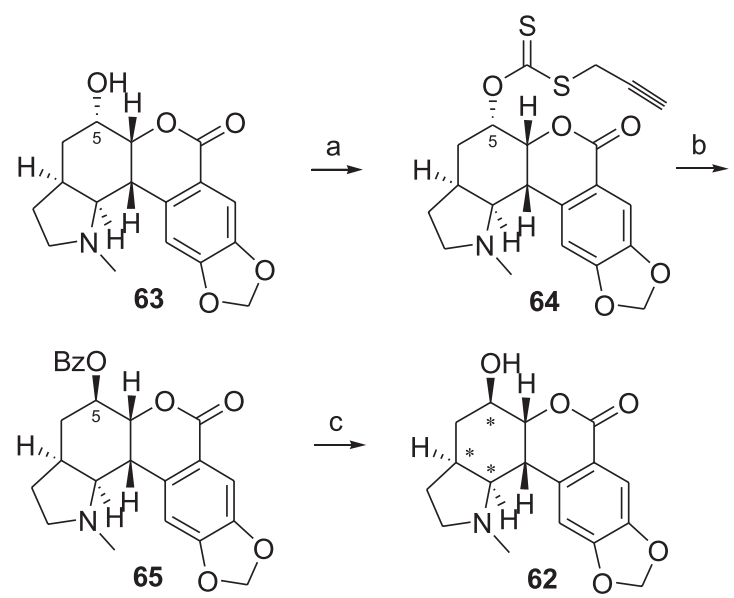

Scheme 8. Total synthesis of the most likely structure of nobilisitine A according to NMR calculations. Selected reagents and conditions: (a) $\mathrm{NaH}, \mathrm{CS}_{2}, \mathrm{BrCH}_{2} \mathrm{CCH}(67 \%)$; (b) $\mathrm{BzOH}$, chlorobenzene, reflux (21\%); (c) $\mathrm{K}_{2} \mathrm{CO}_{3}, \mathrm{MeOH}(91 \%)$.

\section{Madeirolide A}

Madeirolide A (66, Figure 16) was isolated by Wright and Winder ${ }^{48}$ from the marine sponge Leiodermatium sp., collected in depth near Porto Santo, Ilhéu de Ferro, Madeira Archipielago. Its planar structure, featuring a 24-membered macrolactone and four cyclic domains, was elucidated after exhaustive 1D and 2D NMR experiments (Figure 16). The determination of the relative configuration represented a great challenge, considering that the molecule contains 16 stereocenters, and was performed on the basis of the analysis of the ${ }^{1} \mathrm{H}-{ }^{1} \mathrm{H}$ scalar coupling constants and NOESY experiments. Preliminary biological essays demonstrated that madeirolide $\mathrm{A}$ was a 


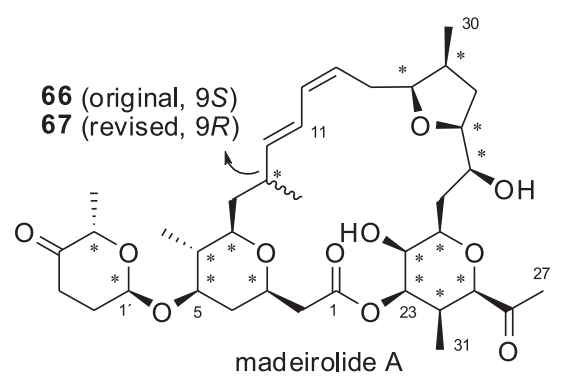

Figure 16. Originally proposed (66) and most likely (67) structures of madeirolide $\mathrm{A}$. The carbon atoms that were varied to generate the candidate isomers are marked with an asterisk.

potent inhibitor of the fungal pathogen Candida albicans, with a fungicidal minimum inhibitory concentration (MIC) value of $12.5 \mathrm{mg} \mathrm{mL}^{-1}$. However, the low amount of isolated sample hampered a broader biological evaluation.

On the basis of the complex structure and promising biological activities of madeirolide A, Paterson and Haslett ${ }^{49}$ became interested in the total synthesis of this complex polyketide. Considering the challenge involved to succeed, and the separation of the stereoclusters present in the molecule, the authors prudently re-analyzed the originally proposed structure $\mathbf{6 6}$ before venturing into the total synthesis. As discussed above, madeirolide A contains sixteen stereocenters, affording more than 30,000 different diastereoisomers to be evaluated. Such number is undoubtedly prohibitive for any NMR calculation procedure, and the authors had to narrow down the candidate isomers. Hence, they properly supposed that the relative configurations within each six-membered ring was right by assuming that the NOESY and coupling analysis generally afford accurate results when applied to these systems. Considering each tetrahydropyran as a single variable, all possible configurations at the tetrahydrofuran were evaluated, as well as the C-9 and C-19 centers. Following the original DP4 procedure, the NMR calculations of the resulting 128 isomers were computed at the B3LYP/6-31G**//MMFF level of theory, using a 10,000 step Monte Carlo conformational search for each candidate. Interestingly, the DP4 results suggested in high confidence $(99.6 \%)$ that the most likely structure of madeirolide A was 67 (Figure 16), featuring the inverted configuration at C-9 as originally proposed. Caught by this outcome, the authors contacted the isolation team, which revealed that they actually had assigned the natural product as $\mathbf{6 7}$ (with an $11 R$ configuration), but accidently made a mistake inverting the configuration at $\mathrm{C}-9$ when drawing the molecule in the $2 \mathrm{D}$ format. ${ }^{48}$ This can be verified by examinating the original 3D-drawing by Wright and Winder ${ }^{48}$ of the C-3/C-9 and C-1'/C-6' segment to account for the observed NOESY correlations (Figure 17).

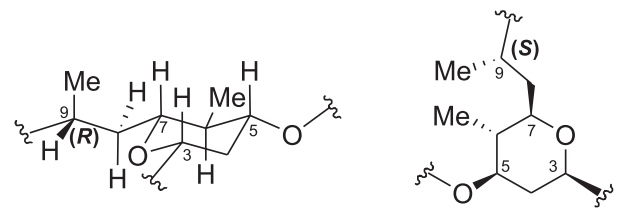

Figure 17. Left: 3D representation of the C-3/C-9 segment of madeirolide $\mathrm{A}$ as shown by Wright and Winder ${ }^{48}$ showing the correct $R$ configuration at C-9. Right: 2D representation of the C-3/C-9 segment of madeirolide $\mathrm{A}$ as originally represented by Wright and Winder ${ }^{48}$ with the accidentally inverted configuration at C-9.

Next, Paterson et al. ${ }^{49}$ undertook the synthesis of the C-1/C-11 western fragment of the most likely structure of madeirolide starting from ester $(S)-\mathbf{6 8}$, further transformed into ketone $\mathbf{6 9}$ by standard transformations (Scheme 9). Coupling of 69 and TBS-protected 3-hydroxypropanal with controlled installation at the C-5 and C-6 stereocenters was carried out using a chiral ligand-mediated boron aldol reaction, affording the desired syn adduct $\mathbf{7 0}$ in good yield and selectivity. 1,3-anti Reduction of ketone 70, followed by standard functional group manipulations, afforded the desired C-5/C-9 stereotetrad 71. Condensation of aldehyde $\mathbf{7 1}$ with a thioester phosphonate provided $(E)$-alkene $\mathbf{7 2}$ in high yield. Acetonide removal under acidic conditions led to the formation of the target 2,6-cis tetrahydropyran, which was transformed into vinyl iodide $\mathbf{7 3}$ by deprotection, selective primary alcohol
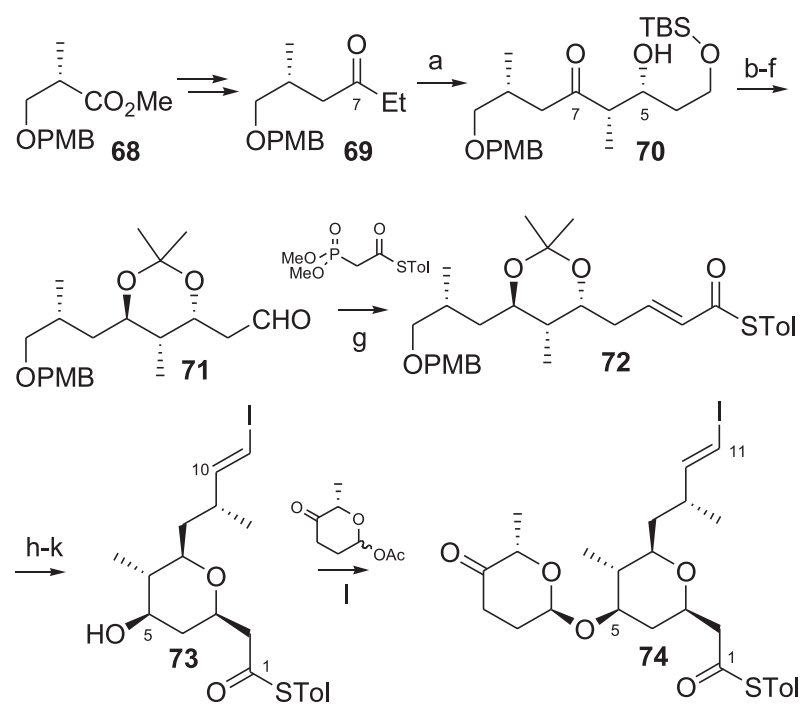

Scheme 9. Total synthesis of the C-1/C-11 fragment of madeirolide A. Selected reagents and conditions: (a) (-)-(Ipc) ${ }_{2} \mathrm{BOTf}, i$ - $\mathrm{Pr}_{2} \mathrm{NEt}$, DCM, then $\mathrm{TBSOCH}_{2} \mathrm{CH}_{2} \mathrm{CHO}$ (93\%, dr > 95:5); (b) $\mathrm{SmI}_{2}, \mathrm{EtCHO}_{2}$ THF (dr > 95:5); (c) $\mathrm{K}_{2} \mathrm{CO}_{3}, \mathrm{MeOH}$; (d) $(\mathrm{MeO})_{2} \mathrm{CMe}_{2}$, PPTS $(86 \%$, three steps); (e) TBAF, THF (98\%); (f) DMP, $\mathrm{NaHCO}_{3}, \mathrm{DCM}(97 \%)$; (g) LiCl, Et ${ }_{3} \mathrm{~N}$, THF (95\%, E:Z 19:1); (h) TsOH, DCM (dr > 20:1); (i) 2,3-dichloro-5,6-dicyano- $p$-benzoquinone (DDQ), DCM (61\%, two steps); (j) (2,2,6,6-tetramethylpiperidin-1-yl)oxyl (TEMPO), bis(acetoxy)iodobenzene (BAIB), DCM (97\%); (k) $\mathrm{CrCl}_{2}, \mathrm{CHI}_{3}, \mathrm{THF}$ (55\%); (1) $\mathrm{BF}_{3} \cdot \mathrm{OEt}_{2}, \mathrm{DCM}(78 \%, \alpha: \beta 19: 1)$. 
oxidation and Takai olefination. Finally, a $\mathrm{BF}_{3} \cdot \mathrm{OEt}_{2}$ promoted glycosylation afforded the $\mathrm{C}-1 / \mathrm{C}-11$ fragment of madeirolide $\mathbf{7 4}$ conveniently functionalized at both ends for further connection with the eastern fragment. The authors observed a convincing level of homology when comparing the NMR data of synthetic $\mathbf{7 4}$ with those of the natural product. In the following years, two other groups reported alternative synthetic procedures for related molecular fragments, ${ }^{50}$ though the total synthesis of the natural product has not yet been accomplished.

All in all, this is a fine study highlighting the power or NMR calculations in structural elucidation of complex organic molecules, and also, revealing how diverse the sources of misassignments can be.

\section{Leiodermatolide}

In 2011, Paterson, Wright and co-workers ${ }^{51}$ reported the isolation of leiodermatolide (75, Figure 18) from the marine sponge Leiodermatium sp., collected in depth near the cost of Fort Lauderdale, Florida, USA. The natural product exhibited potent and selective antimitotic activity $\left(\mathrm{IC}_{50}<10 \mathrm{nM}\right)$ against a range of human cancer cells by inducing G2/M cell cycle arrest. The planar structure, featuring a 16-membered macrolide skeleton and an unsaturated side chain terminating in a $\delta$-lactone, was elucidated through a combination of extensive NMR analysis, including double quantum filter (DQF)-COSY, $\mathrm{g}$-HSQC and HMBC experiments. On the other hand, the relative configuration within the macrolide and lactone cores relied heavily on $J$-based analysis (JBA) and NOE observations.

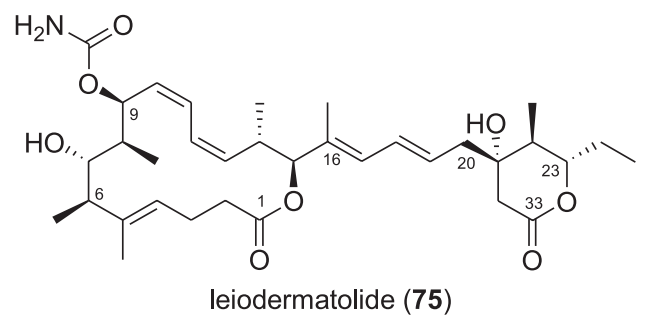

Figure 18. Originally proposed structure of leiodermatolide.

Given the high structural complexity of the natural product, the authors also carried out NMR calculations at the B3LYP/6-31G**//MMFF level of theory to gain further confidence on their assignment. In order to simplify the procedure, and taking into consideration the separation of the $\mathrm{C}-1 / \mathrm{C}-15$ and $\mathrm{C}-21 / \mathrm{C}-33$ stereoclusters, the authors undertook a fragment-based analysis. Hence, the NMR shifts of all possible diastereoisomers of model fragments 76 and 77 (32 and 4, respectively, Figure 19) were computed
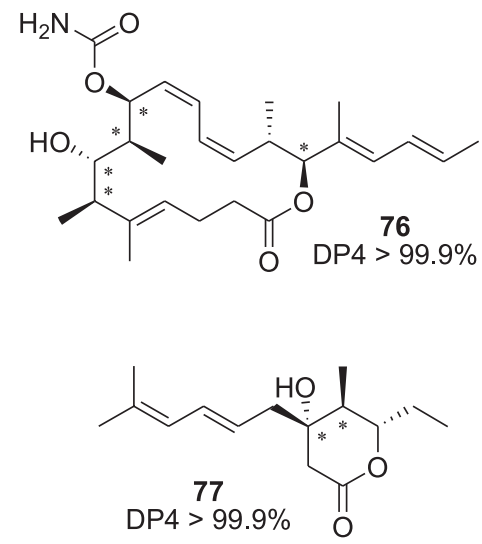

Figure 19. Model fragments used to determine the most likely structure of the $\mathrm{C}-1 / \mathrm{C}-15$ and $\mathrm{C}-21 / \mathrm{C}-33$ region of leiodermatolide. The carbon atoms that were varied to generate the candidate isomers for DP4 calculations are marked with an asterisk.

at the B3LYP/6-31G**//MMFF level of theory, and the results were further correlated with the experimental NMR shifts of the natural product using DP4. In perfect agreement with the stereochemical assignment based on JBA and NOE, the most likely isomers according to the calculations displayed the same relative configurations previously suggested in high confidence (>99\%).

Naturally, as the stereochemical connection between both fragments was not possible, the authors arbitrarily reported one of the two possible diastereoisomers. In addition, the attempts to settle the absolute configuration at C-7 via Mosher analysis was unsuccessful, as irregular $\Delta \delta^{\mathrm{SR}}$ values were measured at both side of the stereocenter. Hence, the full configuration of leiodermatolide could only be solved by total synthesis, and it did not take long until the first studies began to appear. The first approach was carried out by Maier and co-workers ${ }^{52}$ which synthesized the macrolide region of the natural product (78, Figure 20). Interestingly, the authors relied on an earlier preliminary structural proposal of leiodermatolide with an inverted configuration at C-6 and C-8. From Kishi analysis, it was recognized that such proposal was probably not the correct stereostructure of leiodermatolide, but anyway they decided to take the risk. Ultimately, once the synthesis of $\mathbf{7 8}$ was completed, its NMR data showed significant differences from those reported for the natural product, indicating inconsistencies with the original tentative assignment. Within few days of the publication of this synthetic work, the report with the proposed structure of leiodermatolide by Wright and co-workers ${ }^{51}$ discussed above was published. Few months later, Paterson et al. ${ }^{53}$ reported the synthesis of the macrolide fragment with the correct stereochemistry (79, Figure 20). Detailed NMR comparison with the $\mathrm{C}-1 / \mathrm{C}-16$ region of the natural product indicated some deviations at C-15, C-16 and C-30, expected 


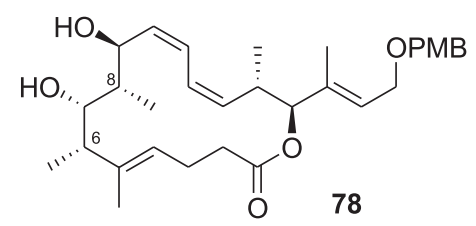

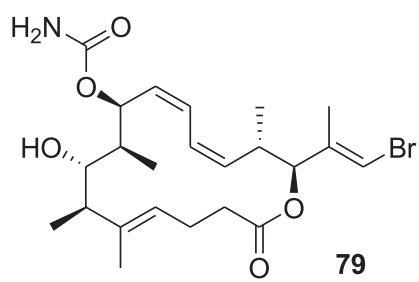

Figure 20. Western fragments of leiodermatolide synthesized by Maier and co-workers ${ }^{52}$ (78) and Paterson et al. ${ }^{51}(\mathbf{7 9})$.

for the truncated macrocycle, but the remaining ${ }^{1} \mathrm{H}$ and ${ }^{13} \mathrm{C}$ resonances fell within \pm 0.03 and $\pm 1.0 \mathrm{ppm}$, respectively, of the corresponding values of leiodermatolide. In addition, good correlation was also observed for the ${ }^{3} \mathrm{JH}_{\mathrm{HH}}$ coupling constants of the macrolide, as well as key NOE enhancements, providing a strong argument in favor of the proposed stereostructure for this region of the natural product.

The first total synthesis and final structural confirmation of leiodermatolide took place in 2012 by Fürstner and co-workers. ${ }^{54}$ As shown in Scheme 10, the synthesis began with the asymmetric aldol reaction of $\mathbf{8 0}$ and propanal yielding chiral ketone $\mathbf{8 1}$, that was submitted to a $\operatorname{Sn}(\mathrm{OTf})_{2}$-mediated aldol reaction with butynal to generate 82. Standard functional group manipulations afforded the advanced intermediate $\mathbf{8 3}$, featuring the desired syn-anti-syn-configured stereotetrad. Upon treatment with $\mathrm{PBr}_{3}, 83$ rearranged to the labile allylic bromide 84 , which was reacted with the lithium enolate of ethyl acetate under $\mathrm{CuI}$ catalysis to furnish $\mathbf{8 5}$ after saponification of the resulting ester. In a parallel fashion, the authors undertook the asymmetric synthesis of fragments $\mathbf{8 6}$ and $\mathbf{8 7}$ for final assembly. Hence, esterification of $\mathbf{8 5}$ and $\mathbf{8 6}$ gave the diyne $\mathbf{8 8}$, which was further treated with molybdenum alkylidyne complex $\mathbf{8 9}$ to afford the 16-membered macrocycle through a key alkyne metathesis reaction. Suzuki-Miyaura cross-coupling between vinyl iodide $\mathbf{9 0}$ and boronate 87 using $\mathrm{Tl}(\mathrm{OEt})$ in aqueous THF allowed the connection between eastern and western fragments of leiodermatolide, finally prepared by deprotection and introduction of the carbamate group at C-9. To indisputably assign the correct relative configuration between the two separated stereoclusters (macrolide and $\delta$-lactone), the authors also synthesize the other possible diastereoisomer of the natural product by changing the coupling partner of<smiles>CCC(=O)N1C(=O)OCC1Br</smiles><smiles>[M]O[C@@H](C#CC)[C@@H](C)[C@H](O[M])[C@@H](C)/C(C)=C/CBr</smiles>

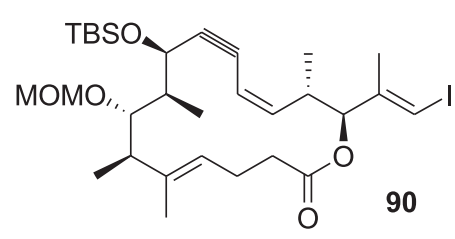<smiles>CCC(=O)[C@H](Br)C(=O)N1C(=O)OC[C@@H]1Br</smiles>

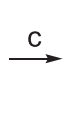<smiles>C=C[C@H](C)[C@@H](O)C(=O)[C@H](C)C(=O)N1C(=O)OC[C@H]1Br</smiles>

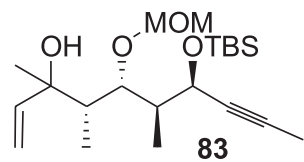

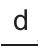
82<smiles>C=C(C)[C@H](C)[C@@H](OC)[C@@H](C)[C@@H](C)O[Sb](C)(C)C</smiles><smiles>CC#C/C=C\[C@H](C)[C@H](OC(=O)CCC)/C(C)=C/I</smiles>
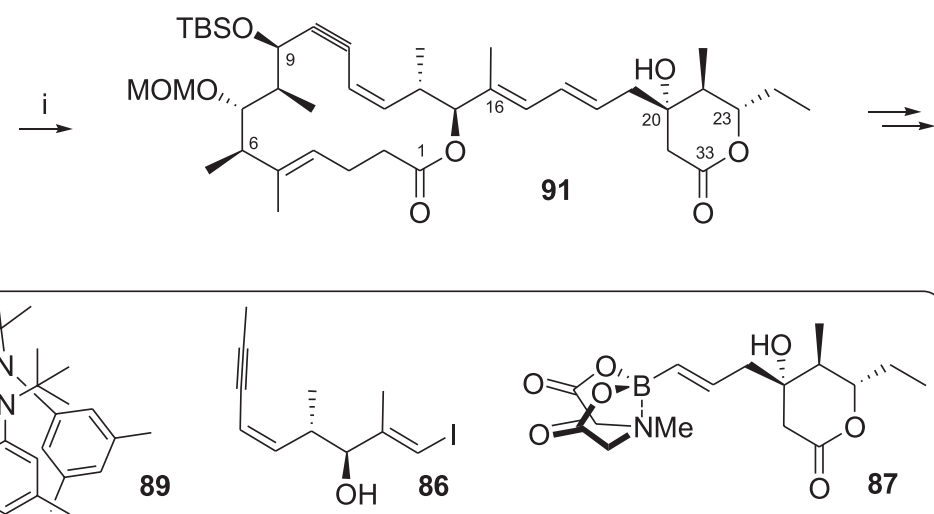

Scheme 10. Total synthesis of the most likely structure of leiodermatolide. Selected reagents and conditions: (a) $\mathrm{Bu}_{2} \mathrm{BOTf} \mathrm{NEt}_{3}$, propanal (97\%); (b) $\mathrm{SO}_{3}$-pyridine, DCM, dimethyl sulfoxide (DMSO), $\mathrm{Et}_{3} \mathrm{~N}$ (88\%); (c) but-2-ynal, $\mathrm{Sn}(\mathrm{OTf})_{2}, \mathrm{NEt}_{3}, \mathrm{DCM}(55 \%)$; (d) $\mathrm{PBr}_{3}, \mathrm{pyridine}, \mathrm{Et}_{2} \mathrm{O}$; (e) $\mathrm{AcOEt}_{\text {, }}$ LDA, CuI, THF (63\%, two steps); (f) $\mathrm{Me}_{3} \mathrm{SiOK}, \mathrm{Et}_{2} \mathrm{O}$ (100\%); (g) EDC.HCl, DMAP, DCM (89\%); (h) 89, DCM/PhMe, $100{ }^{\circ} \mathrm{C}(72 \%)$; (i) 87, $\mathrm{Pd}\left(\mathrm{PPh}_{3}\right)_{4}$ (20 $\mathrm{mol} \%)$, Tl(OEt), THF/ $\mathrm{H}_{2} \mathrm{O}$, tert-butyl methyl ether (TBME) (55\%). 
$\mathbf{9 0}$ to ent-87 to finally afford the corresponding isomer of 75 with all the configurations at the $\delta$-lactone unit inverted. Interestingly, the ${ }^{13} \mathrm{C}$ NMR data of both isomers was almost indistinguishable, and only subtle differences were noted in the ${ }^{1} \mathrm{H}$ NMR spectra. However, such discrepancies were enough to indisputably determine that the correct relative and absolute configuration of leiodermatolide was 75 (the same that Paterson et al..$^{51}$ arbitrarily drawn in the original publication). The structure of leiodermatolide was further validated and re-confirmed by Paterson et al. ${ }^{55}$ using a stereocontrolled total synthesis approach based on a convergent palladium-mediated assembly and macrolactonization sequence.

\section{Elatenyne}

In 1986, Hall and Reiss ${ }^{56}$ reported the isolation and structural elucidation of elatenyne (92), a non-isoprenoid halogenated ether obtained from Laurencia elata, collected from the western reef of St. Paul's Beach (Mornington Peninsula, Victoria). Its planar structure was proposed on the basis of 1D and 2D NMR experiments as well as derivatization experiments. Detailed analysis of the coupling constants and selective decoupling experiments provided further evidence for the proposed pyrano[3,2,b] pyran system, accounting for the relative configuration of the molecule as well (92, Figure 21).

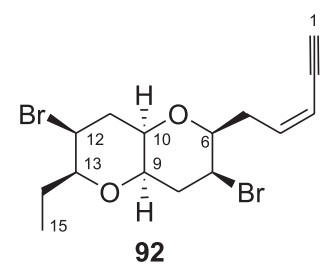

Figure 21. Originally proposed structure of elatenyne.

For two decades, the structure of elatenyne remained unchallenged, until Burton and co-workers ${ }^{57}$ revised it by total synthesis. As depicted in Scheme 11, one of the key steps in their synthetic approach was the generation of the pyrano[3,2-b]pyran system 96 from the thermodynamically favored rearrangement of the corresponding 2,2'-bifuranyl compound 95a. Subsequent epoxidation and ring-opening with inversion at $\mathrm{C}-2$ and C-6 by treatment with diallylmagnesium provided the corresponding $\mathrm{C}_{2}$-symmetric diol $\mathbf{9 8}$, key intermediate in the synthesis of $\mathbf{9 2}$.

As the synthetic work proceeded, the authors noticed that the two ring systems (pyrano[3,2-b]pyran and 2,2'-bifuranyl) are spectroscopically similar, sharing the same carbon and proton connectivity. Moreover,
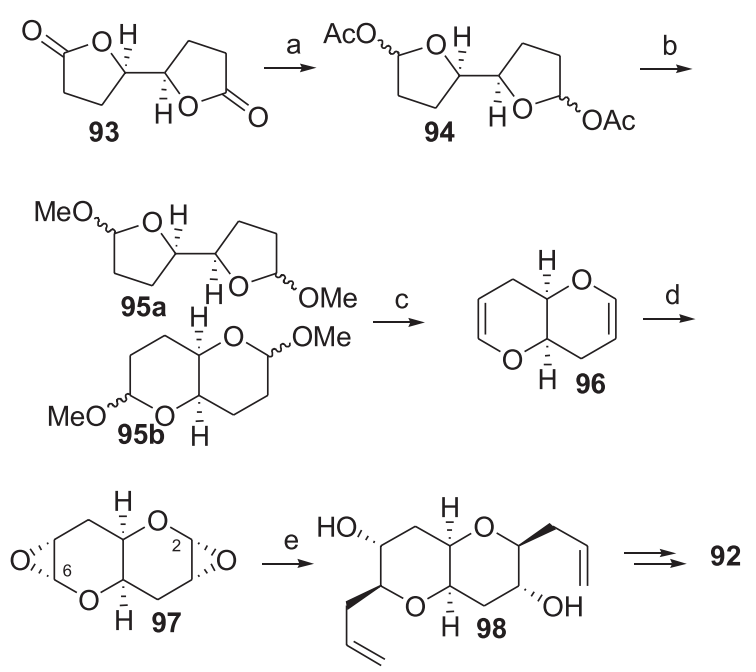

Scheme 11. Synthesis of the pyrano[3,2-b]pyran core of the originally proposed structure of elatenyne. Selected reagents and conditions: (a) DIBAL, DCM, then $\mathrm{Ac}_{2} \mathrm{O}$, DMAP, pyridine, DCM (83\%); (b) $\mathrm{MeOH}, \mathrm{HCl}$ (90\%); (c) $\mathrm{Me}_{3} \mathrm{SiI}, \mathrm{MeCN}$, then, $\left(\mathrm{Me}_{3} \mathrm{Si}\right)_{2} \mathrm{NH}$; (d) 3,3-dimethyldioxirane, $\mathrm{NaHCO}_{3}, \mathrm{DCM}$; (e) $\mathrm{Allyl}_{2} \mathrm{Mg}, \mathrm{Et}_{2} \mathrm{O}$, THF (57\%, three steps).

detailed analysis of the ${ }^{13} \mathrm{C}$ NMR data of different synthetic intermediates revealed that the shifts of the central oxygen-bearing carbon atoms fell in two different categories (Figure 22): in the case of pyrano[3,2-b]pyran systems, the ${ }^{13} \mathrm{C}$ NMR shifts of C-4a and C-8a resonate higher than $76 \mathrm{ppm}\left(\delta_{\mathrm{C}}<76 \mathrm{ppm}\right)$, whereas in the case of 2,2'-bifuranyl analogues, both carbons are shifted to lower field $\left(\delta_{\mathrm{C}}>76 \mathrm{ppm}\right)$. Taking into consideration that the relevant carbons in elatenyne resonate at $\delta_{\mathrm{C}} 79.5$ and $80.0 \mathrm{ppm}$, the authors concluded that the correct structure of the natural product should display a central 2,2'-bifuranyl system. However, they could not unequivocally determine the relative configuration of the natural product. ${ }^{57}$

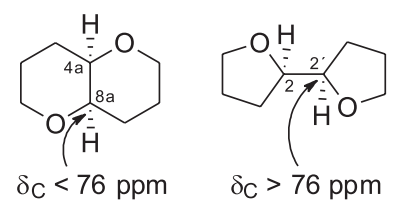

Figure 22. Selected ${ }^{13} \mathrm{C}$ NMR chemical shifts for pyrano $[3,2, b]$ pyran and 2,2'-bifuranyl systems.

To settle this issue, Burton and co-workers established a collaboration with Goodman and co-workers to computationally unravel the most likely tridimensional structure of elatenyne. ${ }^{58}$ From NMR calculations at the affordable B3LYP/6-31G**//MMFF level of theory, in one of the most exquisitely discussed papers in the pre-DP4 era, the authors compared the correlation coefficients and the averaged and maximum errors computed for the 32 possible diastereoisomers (including different approaches to deal with the large errors computed for the bromine- 
containing carbons) and concluded that structure 99 was the most likely candidate (Figure 23).

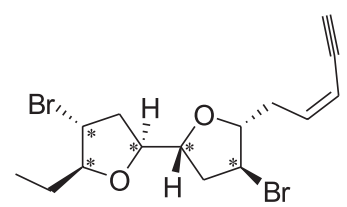

99

Figure 23. Most likely structure 99 for elatenyne according to NMR calculations. The carbon atoms that were varied to generate the candidate isomers are marked with an asterisk.

Inspired by this computational result, Burton, Kim and co-workers ${ }^{59}$ joined forces and undertook the necessary synthetic work to finally settle the real structure of elatenyne. First, they proposed a biosynthetic path that relied on previous work by Murai and co-workers ${ }^{60}$ disclosing that many $\mathrm{C}-15$ halogenated natural products may be derived from laurediol through a bromoperoxidasemediated bromonium ion-induced cyclization. On the basis of this background, the authors hypothesized that elatenyne might be generated from $(3 Z, 12 E)$-laurediol 100, that would be converted into bromonium ion $\mathbf{1 0 1}$ by the action of a bromoperoxidase. Nucleophilic attack of the hydroxy group at C-7 to the electron-deficient C-13 would afford the 8-membered ether 102. A second bromoperoxidasemediated endocyclic bromonium ion formation and further cyclization with the hydroxy group at C-6 would generate 104. Transannular displacement of bromide might give the tricyclic oxonium ion $\mathbf{1 0 5}$ that could be opened by nucleophilic attack of a bromide ion at C-7 to finally generate the most likely isomer of elatenyne according to the computational studies (Scheme 12).

However, since laurediols exist naturally as mixtures of the $(3 E / Z, 12 E / Z, 6 R / S, 7 R / S)$ stereoisomers, ${ }^{60}$ both authors considered prudent to synthesize the two opposite enantiomers of elatenyne. Given the challenge to pursue that goal, the teams divided the work to simplify the problem. Burton and co-workers ${ }^{59}$ followed a modular approach using stereochemically unambiguous reactions to synthesize ent-99, whereas Kim and co-workers ${ }^{59}$ devised a biomimetic route to prepare its enantiomer 99 and provide additional insight to the biosynthetic path discussed above.

The synthesis performed by Burton and co-workers ${ }^{59}$ is depicted in Scheme 13 and started with Sharpless asymmetric epoxidation (with concomitant kinetic resolution) of 1,5-hexadien-3-ol (106). The resulting epoxy alcohol 107 was protected and the epoxide opened at the terminal position with methylmagnesium bromide. A cross metathesis reaction between $\mathbf{1 0 8}$ and the $p$-bromobenzyl (PBB) protected derivative of $\mathbf{1 0 7}$ yielded 109, which was submitted to a Sharpless asymmetric dihydroxylation and subsequent acid-promoted cyclization to furnish 110. Diol 110 was converted into the bis-mesylate derivative, which after deprotection of the triethylsilyl (TES)-protected hydroxy group was readily converted to the 2,2'-bifuranyl 111. Standard functional group manipulation led to the dibromide $\mathbf{1 1 3}$ with perfect stereochemical control in each step. Finally, ozonolysis of the pendant alkene and Yamamoto-Peterson reaction between the resulting aldehyde and the in situ prepared 114 gave elatenyne ent-99. ${ }^{59}$

Meanwhile, Kim and co-workers ${ }^{59}$ carried out the biomimetic synthesis of $\mathbf{9 9}$ as summarized in Scheme 14. The hydroxyamide $\mathbf{1 1 6}$ was prepared in few steps from the known allylic alcohol 115. Treatment of $\mathbf{1 1 6}$ with LiHDMS followed by addition of allyl bromide led to the formation of the desired $\alpha, \alpha^{\prime}$-anti isomer 117. Transformation of the secondary alcohol into a leaving group followed by bromide displacement (with inversion of configuration) and RCM afforded the key oxocene 118. Transformation of the amide group in $\mathbf{1 1 8}$ to the corresponding ketone, followed by reduction with $L$-selectride provided the desired Felkin-Anh type alcohol 119. In perfect agreement with their biosynthetic proposal, upon treatment with $\mathrm{PhSeBr}$, activated silica and potassium carbonate, oxocene 119 was smoothly transformed into dibrominated 2,2'-bifuranyl compound 120. It was proposed that this intrincate
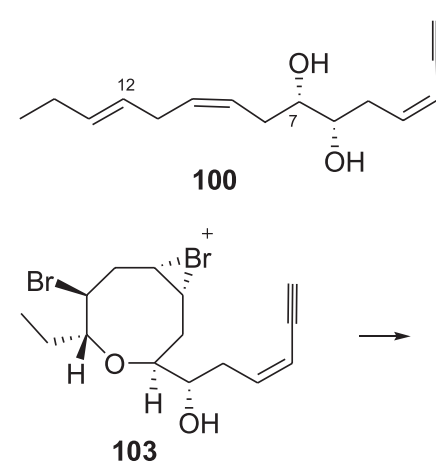<smiles>C#C/C=C\C[C@H](O)[C@@H](O)C/C=C/CC1(Br)C2(Br)CC1(CC)C2Br</smiles>

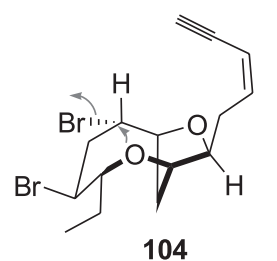

101

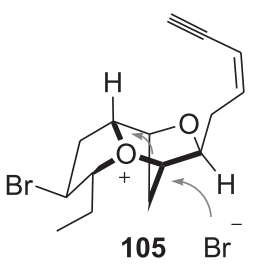

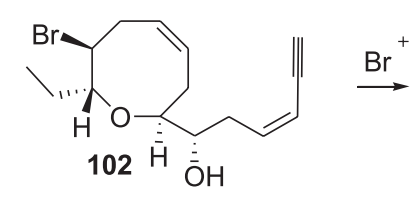

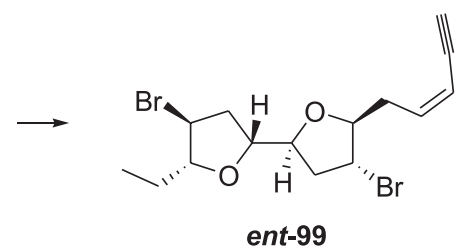

Scheme 12. Proposed biosynthesis of elatenyne. 

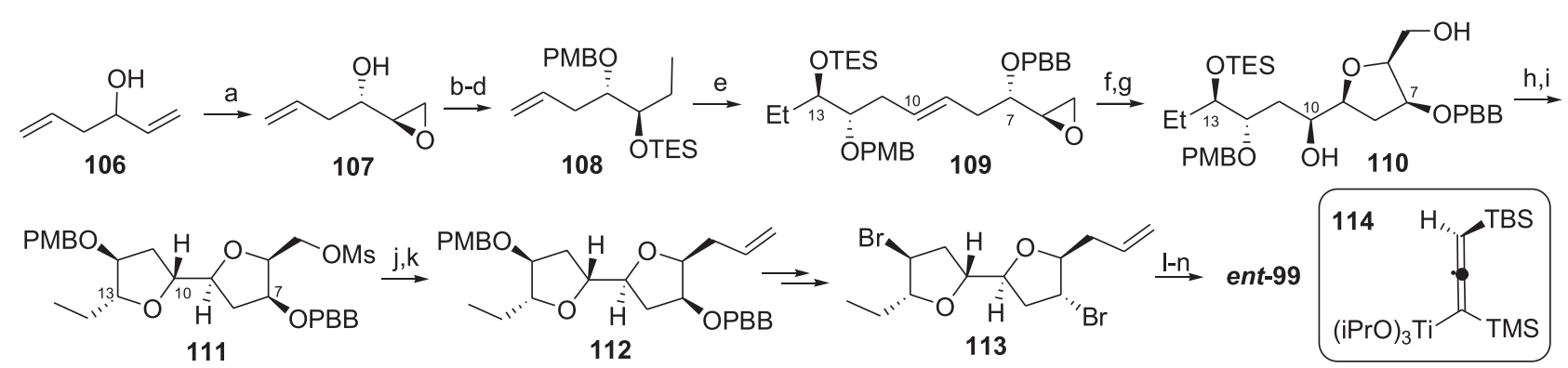

Scheme 13. Synthesis of the most likely structure of ent-99 by Burton and co-workers.$^{59}$ Selected reagents and conditions: (a) $L-(+)-\mathrm{DCT}, \mathrm{Ti}\left(\mathrm{O} \mathrm{Pr}_{4}\right.$, ${ }^{t} \mathrm{BuOOH}$, DCM (38\%, ee > 95\%); (b) NaH, PMBBr, TBAI, THF; (c) MeMgBr, CuI, THF; (d) TESCl (87\%, three steps); (e) $p$-bromobenzyl-protected 107, Grubbs II, 1,4-benzoquinone, DCM (45\%); (f) AD-mix- $\alpha, t \mathrm{BuOH} / \mathrm{H}_{2} \mathrm{O}(71 \%)$; (g) CSA, DCM (72\%); (h) MsCl, Et 3 N, DCM. (i) TBAF, THF (66\%, two steps); (j) TBAI, PhMe (83\%); (k) VinylMgBr, PhH/THF (58\%); (1) $\mathrm{O}_{3}, \mathrm{Ph}_{3} \mathrm{P}, \mathrm{DCM}$ (85\%); (m) 114, THF (83\%, Z:E > 30:1); (n) TBAF, DCM (80\%).

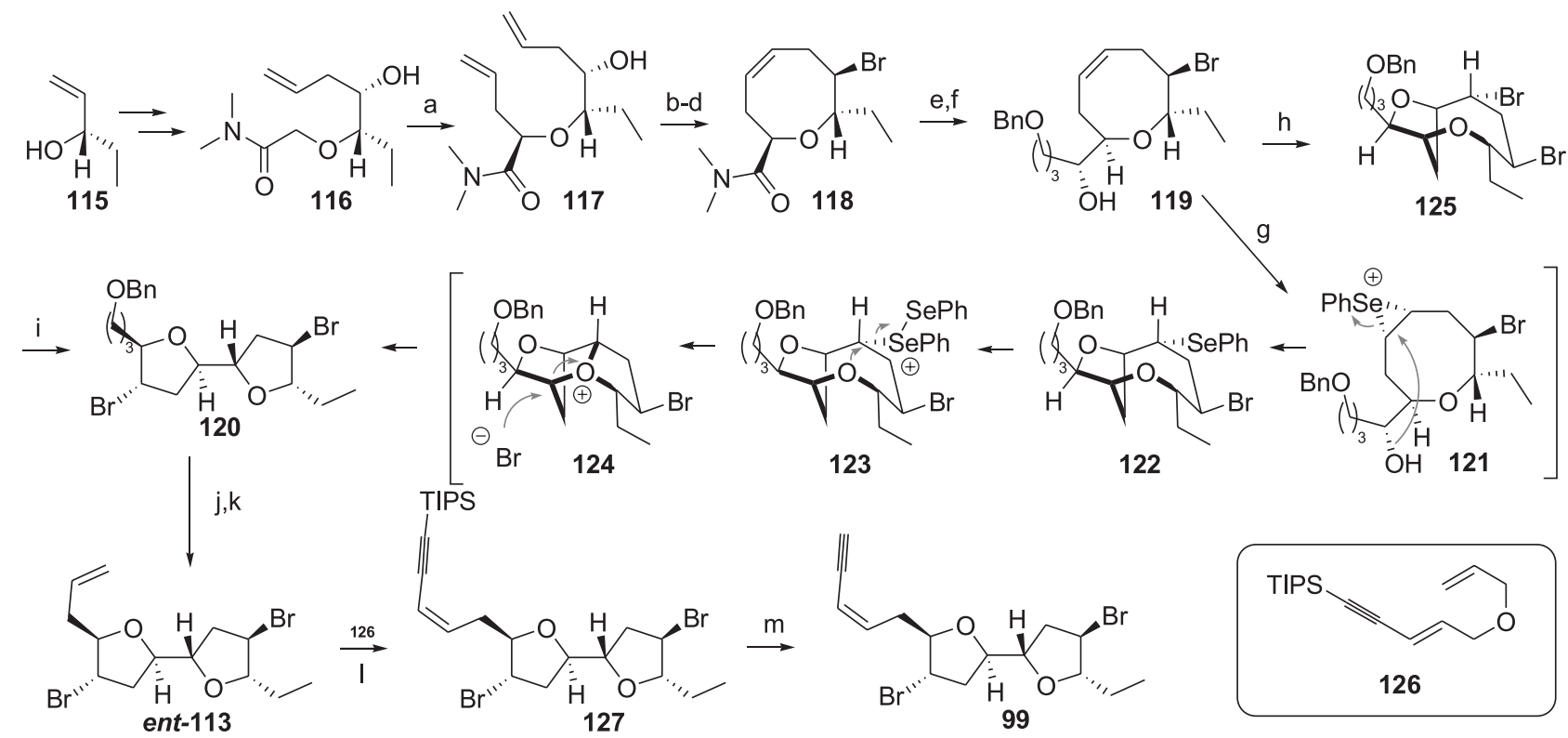

Scheme 14. Synthesis of the most likely structure 99 by Kim and co-workers. ${ }^{59}$ Selected reagents and conditions: (a) $\mathrm{LiHDMS} \mathrm{CH}_{2}=\mathrm{CHCH}_{2} \mathrm{Br}$, THF (85\%, anti/syn 9.3:1); (b) $\mathrm{ClSO}_{2} \mathrm{CH}_{2} \mathrm{Cl}$, 2,6-lutidine, DCM; (c) $\mathrm{LiBr}, \mathrm{Et}_{2} \mathrm{O} / \mathrm{THF}$ (72\%, two steps); (d) Grubbs I, $\mathrm{DCM}(94 \%) ;(\mathrm{e}) \mathrm{BnO}(\mathrm{CH})_{3} \mathrm{MgBr}$, THF (94\%); (f) $L$-selectride, THF (99\%); (g) PhSeBr, $\mathrm{SiO}_{2}, \mathrm{~K}_{2} \mathrm{CO}_{3}, \mathrm{DCM}(70 \%)$; (h) NBS, DCM (91\%); (i) MeCN, $80{ }^{\circ} \mathrm{C}(93 \%)$; (j) $\mathrm{H}_{2}, \mathrm{Pd}(\mathrm{OH}) 2, \mathrm{THF}$ (95\%); (k) o-nitrophenylselenocyanide, (Oct) ${ }_{3} \mathrm{P}, \mathrm{THF}$, then $\mathrm{H}_{2} \mathrm{O}_{2}$ (97\%); (1) enyne 126, Grubbs-Hoveyda II, PhH (68\%, Z:E 4.6:1); (m) TBAF, THF (98\%).

rearrangement was likely initiated by selenonium ion $\mathbf{1 2 1}$ formation. Subsequent nucleophilic attack of the secondary alcohol may generate seleno ether $\mathbf{1 2 2}$ that could react with an additional molecule of $\mathrm{PhSeBr}$ to generate the activated species 123. Transannular attack of the oxocene oxygen with concomitant displacement of the selenium-derived leaving group would yield the dioxatricyclic oxonium ion 124. Finally, $\mathrm{S}_{\mathrm{N}} 2$-like bromide-mediated regioselective ring opening of $\mathbf{1 2 4}$ would furnish 120. Alternatively, the authors indirectly achieved this transformation by initial treatment of $\mathbf{1 1 9}$ with $\mathrm{N}$-bromosuccinimide (NBS), resulting in the formation of $\mathbf{1 2 5}$, which was rearranged to 120 upon heating at $80^{\circ} \mathrm{C}$. With the key intermediate $\mathbf{1 2 0}$ in hand, the final stages towards the synthesis of $\mathbf{9 9}$ were carried out. Deprotection of the primary alcohol and Grieco elimination generated ent-113. To install the pendant $(Z)$ - enyne side chain, a cross metathesis of enyne $\mathbf{1 2 6}$ with the alkene ent-113 was carried out yielding the desired product in moderate selectivity and good yield, which was finally transformed into elatenyne 99 by removal of the acetylene protecting group. ${ }^{59}$

At the end, both groups accomplished their goals, being the NMR data of synthetic samples identical between each other and to natural elatenyne, indicating that the relative configuration of the molecule had been correctly proposed according to the computational work made by Goodman and co-workers. ${ }^{58}$ On the other hand, despite the authors measured different signs in the optical rotations using the sodium D line, such values were close to zero and significantly different to the one reported by the isolation team (Burton and co-workers' ${ }^{59}$ ent-99 $[\alpha]_{\mathrm{D}}=-1.6(c 0.25, \mathrm{DCM})$; Kim and co-workers ${ }^{59} 99$ 
$[\alpha]_{\mathrm{D}}=+0.8(c 0.80, \mathrm{DCM}) ;$ Hall and Reiss ${ }^{56}$ natural elatenyne $\left.[\alpha]_{D}=+16.8(c 1.4, D C M)\right)$. In a final effort to determine the absolute configuration of elatenyne, the authors synthesized bromofucin (compound 104, Scheme 12), a common biosynthetic precursor of elatenyne, and from comparison of the optical rotations with the reported for the natural product, they settled the absolute configuration of $\mathbf{1 0 4}$ as drawn in Scheme 12. For that reason, the authors concluded that the likely absolute configuration of elatenyne should be ent-99. ${ }^{59}$

\section{Laurefurenyne $A$ and $B$}

In 2010, Jaspars and co-workers ${ }^{61}$ reported the isolation and structure determination of novel cyclic ether acetogenins, termed laurefurenynes A-F, from the aqueous extract of the alga Laurencia sp. collected in the Philippines. During the structural elucidation of laurefurenynes A and B (128 and 129, Figure 24) from standard 1D and 2D NMR experiments, the authors considered the pyrano[3,2-b] pyran system originally proposed for elatenyne as an option. However, they finally opted for the 2,2'-bisfuran system based on the relative downfield chemical shift of C-9 and C-10 $\left(\delta_{\mathrm{C}}>76 \mathrm{ppm}\right)$, considerably shifted upfield in the case of pyrano[3,2-b]pyran analogues. ${ }^{57}$ The relative configuration of $\mathbf{1 2 8}$ was determined from NOESY experiments, revealing that protons $\mathrm{H}-6, \mathrm{H}-7$ and $\mathrm{H}-9$ were syn to $\mathrm{H}-8 \mathrm{a}$, whereas $\mathrm{H}-10, \mathrm{H}-12$ and $\mathrm{H}-13$ were syn to H-11a. On the other hand, the connection between both tetrahydrofuran fragments could not be irrefutably assigned, and two possible stereoisomers were taken into consideration (9,10-syn and 9,10-anti). From dubious molecular modeling results, the authors hypothesized that the experimentally observed NOESY correlations could be better accounted by the syn adduct. Thus, the structure of 128 was proposed as shown in Figure 24. By comparing the NMR data of $\mathbf{1 2 8}$ and 129, the authors concluded that $\mathbf{1 2 9}$ should be the 3,4-trans isomer of $\mathbf{1 2 8}$, bearing the same relative configuration from $\mathrm{C}-6$ to $\mathrm{C}-13 .{ }^{61}$

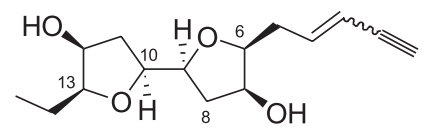

laurefurenyne $A(3 Z, 128)$

laurefurenyne $\mathrm{B}(3 E, 129)$

Figure 24. Originally proposed structures 128 and 129 for laurefurenynes A and $\mathrm{B}$, respectively.

Despite preliminary biological essays indicated that laurefurenynes A and B were inactive against tumoral cell inhibition, the originally proposed structure caught the attention of Paton, Burton and co-workers. ${ }^{62}$ In particular, they noticed that the originally proposed structures of 128 and $\mathbf{1 2 9}$ did not match the structures of related 2,2'-bifuranyl natural products also isolated from Laurencia spp., including elatenyne (99, Figure 23), notoryne and lauredendecumenyne (130 and 131, respectively, Figure 25).
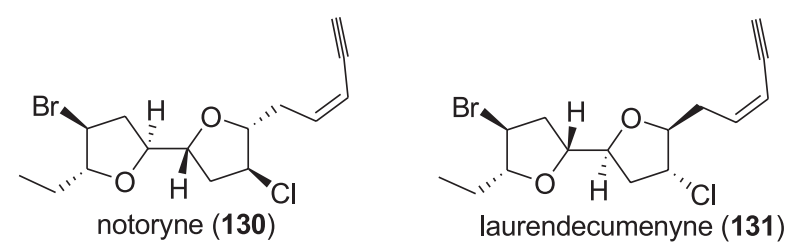

Figure 25. Structures of notoryne (130) and laurendecumenyne (131).

Interestingly, in all these examples an anti-9,10 relationship was determined, in contrast to the cis relative configuration proposed for laurefurenynes $\mathrm{A}$ and $\mathrm{B}$. As part of the ongoing interest of Burton and co-workers ${ }^{62}$ in the synthesis of similar natural products, the authors synthesized structurally related fragments and found modest correlation with the NMR data reported for the natural product. In tandem with the synthetic studies, they also performed quantum chemical calculations of NMR shifts to suggest the most likely structure of the natural products. Briefly, the authors first explored and benchmarked the performance of the mPW1PW91/6$311 \mathrm{G}^{* *} / / \omega \mathrm{B} 97 / 6-31 \mathrm{G}^{*}$ level of theory using a set of 113 rigid small molecules. In an insightful discussion the authors concluded that whenever possible, DFT-optimized geometries afforded better results than Merck molecular force field (MMFF) (or related) geometries as inputs for further NMR calculations. Since the DP4 formalism was built over MMFF geometries, the authors used the NMR calculations of the data set to estimate the key statistical terms of the error distributions, and used this to update the DP4 equations. Next, they computed the NMR shifts of all possible 32 diastereoisomers of laurefurenyne B at the above mentioned level of theory, and correlated the NMR simulations with the experimental data of the natural product using the modified DP4 probability. As a result, the originally proposed structure showed a very low probability, confirming the suspected misassignment. On the other hand, both proton and carbon data suggested that the most likely structure of laurefurenyne B was isomer $\mathbf{1 3 2}$ (Figure 26), showing a marked stereochemical difference respecting the original proposal. Both the fusion of the two tetrahydrofuran moieties and the relative configuration of C-6/C-7 are anti in 132, in contrast to the former cis arrangement between these groups. ${ }^{62}$

With these computational results, the authors moved towards the total synthesis of 132. Given that Burton and 


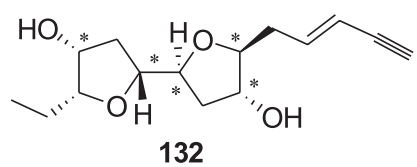

Figure 26. Most likely structure $\mathbf{1 3 2}$ for laurefurenyne B according to NMR calculations. The carbon atoms that were varied to generate the candidate isomers are marked with an asterisk.

co-workers ${ }^{59}$ had previously reported the synthesis of the revised structure of elatenyne, the advanced intermediate 112 (Scheme 13) was employed in the preparation of laurefurenyne B. To achieve their goals, the authors had to invert the configuration at $\mathrm{C}-7$ and $\mathrm{C}-12$, which was successfully carried out using a double Mitsunobu reaction (Scheme 15). ${ }^{62}$

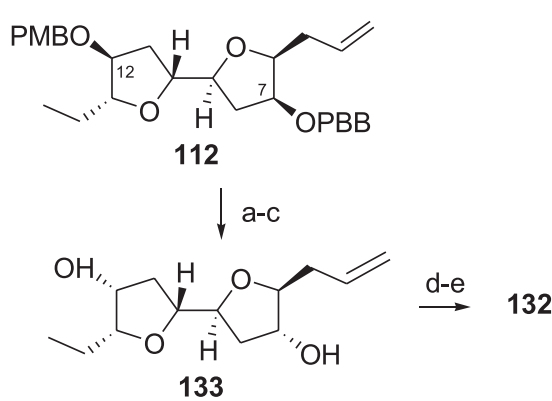

Scheme 15. Synthesis of the most likely structure $\mathbf{1 3 2}$ for laurefurenyne B. Selected reagents and conditions: (a) $\mathrm{BCl}_{3}, \mathrm{DCM}(94 \%$ ); (b) diisopropyl azodicarboxylate (DIAD), $\mathrm{PPh}_{3}$, p-nitrobenzoic acid, THF; (c) $\mathrm{K}_{2} \mathrm{CO}_{3}$, $\mathrm{MeOH}$ (75\%, two steps); (d) crotonaldehyde, Grubbs II, DCM; (e) $\mathrm{TMSCH}_{2} \mathrm{~N}_{2}, \mathrm{LDA}$, THF, then $2 \mathrm{M} \mathrm{HCl}$ (45\%, two steps).

The NMR spectra of synthetic sample $\mathbf{1 3 2}$ showed excellent agreement with the reported data of the natural product, showing an excellent example for the computerguided synthesis concept. This finding was also consistent with a common biosynthetic path proposed for related natural products.

\section{Hexacyclinol}

In 2002, Udo Gräfe and co-workers ${ }^{63}$ isolated a novel compound from the fungal strain Panus rudis HKI 0254 and termed it hexacyclinol. The structural elucidation, which relied on different techniques such as high resolution mass spectrometry (HRMS), infrared (IR) and NMR, including ${ }^{1} \mathrm{H},{ }^{13} \mathrm{C}$, distortionless enhancement by polarization transfer (DEPT), COSY, HMQC, HMBC and NOESY experiments, led to the proposal depicted in Figure 27.

In 2006, La Clair ${ }^{64}$ reported the first total synthesis of the originally proposed structure of hexacyclinol (134), claiming excellent agreement between the NMR data of synthetic sample and the natural product. The 37-step synthesis (not discussed in this review) involved several

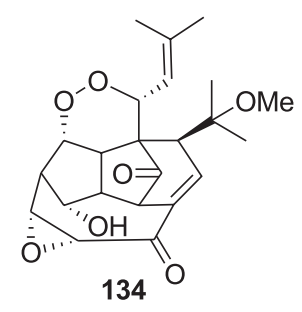

Figure 27. Originally proposed structure of hexacyclinol.

challenging steps, and allowed to obtain $3.6 \mathrm{~g}$ of the natural product. Such impressive results, coupled with the doubtful stability of the endo-peroxide present in 134, generated some skepticism among the scientific community. A few months after La Clair's publication, Scott Rychnovsky ${ }^{65}$ challenged the structure of hexacyclinol by computational means in a seminal work on the use of quantum calculations of NMR shifts in structural elucidation. The NMR shifts of the originally proposed structure was carried out at the mPW1PW91/6-31G**//HF/3-21G level of theory (previously validated with related known compounds) and a significantly poor match between experimental and calculated values was noticed, with several carbons showing errors higher than $10 \mathrm{ppm}$. Such poor correlation suggested that the proposed structure was in error, though the real identity of hexacyclinol had to be solved. To make progress in this regard, Rychnovsky ${ }^{65}$ became interested in panepophenanthrin (135), isolated in 2002 from a different strain of Panus rudis, ${ }^{66}$ and synthesized by several research groups ${ }^{67}$ Despite the ring systems of $\mathbf{1 3 4}$ and $\mathbf{1 3 5}$ bear no relationship, both display similar functional groups, molecular weights and biological source. Since hexacyclinol was purified by column chromatography on silica gel with methanol, Rychnovsky ${ }^{65}$ envisioned that $\mathbf{1 8 8}$ might be an isolation artifact from the acid-promoted decomposition of panepophenanthrin (135), as shown in Scheme 16. In addition, the NMR calculations carried out with structure $\mathbf{1 3 8}$ showed very nice agreement with the experimental NMR data of the natural product, strengthening Rychnovsky's proposal. ${ }^{65}$

In the meantime, Rychnovsky teamed up with Porco and co-workers (which had previously synthesized panepophenanthrin), ${ }^{67}$ to experimentally prove this structural hypothesis. ${ }^{68}$ Unfortunately, treatment of synthetic $\mathbf{1 3 5}$ under a variety of acidic conditions did not lead to any observable conversion towards $\mathbf{1 3 8}$, suggesting that the hemiacetal structure of $\mathbf{1 3 5}$ might lock the dimeric framework, preventing further ring opening events. Hence, the authors revised their synthetic route towards $\mathbf{1 3 8}$ by preparing precursor 139 (termed "pre-hexacyclinol") from an exo selective Diels-Alder dimerization of epoxyquinol (the TES-deprotected compound 140, Scheme 17). Preparation 


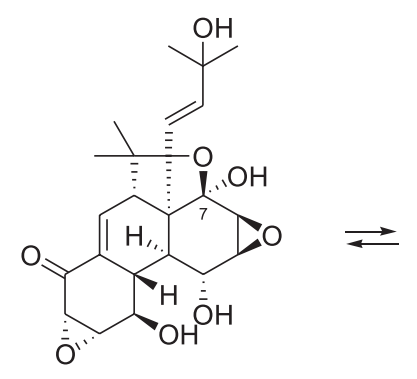

panepophenanthrin (135)
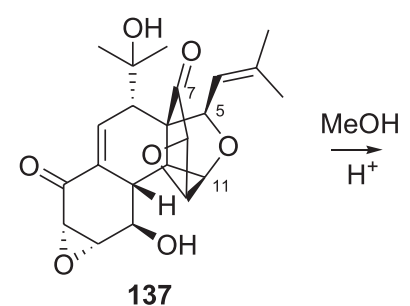
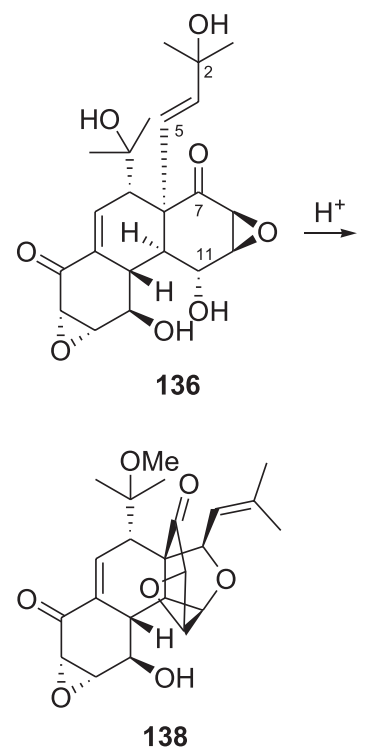

138

Scheme 16. Rychnovsky's ${ }^{65}$ proposal of structure $\mathbf{1 3 8}$ for hexacyclinol to be obtained from panepophenanthrin (135).

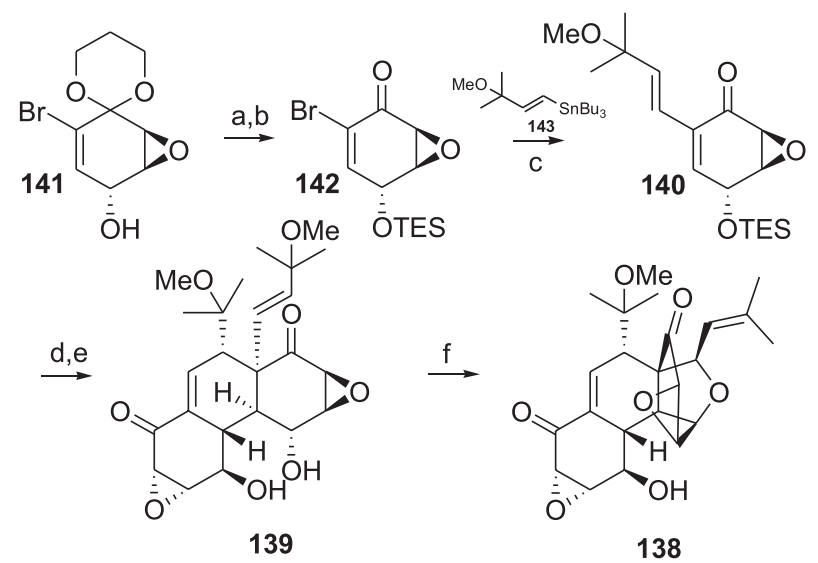

Scheme 17. Synthesis of the revised structure of hexacyclinol (138). Selected reagents and conditions: (a) K10 clay, DCM (98\%); (b) $\mathrm{Et}_{3} \mathrm{SiCl}$, 2,6-lutidine, DMAP, DCM (83\%); (c) $\mathrm{Pd}_{2}(\mathrm{dba})_{3}, \mathrm{AsPh}_{3}, \mathrm{PhMe}(96 \%)$; (d) $\mathrm{Et}_{3} \mathrm{~N} \cdot 3 \mathrm{HF}, \mathrm{MeCN}$; (e) neat, rt, $72 \mathrm{~h}$ (87\%, two steps); (f) K10, AcOEt $(99 \%)$.

of monomer 140 started from the readily available epoxy alcohol 141, which after standard manipulation of protecting groups was transformed into bromide 142. Subsequent Stille coupling with vinyl stannane $\mathbf{1 4 3}$ allowed the installation of the allylic side chain in $\mathbf{1 4 0}$. As expected, compound 140 dimerized after deprotection, leading to the formation of $\mathbf{1 3 9}$ in good yields. Finally, treatment of $\mathbf{1 3 9}$ with K10 clay generated the target compound $\mathbf{1 3 8}$ following a $\mathrm{S}_{\mathrm{N}} 2 \%$ cyclization path. The NMR data of the synthetic sample, whose structure was confirmed by X-ray analysis, was identical to those reported by Gräfe and co-workers ${ }^{63}$ for hexacyclinol. ${ }^{68}$ After this work, there were two synthesis of remarkably different structures (134 and 138), for which both were claimed having identical NMR data compared to natural hexacyclinol. This debate opened a new dilemma if the two

structures could have exactly the same NMR properties. Nevertheless, according to new calculations carried out by Saielli and Bagno, ${ }^{69}$ this should not be the situation in this case. After this controversy, the article from La Clair was retracted from Angewandte Chemie (in agreement with the author) due to the lack of sufficient Supporting Information to validate the author claim. ${ }^{70}$

\section{Aldingenins}

Lago and co-workers ${ }^{71}$ described the isolation of four metabolites from $L$. aldingensis (aldingenin A, in 2003 and B-D, in 2006) which were assigned structures 139-142 based on spectroscopic studies and biogenetic considerations (Figure 28).

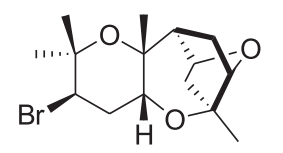

Aldingenin A (139)

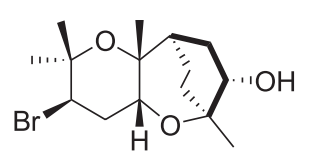

Aldingenin C (141)

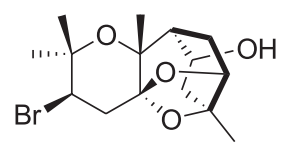

Aldingenin B (140)

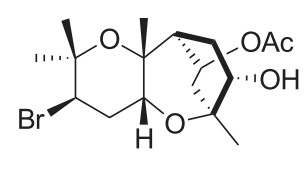

Aldingenin $D(142)$
Figure 28. Proposed structures for aldingenins A-D.

In 2012, Crimmins and Hughes ${ }^{72}$ reported the total synthesis of the proposed structure for aldingenin B (140) based on a late stage bromoetherification of the tertiary alcohol corresponding to ketone $\mathbf{1 4 3}$, which was obtained from the cyclization of hydroxyketone 144 (Scheme 18). Diastereoselective alkylation of the titanium(IV) enolate of ( $R$ )-thiazolidin-2-thione 147 with the dibenzylacetal of 3-methyl-3-butenal in the presence of $\mathrm{SnCl}_{4}$, followed by removal of the chiral auxiliary and RCM provided diene 146. Dihydroxylation of the double bond, conversion of the diol to the corresponding ketal and tetrapropylammonium perruthenate (TPAP)/NMO oxidation provided aldehyde 145 (Scheme 18). Alkylation of $\mathbf{1 4 5}$ with the lithium anion of the required dithiane (not shown) could only be secured with the use of $\mathrm{CeCl}_{3} .2 \mathrm{LiCl}$ in THF at $-78^{\circ} \mathrm{C}$ to afford $\mathbf{1 4 4}$ as an inconsequential 2.7:1 mixture of diastereoisomers. Exposure of hydroxyketone 144 to $\mathrm{Hg}\left(\mathrm{ClO}_{4}\right)_{2}$ in $\mathrm{THF} / \mathrm{H}_{2} \mathrm{O}$ in the presence of $\mathrm{CaCO}_{3}$ afforded the corresponding ketone which was treated with $\mathrm{HClO}_{4}$ at $0{ }^{\circ} \mathrm{C}$ and under ultrasound irradiation to yield the corresponding tricyclic ketal bearing a primary alcohol, after triisopropylsilyl (TIPS) ether cleavage. Oxidation of the primary alcohol obtained, followed by methylenation 

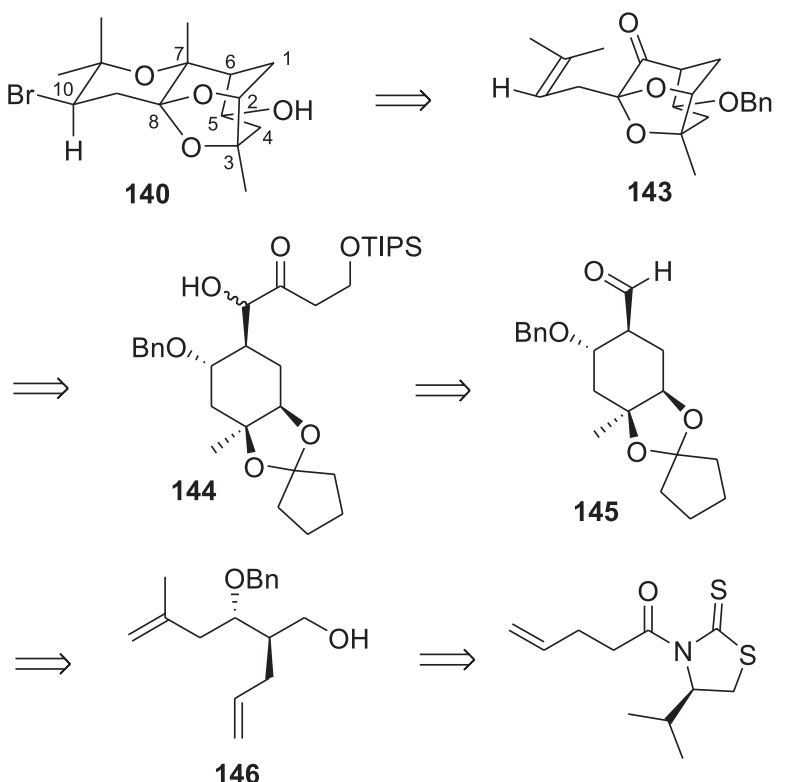

147

Scheme 18. Synthetic plan by Crimmins and Hughes ${ }^{72}$ for structure 140 proposed for aldingenin $\mathrm{B}$.

with Nysted reagent and cross metathesis reaction in neat 2-methyl-2-butene, afforded prenylated ketone 143 which, after treatment with $\mathrm{MeLi}$ in the presence of $\mathrm{CeCl}_{3} .2 \mathrm{LiCl}$, set the stage for the bromoetherification reaction which was carried out with 2,4,4,6-tetrabromocyclohexa2,5-dienone (TBCO). The benzylic ether obtained in low yield was uneventfully converted to the proposed structure of aldingenin B (140) upon hydrogenolysis.

Comparison of the NMR data of synthetic $\mathbf{1 4 0}$ and those of natural aldingenin $\mathrm{B}$ exposed significant differences that led the authors to disclaim the proposed structure. In fact, inspection of the NMR spectra of the natural compound and the expected coupling constants involving H-2, H-5 and $\mathrm{H}-6$ for the proposed structure cast doubts about its correctness. Additionally, HMBC spectrum of the natural sample did not show the H-2/C-8 crosspeak expected for the proposed structure, which was indeed present in the HMBC spectrum of synthetic $\mathbf{1 4 0}$.

In 2014, Takahashi et al..$^{73}$ reported a concise synthesis of the structure proposed by Lago and co-workers ${ }^{71}$ for aldingenin C (141) from trans-limonene oxide, which was further converted to the corresponding primary alcohol 149 (Scheme 19). 10-Camphorsulfonic acid (CSA)-mediated cyclization provided a mixture of two bicyclic alcohols which after an acetylation/deacetyaltion sequence for separation of the stereoisomers, and protection of the secondary alcohol of the minor isomer as its TBS ether, provided bicyclic alkene 150. Lemieux-Johnson oxidation of $\mathbf{1 5 0}$ provided the corresponding ketone which was converted to the corresponding lithium enolate previous to prenylation, affording the desired diastereoisomer $\mathbf{1 5 1}$ as the minor product. The major isomer (not shown) could be converted to the desired stereoisomer $\mathbf{1 5 1}$ via protonation of the corresponding lithium enolate with dimethyl $D$-tartrate. Addition of MeLi, followed by bromocyclization with TBCO, afforded the desired TBS ether as the major isomer, which yielded aldingenin $\mathrm{C}$ (141) after treatment with TBAF.

Comparison of the ${ }^{1} \mathrm{H}$ and ${ }^{13} \mathrm{C}$ NMR data of synthetic 141 with those reported by Lago and co-workers ${ }^{71}$ for natural aldingenin $\mathrm{C}$ revealed inconsistencies with clear differences in the chemical shift values of H-2, H-4 and Me-15 in the ${ }^{1} \mathrm{H}$ NMR spectrum. In particular, the signal of $\mathrm{H}-2$ in synthetic $\mathbf{1 4 1}$ was observed at $3.87 \mathrm{ppm}$, while the corresponding signal in the natural product appeared at $4.37 \mathrm{ppm}$. In the ${ }^{13} \mathrm{C}$ NMR spectrum of synthetic 141, the signals for C-1 to C-6, C-8, and C-15 deviated by 2.8 $13.9 \mathrm{ppm}$ when compared with the corresponding signals of natural aldingenin $\mathrm{C}$. These data suggest that structure $\mathbf{1 4 1}$ proposed for natural aldingenin $\mathrm{C}$ should be revised, and the right half part of the natural product, namely, the 2-oxabicyclo[3.2.2]nonane system, was obviously questionable.

In order to shed light to the real structure of aldingenin C, the authors searched similar ${ }^{13} \mathrm{CNMR}$ data from the literature using the canonical representation of stereochemistry (CAST)/CNMR system and found that caespitol, a dibromo monochlorinated metabolite isolated from Laurencia caespitosa, displayed identical ${ }^{13} \mathrm{C}$ NMR and very similar ${ }^{1} \mathrm{H}$ NMR data to those reported for aldingenin C. However, the authors acknowledged an inconsistency in the MS data
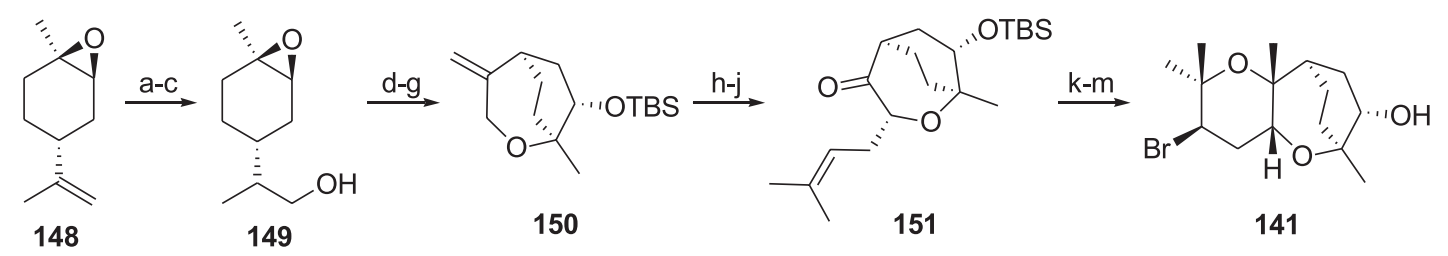

Scheme 19. Synthesis of structure 141 proposed for aldingenin C. Selected reagents and conditions: (a) HOCl, DCM (83\%); (b) KOAc, DCM (80\%); (c) $\mathrm{K}_{2} \mathrm{CO}_{3}, \mathrm{MeOH}\left(71 \%\right.$ ); (d) CSA, DCM, $0{ }^{\circ} \mathrm{C}$, rt; (e) $\mathrm{Ac}_{2} \mathrm{O}$, pyr, rt; (f) $\mathrm{K}_{2} \mathrm{CO}_{3}, \mathrm{MeOH}$; (g) TBSOTf, 2,6-lutidine, DCM, $-78^{\circ} \mathrm{C}\left(18 \%\right.$, four steps); (h) OsO ${ }_{4}$, $\mathrm{NaIO}_{4}$, aq THF, room temperature (rt) (88\%); (i) LDA, prenylbromide, THF, HMPA, $-78^{\circ} \mathrm{C}, 0^{\circ} \mathrm{C}$; (j) LHMDS, THF, HMPA, then dimethyl $D$-tartrate, $-78{ }^{\circ} \mathrm{C}$, rt (44\%, two steps); (k) MeLi, THF, $-78{ }^{\circ} \mathrm{C}(94 \%)$; (1) TBCO, $\mathrm{MeNO}_{2}, 0{ }^{\circ} \mathrm{C}(25 \%)$; (m) TBAF, THF, $0{ }^{\circ} \mathrm{C}(85 \%)$. 
as aldingenin $\mathrm{C}$ was reported to have a molecular ion at $\mathrm{m} / \mathrm{z} 332.0971$ in the high-resolution electron ionization mass spectrometry (HREIMS) (corresponding to a formula $\mathrm{C}_{15} \mathrm{H}_{25} \mathrm{O}_{3} \mathrm{Br}$ ) while caespitol displayed $\mathrm{C}_{15} \mathrm{H}_{25} \mathrm{O}_{2} \mathrm{ClBr}_{2}$ as its molecular formula.

In 2014, Kutateladze and Mukhina ${ }^{74}$ reported on a fast and more precise parametrization approach to calculate coupling constants in the ${ }^{1} \mathrm{H}$ NMR spectra and after computationally analyze the spectrum of aldingenin A, these authors suggested that there is no oxabicyclo[2.2.1] heptane moiety in the structure of the natural compound. In the following year, the same group reinvestigated the structures of aldingenins A and B through computational studies, based primarily on proton spin-spin coupling constants (but also including ${ }^{13} \mathrm{C}$ NMR chemical shifts). ${ }^{75}$ They concluded that although aldingenin A appears to have the bromopyran ring it does not display the 7-oxabicyclo [2.2.1] heptane moiety proposed by Lago and co-workers ${ }^{71}$ and assigned the structure of (5S)-hydroxycaespitol to aldingenin $\mathrm{A}$ and the corresponding hemiketal to aldingenin B (Figure 29).

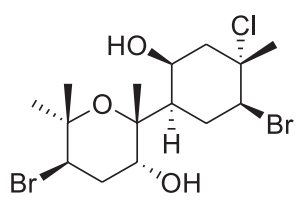

Aldingenin A

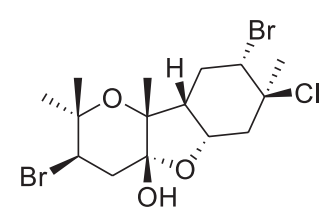

Aldingenin B
Figure 29. Structures proposed by Kutateladze and co-workers ${ }^{74}$ for aldingenins $\mathrm{A}$ and $\mathrm{B}$.

It is rather surprising that compounds which are not even constitutional isomers are under consideration to describe the structure of a natural product. One has to wonder the reasons behind this failure to unambiguously describe the correct structure when so many analytical tools are available for such a task. In summary, despite all efforts so far, the real structures of aldingenins A-D await experimental proof either by total synthesis or reisolation and reinvestigation of its spectroscopic and/or crystallographic properties.

\section{Aquatolide}

In 1989, San Feliciano et al..$^{76}$ isolated a novel sesquiterpene lactone from the hexane extracts of Asteriscus aquaticus, named aquatolide, to which structure 152 was proposed based on spectroscopic studies, mainly homo- and heteronuclear two-dimensional NMR correlations (Figure 30). In 2012, Tantillo and co-workers ${ }^{77}$ computed NMR chemical shifts for structure $\mathbf{1 5 2}$ at the CPCM/mPW1PW91/6-311+G(2d,p)//B3LYP/6-31+G(d,p) level of theory, and although the proposed structure was consistent with all the reported experimental data, including NOE, the calculated chemical shifts for the proposed structure deviated from the experimental data available for the natural product. The authors undertook a combination of both rational and arbitrary changes to the proposed structure, followed by recalculation of the ${ }^{1} \mathrm{H}$ and ${ }^{13} \mathrm{C}$ chemical shifts and coupling constants at the more affordable CPCM/B3LYP/6-31+G(d,p)//B3LYP/6$31 \mathrm{G}(\mathrm{d})$ level, and concluded that structure $\mathbf{1 5 3}$ was the most probable one for aquatolide (Figure 30). These authors attempted to isolate the natural product from A. aquaticus as well as other metabolites which could serve as synthetic precursors for structures $\mathbf{1 5 2}$ and 153. In fact, a metabolite was isolated which displayed the expected molecular mass, spectroscopic data, melting point and specific optical rotation as aquatolide but its NMR data was not immediately reconciled with those of structure $\mathbf{1 5 3}$. X-ray studies carried out with such metabolite confirmed its structure as 153. More recently, Gary Williamson and coworkers ${ }^{77}$ alternatively revealed the structure of aquatolide as $\mathbf{1 5 3}$ using anisotropic NMR measurements, including residual dipolar coupling (RDCs) and residual chemical shift anisotropy (RCSAs).

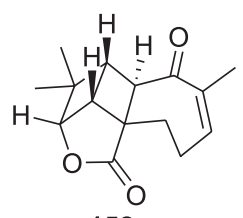

152

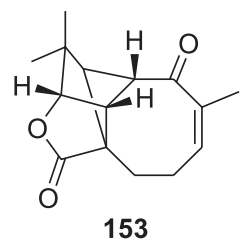

153
Figure 30. Proposed structures for aquatolide by San Feliciano et al. ${ }^{76}$ (152) and Tantillo and co-workers ${ }^{77}(\mathbf{1 5 3})$.

In 2016, Tantillo and co-workers ${ }^{78}$ pointed out the importance of retrieving free induction decay (FID) data from NMR analyses in order to support reprocessing and reanalysis of published data and they introduced quantum interaction and linkage tables (QuILTs) for a more intuitive visualization of 1D $J$-coupling relationships, NOESY correlations, and heteronuclear experiments. The structure 153 proposed by Tantillo and co-workers ${ }^{77}$ was eventually prepared by Hiemstra and co-workers ${ }^{77}$ featuring an intramolecular $[2+2]$-photocycloaddition between an allene and an $\alpha, \beta$-unsaturated $\delta$-lactone as the key step to construct its tricyclic core (Scheme 20). ${ }^{79}$

The synthesis started with a $\mathrm{Ti}\left(\mathrm{O}^{i} \mathrm{Pr}\right)_{4}$ promoted cross aldol involving isobutyraldehyde (154) and propargylic aldehyde which required conversion of the product into the corresponding dimetylacetal $\mathbf{1 5 5}$. Esterification of $\mathbf{1 5 5}$ provided the requisite phosphonate $\mathbf{1 5 6}$ and paved the way for the intramolecular Horner-Wadsworth- 
<smiles>C[13CH]C(=O)C(C)C</smiles>

154<smiles>C=C=C1OC(=O)C(C2CC2)=CC1(C)C</smiles>

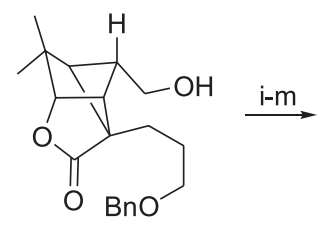

158

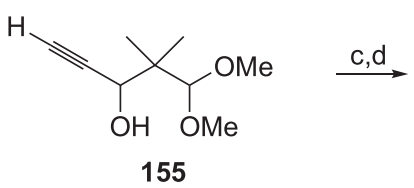

155

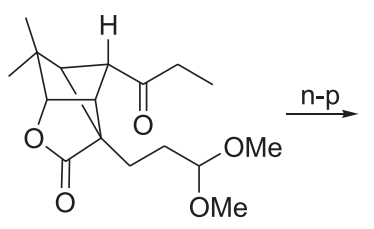

159
Scheme 20. Total synthesis of the most likely structure $\mathbf{1 5 3}$ for aquatolide. Selected reagents and conditions: (a) $\mathrm{Ti}\left(\mathrm{O}^{i} \mathrm{Pr}\right)_{4}, \mathrm{KO}^{\prime} \mathrm{Bn}, \mathrm{THF},-10{ }^{\circ} \mathrm{C}$; (b) $\mathrm{HC}(\mathrm{OMe})_{3}, p \mathrm{TsOH}, \mathrm{MeOH}\left(62 \%\right.$, two steps); (c) $\mathrm{BnO}\left(\mathrm{CH}_{2}\right)_{3} \mathrm{CH}\left(\mathrm{CO}_{2} \mathrm{H}\right)$ $\mathrm{P}(\mathrm{O}) \mathrm{Et}_{2}$, DCC, DMAP, DCM; (d) $\mathrm{HCl}$ (aq), acetone (92\%, two steps); (e) $\mathrm{NaH}, \mathrm{THF}$ (76\%); (f) $\left(\mathrm{CH}_{2} \mathrm{O}\right) \mathrm{n}, \mathrm{Cy}_{2} \mathrm{NH}, \mathrm{CuI}, 1,4$-dioxane, reflux (79\%); (g) hv (300 nm), acetone (77\%); (h) $\mathrm{BH}_{3}, \mathrm{THF}$, then $\mathrm{H}_{2} \mathrm{O}_{2}, \mathrm{NaOH}(36 \%)$; (i) DMP, DCM, $0{ }^{\circ} \mathrm{C}$; (j) EtMgBr, $\mathrm{Et}_{2} \mathrm{O}, 0{ }^{\circ} \mathrm{C}$; (k) $\mathrm{H}_{2}, 10 \% \mathrm{Pd} / \mathrm{C}$, EtOAc; (l) DMP, DCM, $0{ }^{\circ} \mathrm{C}$, (49\%, 4 steps); (m) $\mathrm{HC}(\mathrm{OMe})_{3}, \mathrm{CeCl}_{3} .7 \mathrm{H}_{2} \mathrm{O}, \mathrm{MeOH}$ (82\%); (n) LHMDS, THF, $-78{ }^{\circ} \mathrm{C}$, then TMSCl, $-78{ }^{\circ} \mathrm{C}$, rt; (o) $\mathrm{BF}_{3} \cdot \mathrm{OEt}_{2}$, $\mathrm{DCM},-78{ }^{\circ} \mathrm{C}$, rt; (p) $p \mathrm{TsOH}$, tol, reflux (59\%, three steps).

Emmons reaction which afforded the corresponding $\alpha, \beta$-unsaturated- $\delta$-lactone which was finally converted to allenic lactone $\mathbf{1 5 7}$. The key photochemical cycloaddition reaction successfully provided tricyclic lactone $\mathbf{1 5 8}$ after hydroboration/oxidation of the terminal double bond which underwent the requisite functionalization to provide dimethylacetal 159. An intramolecular Mukaiyama aldol reaction, followed by acid treatment provided racemic 153, which displayed ${ }^{1} \mathrm{H}$ and ${ }^{13} \mathrm{C}$ NMR spectra identical to those reported for aquatolide. Chiral HPLC resolution of racemic $\mathbf{1 5 3}$ provided natural aquatolide as the dextrorotatory enantiomer.

\section{Decurrensides}

Decurrenside A-D were isolated from the methanolic extracts of the plant Solidago decurrens by Kuono and co-workers ${ }^{80}$ in 2012. The molecular structure $\mathbf{1 6 0}$ was assigned to decurrenside D by $1 \mathrm{D}$ and 2D NMR spectra analyses and by comparison with spectroscopic data of known compounds (Figure 31). The HMBC correlation between $\mathrm{H}-4$ and C-7 indicated an ether bond between C-4 and C-7, while the NOESY correlation between hydroxyl groups at C-2 and C-5 suggested an endo orientation.

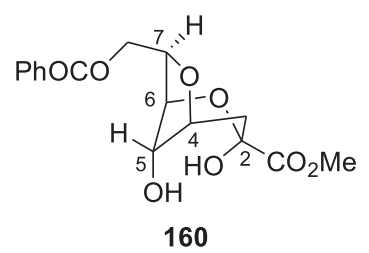

Figure 31. Structure proposed by Kuono and co-workers ${ }^{80}$ for decurrenside D.

In 2015, Sartillo-Piscil and co-workers ${ }^{81}$ reported their attempts to synthesize the proposed structure $\mathbf{1 6 0}$ containing the dioxabicyclo[3.2.1]octane moiety fused on a 3-deoxy-D-manno-2-octulosonic acid (KDO) derivative skeleton (Scheme 21A). These authors started from $D$-allofuranose bisacetonide $\mathbf{1 6 1}$ which was protected as the corresponding benzyl ether before selective acetonide deprotection and cleavage of the corresponding glycol with periodic acid, followed by reduction of the aldehyde, to afford primary alcohol $\mathbf{1 6 2}$. After its protection as the corresponding benzoate ester, a Hosomi-Sakurai reaction with excess of allyltrimethylsilane afforded the 2,3-cis-allyl

(4)<smiles>CC1(C)OC2OC([C@H]3COC(C)(C)[C@H]3[18OH])C(O)C2O1</smiles><smiles>CC1(C)OC2OC(CO)C(Br)C2O1</smiles><smiles>C=CC[C@@H]1O[C@H](CO[13CH3])[C@@H](O)[C@H]1O</smiles><smiles>COC(=O)C(=O)C[C@H]1OC(CO[18O])CC1OC(C)(C)C</smiles>

(B)
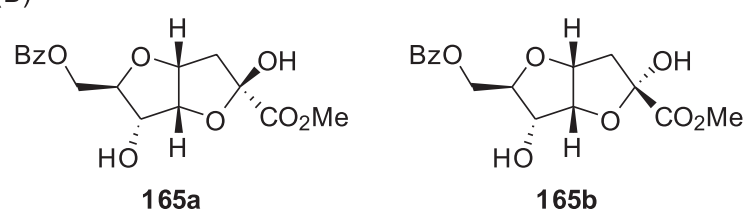

Scheme 21. (A) Reported synthesis towards decurrenside D according to Sartillo-Piscil and co-workers. ${ }^{81}$ (a) $\mathrm{BnBr} \mathrm{NaH}_{(90 \%)}$; (b) $\mathrm{H}_{5} \mathrm{IO} \mathrm{O}_{6}, \mathrm{EtOAc}$; (c) $\mathrm{NaBH}_{4}$, EtOH (75\%, two steps); (d) BzCl, pyr (85\%); (e) AllylTMS (exc.), $\mathrm{BF}_{3} \cdot \mathrm{OEt}_{2}$ (exc.), DCM, $0{ }^{\circ} \mathrm{C}$ (80\%); (f) 2,2-dimethoxypropane, $p$-TsOH (cat.) (80\%); (g) $\mathrm{Br}_{2}, \mathrm{CCl}_{4}$; (h) DBU, DMF (60\%, two steps); (i) $\mathrm{NBS}, \mathrm{AgNO}_{3}\left(64 \%\right.$ ); (j) $\mathrm{KMnO}_{4}, \mathrm{NaHCO}_{3}, \mathrm{MgSO}_{4}, \mathrm{MeOH}_{2} \mathrm{O}$ (65\%); (B) structures of the mixture of compounds obtained after acid treatment of 164 by Sartillo-Piscil and co-workers ${ }^{81}$ as validated by Kutateladze ${ }^{82}$ through computed ${ }^{13} \mathrm{C}$ chemical shifts. 
tetrahydrofuran $\mathbf{1 6 3}$, together with the corresponding benzylic ether at C-3 when the reaction was carried out at $0.3 \mathrm{M}$ concentration. The stereochemistry of the allyllation product was assigned in accordance with Woerpel's inside attack model which predicts the formation of the 1,3-cis adduct as the major allylation product. Diol $\mathbf{1 6 3}$ was protected as the corresponding acetonide before a bromination/debromination and oxidation sequence that afforded 164. Deprotection of the acetonide in structure 164 in acidic media led to the formation of two products which displayed NMR data different from natural decurrenside D.

In 2016, Kutateladze ${ }^{82}$ validated structures 165a and 165b as the compounds isolated by Sartillo-Piscil and co-workers ${ }^{81}$ (Scheme 21b) after acid treatment of 164 and reported on DFT gauge-including atomic orbitals (GIAO) ${ }^{13} \mathrm{C}$ chemical shift calculations at the mPW1PW91/6$311+\mathrm{G}(\mathrm{d}, \mathrm{p}) / / \mathrm{B} 3 \mathrm{LYP} / 6-31 \mathrm{G}(\mathrm{d})$ level for the proposed structure of decurrenside D (structure 160) which revealed poor correlation with the data reported for the natural product. Additionally, coupling constant calculations also revealed irreconcilable discrepancies which led Kutateladze to consider two ketal forms of 3-deoxy-Dmanno-2-octulofuranosonic acid as possible structures for decurrenside $\mathrm{D}$. The rff-calculated $J$-coupling values and GIAO mPW1PW91/6-311+G(d,p)//B3LYP/6-31G(d) ${ }^{13} \mathrm{C}$ NMR chemical shifts computed for structure $\mathbf{1 6 6}$ matched those of natural decurrenside $\mathrm{D}$ better than any other structure and the author proposed the bicyclic core of 2,6-anhydro-3-deoxy-D-manno-2-octulopyranosonate for all decurrensides isolated by Kuono and co-workers ${ }^{80}$ (Figure 32).

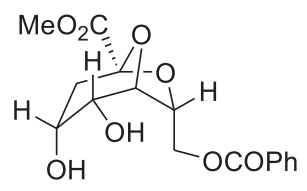

166

Figure 32. Structure of decurrenside D proposed by Kutateladze. ${ }^{82}$

Despite all the studies reported so far, no total synthesis of this family of natural products has appeared in order to validate or rule out the proposed structures above.

\section{Ocimicides}

The hexacyclic quinoline metabolites ocimicides A1 (167) and B1 (168), isolated from the root bark of Ocimum sanctum, and the corresponding methyl ether derivatives $\mathbf{1 6 9}$ (ocimicide A2) and $\mathbf{1 7 0}$ (ocimicide B2) were reported in the patent literature as displaying potent activity against chloroquine-sensitive and chloroquine resistant $P$. falciparum strains, with the semi-synthetic compounds 169 and 170 being twenty times more potent than the natural metabolites (Figure 33 ). ${ }^{83}$ In a second patent report, structurally related compounds were reported to be effective in in vivo experiments with rhesus monkeys without detectable toxicity. ${ }^{84}$
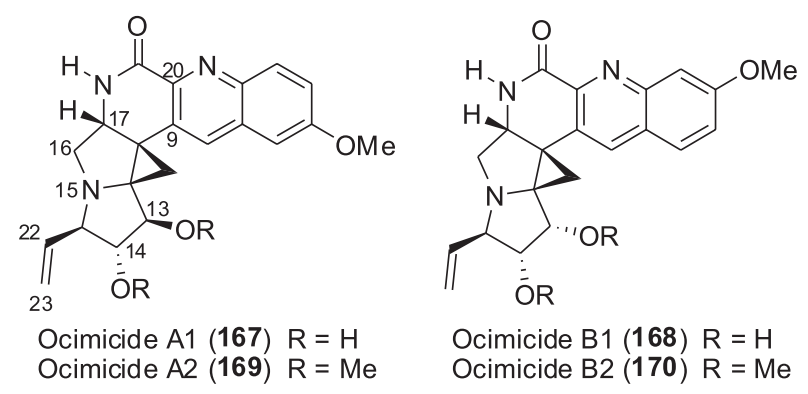

Ocimicide B1 (168) $\mathrm{R}=\mathrm{H}$ Ocimicide B2 (170) $\mathrm{R}=\mathrm{Me}$

Figure 33. Originally proposed structures 167 and 168 for ocimicides $\mathrm{A} 1$ and $\mathrm{B} 1$, and derivatives $\mathbf{1 6 9}$ and $\mathbf{1 7 0}$ for ocimicide $\mathrm{A} 2$ and $\mathrm{B} 2$, respectively.

In 2017, Herzon and co-workers ${ }^{85}$ reported on the synthesis of pentacyclic quinoline 176 (Scheme 22) which was deemed as a late-stage synthetic intermediate for the synthesis of the assigned structure of ocimicide A1 (structure 167). Stille coupling of quinoline stannane 171 and piperidine triflate $\mathbf{1 7 2}$, followed by Lemieux-Johnson cleavage of the trisubstituted alkene and Pinnick oxidation of the intermediate aldehyde, afforded carboxylic acid $\mathbf{1 7 3}$. Its treatment with NBS in the presence of DMAP afforded the corresponding bromolactone which was treated with $\mathrm{K}_{2} \mathrm{CO}_{3}$ in $\mathrm{MeOH}$ to promote a ring-opening/ring-closing sequence, leading to the formation of piperidine epoxide 174. Although deprotonation of epoxide 174 occurred at $24{ }^{\circ} \mathrm{C}$, extensive experimentation was required to develop conditions to effect the epoxide opening/ring contraction sequence. The best reaction conditions found involved treatment of piperidine epoxide $\mathbf{1 7 4}$ with LHMDS in toluene at $103{ }^{\circ} \mathrm{C}$ which provided cyclopropyl alcohol $\mathbf{1 7 5}$ and unreacted 174. Exposure of the cyclopropyl alcohol $\mathbf{1 7 5}$ to methanesulfonyl chloride and triethylamine provided the corresponding mesylate which, after concentration of the crude reaction mixture, was treated with $\mathrm{NaOCH}_{3}$ in methanol to promote the addition of methoxide to the nitrile group and nucleophilic displacement of the mesyl group with inversion of configuration. The imidate formed underwent acid hydrolysis upon treatment with $2 \mathrm{M} \mathrm{H}_{2} \mathrm{SO}_{4}$ to provide $\mathbf{1 7 6}$ in $96 \%$ yield from cyclopropyl alcohol $\mathbf{1 7 5}$. The structural assignment of $\mathbf{1 7 6}$ was carried out through X-ray diffraction analysis of the corresponding Weinreb amide.

Attempted neutralization of the trifluoroacetate salt resulting from the treatment of $N$-Boc pyrrolidine $\mathbf{1 7 6}$ with 
<smiles>CCCCN1CC=C(c2cc3cc(OC)ccc3nc2C#N)CC1C(=O)O</smiles>

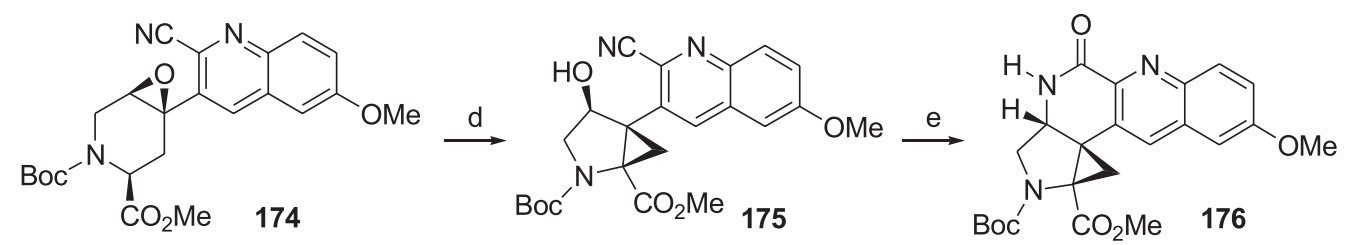

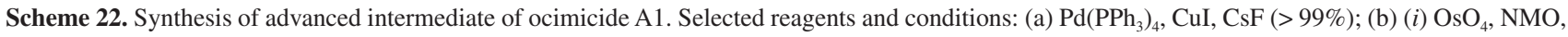
2,6-lutidine, then PIDA; (ii) concentrate, then $\mathrm{NaClO}_{2}, \mathrm{NaH}_{2} \mathrm{PO}_{4}$, 2-methyl-2-butene; (c) (i) NBS, DMAP; (ii) evaporate, then $\mathrm{K}_{2} \mathrm{CO}$, $\mathrm{MeOH}_{\text {( }}$ ( $5 \%$, two steps); (d) LHMDS, tol, $103^{\circ} \mathrm{C}$ (44\%); (e) (i) $\mathrm{MsCl}, \mathrm{Et}_{3} \mathrm{~N}, \mathrm{DCM}$; (ii) concentrate, then $\mathrm{NaOMe}, \mathrm{MeOH}$; (iii) concentrate, then $2 \mathrm{M} \mathrm{H}_{2} \mathrm{SO}_{4}, \mathrm{THF}$ ( $96 \%$, two steps).

trifluoroacetic acid led to extensive decomposition of the corresponding pyrrolidine. These observations combined with the instability of other synthetic intermediates led Herzon and co-workers ${ }^{85}$ to reexamine the original structural assignment of ocimicides using density functional theory. As only spectroscopic data for ocimicide derivatives A2 (169) and B2 (170) were disclosed in the literature, the authors generated 32 structures corresponding to all possible diastereomers at $\mathrm{N}-15$ and $\mathrm{C}-12, \mathrm{C}-13$, C-14 and C-17 of derivative $\mathbf{1 6 9}$ which were subjected to conformational search. All the conformations within $5.02 \mathrm{kcal} \mathrm{mol}^{-1}$ from the lowest energy isomer (8-30 conformers for each diastereomer) were advanced to NMR calculations at the WC04/6-31G(d)//B3LYP/6-31+G(d,p) level of theory, using methanol as solvent. Large deviations, particularly in the proximity of the lactam (C-9 and C-20) and pyrrolidine rings (C-13, C-14, C-22, and C-23), were observed when comparing the calculated and reported ${ }^{13} \mathrm{C}$ chemical shift values with those for ocimicide derivative $\mathbf{1 6 9}$, and none of the diastereomers taken into consideration could replicate the reported values within acceptable error. Comparison of the coupling constants involving the methine proton at $\mathrm{C}-17$ and the methylene protons at C-16 observed for synthetic $\mathbf{1 7 6}$ and the natural derivative ocimicide A2 (169) revealed a poor match, thus suggesting that a structural revision for the ocimicides may be required.

\section{Baulamycins}

Baulamycins A (177) and B (178) were isolated by Sherman and co-workers ${ }^{86}$ in 2014 from a collection of ca. 20,000 marine microbe-derived natural products using an assay to target inhibitors of siderophore biosynthesis (Figure 34). These metabolites were shown to be active against the methicillin-resistant Staphylococcus aureus (MRSA) and Bacillus anthracis. The limited amounts

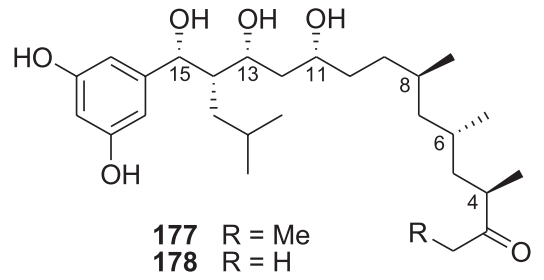

Figure 34. Originally proposed structures of baulamycins A (177) and B (178).

isolated precluded their chemical modification in order to support structural assignments, leading the authors to propose structures $\mathbf{1 7 7}$ and $\mathbf{1 7 8}$ for these metabolites based on NMR studies including empirical $J$-based configurational analysis and mass spectrometry. ${ }^{86}$

In 2017, Goswami and co-workers ${ }^{87}$ reported the first total synthesis of the proposed structure of baulamycin A (177) starting with the aldol reaction of the titanium(IV) enolate of $(R)$-oxazolidin-2-one (179) and di-O-(tercbutyldimethylsilyl)-3,5-dihydroxybenzaldehyde to provide primary alcohol 180 after TBS protection of the secondary hydroxyl group and reductive removal of the chiral auxiliary (Scheme 23). After oxidation of $\mathbf{1 8 0}$ to the corresponding aldehyde, a Crimmins acetate aldol reaction introduced the requisite chirality at C-13 and provided aldol adduct 181 as 5:1 mixture of diastereoisomers. After methanolysis to remove the chiral auxiliary and protection of the hydroxyl group at C-13 as the TES ether, conversion to ketophosphonate $\mathbf{1 8 2}$ was achieved upon treatment of the methyl ester with the lithium anion of dimethyl methylphosphonate. A HornerWadsworth-Emmons reaction of ketophosphonate $\mathbf{1 8 2}$ and aldehyde 183 promoted by barium hydroxide afforded a single isomer of the desired unsaturated ketone which, after hydrogenation of the double bond, removal of the TES protecting group and DIBAL reduction, afforded a 3:1 mixture of epimers at C-13. 1,3-Diol protection as the corresponding acetonide afforded alcohol 184 with 
<smiles>CC(C)CCC(=O)N1C(=O)OCC1Br</smiles>

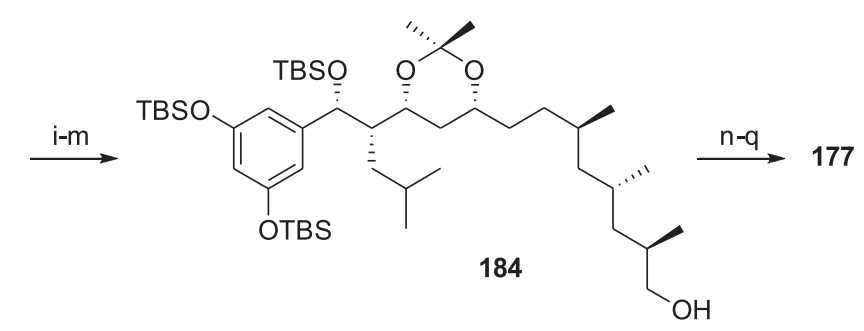

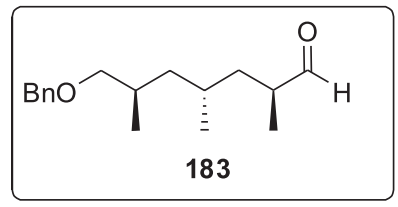

Scheme 23. Synthesis of the proposed structure of balaumcin A. Selected reagents and conditions: (a) (i) $\mathrm{TiCl}_{4}, \mathrm{DIPEA}, \mathrm{NMP}, \mathrm{DCM}, 0{ }^{\circ} \mathrm{C}$, then di-O-(terc-butyldimethylsilyl)-3,5-dihydroxybenzaldehyde (95\%); (b) TBSOTOf, 2,6-lutidine (96\%); (c) $\mathrm{LiBH}_{4}$, THF, $0{ }^{\circ} \mathrm{C}(89 \%)$; (d) Swern oxidation; (e) (S)-4-isopropylthiazolidine-2-thione, $\mathrm{TiCl}_{4}$, DIPEA, DCM, -40 to $-78{ }^{\circ} \mathrm{C}(68 \%, \mathrm{dr}=5: 1)$; (f) imidazole, $\mathrm{MeOH}(88 \%)$; (g) TESOTf, 2,6-lutidine (94\%); (h) $(\mathrm{MeO})_{2} \mathrm{P}(\mathrm{O}) \mathrm{Me}, n$ - BuLi, $-78{ }^{\circ} \mathrm{C}(83 \%)$; (i) $183, \mathrm{Ba}(\mathrm{OH})_{2} .8 \mathrm{H}_{2} \mathrm{O}, \mathrm{THF} / \mathrm{H}_{2} \mathrm{O}, 0{ }^{\circ} \mathrm{C}(84 \%)$; (j) $\mathrm{H}_{2}, 10 \% \mathrm{Pd} / \mathrm{C}$, EtOAc (98\%); (k) CSA, DCM, MeOH, $0{ }^{\circ} \mathrm{C}$ (79\%); (1) DIBAl-H, THF, $-78{ }^{\circ} \mathrm{C}(77 \%, \mathrm{dr}=3: 1)$; (m) 2,2-dimethoxypropane, CSA, DCM/MeOH (89\%); (n) Dess-Martin oxidation (100\%); (o) EtMgBr, THF, $0{ }^{\circ} \mathrm{C}(79 \%, \mathrm{dr}=6: 1)$; (p) Dess-Martin oxidation (78\%); (q) $70 \% \mathrm{HF} \cdot \mathrm{py}, \mathrm{THF}, 0{ }^{\circ} \mathrm{C}$ to rt $(90 \%)$.

the desired stereochemistry at C-11, thus constructing the required stereotetrad for the proposed structure of balaumycin A. Dess-Martin periodinane oxidation of the primary alcohol in $\mathbf{1 8 4}$ to the corresponding aldehyde, allowed its conversion to structure $\mathbf{1 7 7}$ proposed for balaumycin A, after Grignard addition, Dess-Martin periodinane oxidation and removal of the TBS protecting groups.

The ${ }^{1} \mathrm{H}$ and ${ }^{13} \mathrm{C}$ NMR spectra of synthetic $\mathbf{1 7 7}$ as well as its specific optical rotation revealed significant differences when compared to those of natural balaumycin A. As a consequence, the authors considered the possibility that natural balaumycin A could be a diastereoisomer of structure $\mathbf{1 7 7}$ and they set to prepare stereoisomer 185 where the stereotetrad at C-11, C-13, $\mathrm{C}-14$ and $\mathrm{C}-15$ displayed an all syn configuration but with opposite configuration when compared to structure 177 and structure 186 where C-4, C-13, C-14 and C-15 displayed opposite configuration as in structure $\mathbf{1 7 7}$ (Figure 35). In both cases, the NMR data of the synthetic compounds differed from those reported for the natural product leading the authors to propose that the structure of baulamycin A needed to be revised.

Later in 2017, Aggarwal and co-workers ${ }^{88}$ reported their efforts towards the total synthesis of structure 177 proposed for balaumycin A by using a late stage lithiation-borylation strategy to join fragment $\mathbf{1 8 7}$ (see Scheme 24) with $\mathbf{1 8 8}$ or 189 (see Scheme 25).

The synthesis of the 1,2-bis-boronic ester 187 initiated with a rhodium-catalyzed hydroboration of alkyne $\mathbf{1 9 0}$ which provided $Z$-allyl boronic ester 191 employed in an enantioselective allylation with bis-methoxymethyl (MOM) protected 3,5-dihydroxybenzaldehyde promoted<smiles>CCC(=O)[C@H](C)C[C@@H](C)C[C@@H](C)CC[C@H](O)C[C@@H](O)[C@@H](CC(C)C)[C@H](O)c1cc(O)cc(O)c1</smiles><smiles>CCC(=O)[C@H](C)C[C@@H](C)C[C@@H](C)CC[C@@H](O)C[C@@H](O)[C@H](CC(C)C)[C@H](O)c1cc(O)cc(O)c1</smiles>

Figure 35. Diasteroisomers 185 and $\mathbf{1 8 6}$ proposed by Goswami and coworkers ${ }^{87}$ for the structure for balaumycin A.

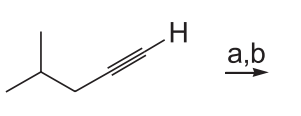

190<smiles>C=C[C@H](CC(C)C)[C@H](O)c1cc(OC)cc(OC)c1</smiles>

Scheme 24. Synthesis of fragment 187. (a) (i) $[\mathrm{Rh}(\mathrm{cod}) \mathrm{Cl}]_{2}(1.5 \mathrm{~mol} \%)$, catecholborane, ${ }^{i} \mathrm{Pr}_{3} \mathrm{P}(6 \mathrm{~mol} \%), \mathrm{Et}_{3} \mathrm{~N}$, cyclohexane; (ii) pinacol, cyclohexane (91\%, Z:E = 99:1); (b) (i) $\mathrm{ICH}_{2} \mathrm{Cl}, n$-BuLi, $\mathrm{Et}_{2} \mathrm{O},-95^{\circ} \mathrm{C}$; (ii) $\mathrm{MeCN},-95{ }^{\circ} \mathrm{C}(85 \%, Z: E=99: 1)$; bis- $O$-methoxymethyl3,5-dihydroxybenzaldehyde, (R)-TRIP-PA $(5 \mathrm{~mol} \%)$, tol, $-30{ }^{\circ} \mathrm{C}(89 \%$, $\mathrm{dr}=98: 2$, er = 95:5); (d) bis(pinacolato)diboron $\left(\mathrm{B}_{2} \mathrm{Pin}_{2}\right), \mathrm{Cs}_{2} \mathrm{CO}_{3}, \mathrm{MeOH}$, $\mathrm{THF}, 70{ }^{\circ} \mathrm{C}$; (e) chlorotriethylsilane (TESCl), $\mathrm{Et}_{3} \mathrm{~N}, \mathrm{DMAP}, \mathrm{DCM}(46 \%$, two steps, $\mathrm{dr}=98: 2$ ). 


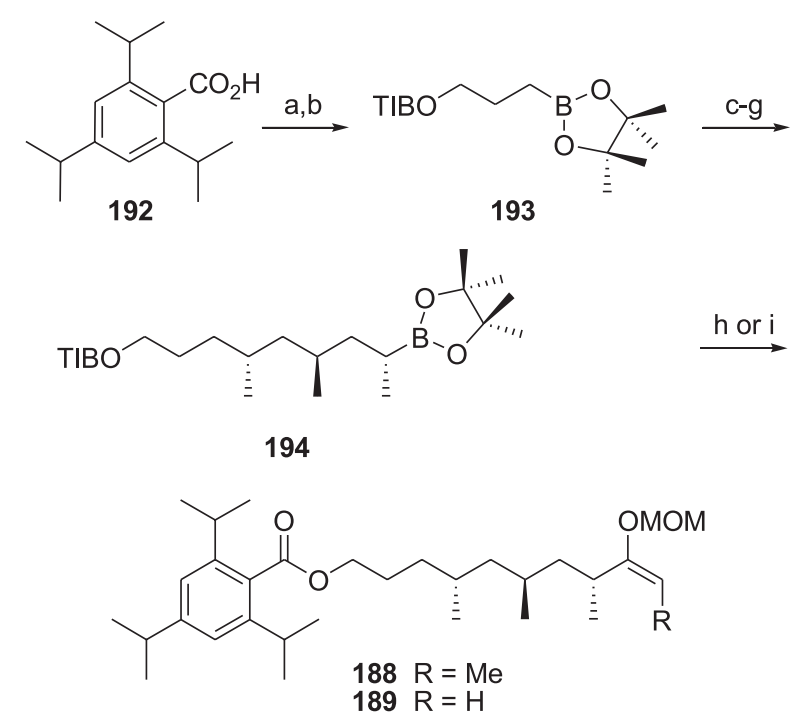

Scheme 25. Synthesis of fragments 188 and 189. (a) AllylBr, $\mathrm{K}_{2} \mathrm{CO}_{3}$, $\mathrm{MeCN}(100 \%)$; (b) $\mathrm{RhCl}\left(\mathrm{PPh}_{3}\right)_{3}$ (1 mol\%), pinBH, DCM (71\%); (c) (S)-TIBOCH(Me) $\mathrm{SnMe}_{3}, n$-BuLi, $\mathrm{Et}_{2} \mathrm{O},-78^{\circ} \mathrm{C}$; (d) $\mathrm{BrCH}_{2} \mathrm{Cl}, n$-BuLi, $\mathrm{Et}_{2} \mathrm{O}$; (e) (R)-TIBOCH(Me)SnMe,$n$-BuLi, $\mathrm{Et}_{2} \mathrm{O}$; (f) $\mathrm{BrCH}_{2} \mathrm{Cl}, n$-BuLi, $\mathrm{Et}_{2} \mathrm{O}(64 \%$, four steps, $\mathrm{dr}>95: 5)$; (h) $\mathrm{MeCH}=\mathrm{CH}(\mathrm{OMOM})(4: 1 \mathrm{Z} / E$ mixture), sec-BuLi, THF, -78 to $-30{ }^{\circ} \mathrm{C}$, then $194,-78{ }^{\circ} \mathrm{C}$ to $\mathrm{rt}$, then $\mathrm{I}_{2}$, THF, $-78{ }^{\circ} \mathrm{C}$, then $\mathrm{EtOCH}=\mathrm{CH}_{2}$ and $\mathrm{NaOMe}, \mathrm{MeOH},-78^{\circ} \mathrm{C}$ to rt $(72 \%)$; (i) $\mathrm{CH}_{2}=\mathrm{CH}(\mathrm{OMOM})$, sec-BuLi, THF, -78 to $-30{ }^{\circ} \mathrm{C}$, then $194,-78^{\circ} \mathrm{C}$ to rt, then $\mathrm{I}_{2}, \mathrm{THF},-78{ }^{\circ} \mathrm{C}$, then EtOCH$=\mathrm{CH}_{2}$ and $\mathrm{NaOMe}, \mathrm{MeOH},-78{ }^{\circ} \mathrm{C}$ to rt $(86 \%)$. TIB $=2,4,6$-triisopropyl benzoyl.

by $(R)$-TRIP-PA (3,3'-bis(2,4,6-triisopropylphenyl)1,1'-binaphthyl-2,2'-diylhydrogenphosphate) to provide homoallylic alcohol 192 in excellent diastereo- and enatioselection. Completion of fragment $\mathbf{1 8 7}$ was successfully achieved after hydroxyl-directed bisborylation of the terminal alkene 192, followed by TES protection of the hydroxyl group.

Preparation of fragments $188(\mathrm{R}=\mathrm{Me})$ and $189(\mathrm{R}=\mathrm{H})$ initiated with a rhodium-catalyzed hydroboration of the allyl benzoate prepared from 2,4,6-triisopropyl benzoic acid (192, TIBOH) to give boronic ester 193 in good yield (Scheme 25) which was required for the implementation of the assembly-line synthesis of boronic ester 194 containing the stereotriad at C-4, C-6 and C-8 present in the putative structures of baulamycin $\mathrm{A}$ (structure 177) and baulamycin B (178).

(E)-Alkene $188(\mathrm{R}=\mathrm{Me})$ and terminal olefin $189(\mathrm{R}=\mathrm{H})$ were employed as masked ketones in the coupling reaction with boronate ester 187. Lithiation of alkenes 188 and 189 with sec-BuLi, followed by regioselective homologation of 1,2-bis(boronic ester) 187, afforded diols 195 and 196 which were deprotected under acid treatment to produce structures 177 and 178, respectively, proposed by Sherman and co-workers ${ }^{86}$ as the structures of balaumycins A and B (Scheme 26).

However, the ${ }^{1} \mathrm{H}$ and ${ }^{13} \mathrm{C}$ NMR spectra of synthetic $\mathbf{1 7 7}$ and $\mathbf{1 7 8}$ did not match those of the natural products

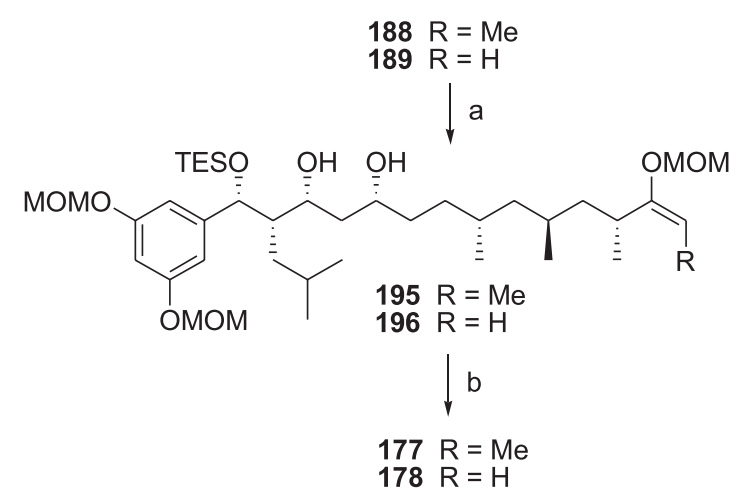

Scheme 26. Synthesis of the proposed structure of balaumcin A. Selected reagents and conditions: (a) (i) sec- $\mathrm{BuLi},(-)$-sparteine, $\mathrm{Et}_{2} \mathrm{O},-78{ }^{\circ} \mathrm{C}$; (ii) 187; (iii) $\mathrm{H}_{2} \mathrm{O}_{2}, \mathrm{NaOH}, \mathrm{THF}(195,70 \% ; 196,48 \%$ ); (b) $\mathrm{HCl}, \mathrm{THF} / \mathrm{MeOH}$ $(\mathbf{1 7 7}, 83 \% ; \mathbf{1 7 8}, 55 \%)$.

leading the authors to conclude that one or more stereogenic centers were misassigned, in accordance with the results of Goswami and co-workers. ${ }^{87}$ Aggarwall and co-workers ${ }^{88}$ then started to evaluate a series of diastereoisomers of the proposed structure $\mathbf{1 7 7}$ guided by NMR calculations with different stereochemical arrays in the stereotetrad C-11, C-13, C-14 and C-15 while keeping the stereotriad at C-4, C-6 and C-8 as originally proposed by Sherman and co-workers. ${ }^{86}$ For each stereoisomer, the NMR shifts and coupling constants were computed at the PCM/mPW1PW91/6-311G(d,p)// mPW1PW91/6-31G(d) level, after conformational sampling using MMFF. The populations of the resulting conformers were refined further on the basis of quantitative interproton distances calculated from ROESY measurements. The most populated conformations were submitted to DFT calculations in order to predict coupling constants for the $\mathrm{C} 10-\mathrm{C} 15$ regions. Comparison of both the calculated ${ }^{1} \mathrm{H}-{ }^{1} \mathrm{H}$ coupling constants and the NOEderived interproton distances for the $\mathrm{C} 10-\mathrm{C} 15$ region of the selected diastereomers with the corresponding experimental data for the isolated natural product, baulamycin A, led the authors to propose the stereotriad present in fragment $(R, R, R)$-199 as the correct relative configuration of the corresponding stereogenic centers in baulamycin A (see Scheme 27).

The authors also undertook computational analysis of the fragment containing the stereotriad at C-4, C-6 and C-8 but, in this case, they considered only the ${ }^{1} \mathrm{H}-{ }^{1} \mathrm{H}$ coupling constants due to signal overlap in the relevant region for ROESY analysis. In opposition to the proposed structure, they found out that the all syn stereotriad gave the best fit. Additionally, they carried out the synthesis of an encoded mixture of four diastereoisomers of the proposed structure for balaumycin A differing in the stereochemistry at C-4, C- 6 and $\mathrm{C}-8$ and found out that indeed the one with the all 


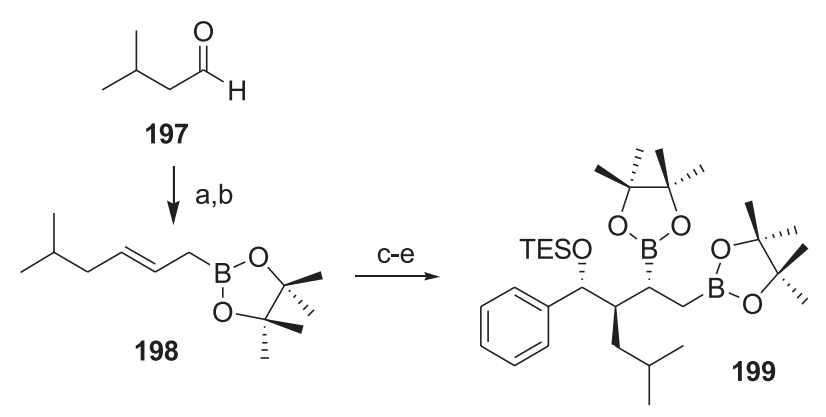

Scheme 27. Preparation of stereotriad 199. Selected reagents and conditions: (a) $\mathrm{CH}_{2}=\mathrm{CHMgBr}$, THF, rt (74\%); (b) $\left[\mathrm{Pd}(\mathrm{dmba}) \mathrm{Cl}_{2}\right.$, $\mathrm{B}_{2} \mathrm{pin}_{2}$, TsOH (5 mol\%), DMSO/MeOH, $50{ }^{\circ} \mathrm{C}(67 \%, E: Z=97: 3)$; (c) bis $(O$-methoxymethyl)-3,5-diydroxybenzaldehyde, $(R)$-TRIP-PA (5 mol\%), tol, $-30{ }^{\circ} \mathrm{C}(95 \%, \mathrm{dr}=97: 3)$, enantiomeric ratio (e.r.) $\left.=97: 3\right)$; $\mathrm{B}_{2} \mathrm{pin}_{2}, \mathrm{Cs}_{2} \mathrm{CO}_{3}, \mathrm{MeOH}$, THF, $70{ }^{\circ} \mathrm{C}$; (e) TESCl, $\mathrm{Et}_{3} \mathrm{~N}$, DMAP, DCM (64\%, two steps).

syn configuration at the above carbons had almost perfect match of its ${ }^{13} \mathrm{C}$ NMR data with those reported for the natural product, in agreement with the results of DFT calculations.

In fact, coupling of fragment $(R, R, R)-\mathbf{1 9 9}$ with the all syn fragment 200, as described earlier for the preparation of $\mathbf{1 7 7}$ and $\mathbf{1 7 8}$, led to $\mathbf{2 0 1}$ which displayed almost identical NMR data as natural balaumycin A but opposite specific optical rotation (Scheme 28). The preparation of the correct enantiomer of balaumycin A required coupling ent-199, displaying $S$ configuration at the three contiguous stereogenic centers, with ent-200 to provide ent-201 after conversion to the corresponding ethyl ketone (Scheme 29). Compound ent-201 displayed NMR data and specific optical rotation in accordance with natural baulamycin A thus establishing its absolute configuration. Baulamycin B (203) was prepared according to the same approach, upon coupling 202 with ent-199, followed by acid hydrolysis to give $\mathbf{2 0 3}$ (34\% yield, two steps), with analytical data fully matching those of natural baulamycin B.

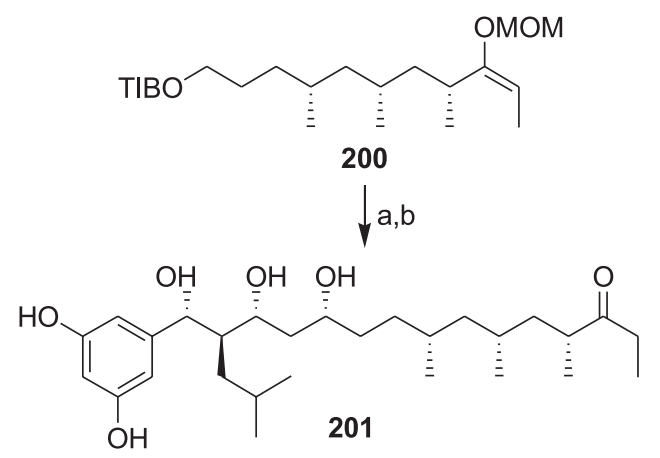

Scheme 28. Preparation of structure 201. Selected reagents and conditions: (a) (i) sec-BuLi, (-)-sparteine, $\mathrm{Et}_{2} \mathrm{O},-78{ }^{\circ} \mathrm{C}$, then 199; (ii) $\mathrm{H}_{2} \mathrm{O}_{2}, \mathrm{NaOH}$, THF (55\%); (b) $2 \mathrm{M} \mathrm{HCl}$, THF/MeOH (82\%).

\section{Goupiolone B}

Goupiolone A and B (Figure 36) are tropolone

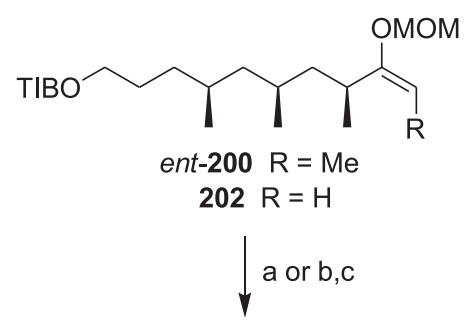<smiles>[R]C(=O)C(C)CC(C)CC(C)CCC(O)CC(O)C(CC(C)C)C(O)c1cc(O)cc(O)c1</smiles>

Scheme 29. Preparation of baulamycin A and B. Selected reagents and conditions: (a) (i) $s$-BuLi, ent-200, (+)-sparteine, $\mathrm{Et}_{2} \mathrm{O},-78{ }^{\circ} \mathrm{C}$, then ent-199, $-78^{\circ} \mathrm{C}$; (ii) $\mathrm{H}_{2} \mathrm{O}_{2}, \mathrm{NaOH}$, THF (63\%, dr > 95:5); (b) (i) $s$-BuLi, 202, (+)-sparteine, $\mathrm{Et}_{2} \mathrm{O},-78^{\circ} \mathrm{C}$, then ent-199, $-78^{\circ} \mathrm{C}$; (ii) $\mathrm{H}_{2} \mathrm{O}_{2}, \mathrm{NaOH}$, THF (60\%, dr > 95:5); (c) $\mathrm{HCl} 2 \mathrm{M}$, THF/MeOH, rt (92\% for ent-201; $56 \%$ for 203 ).<smiles>CCOC(=O)c1cc(O)c(=O)c2c(O)cc(O)cc2c1</smiles>

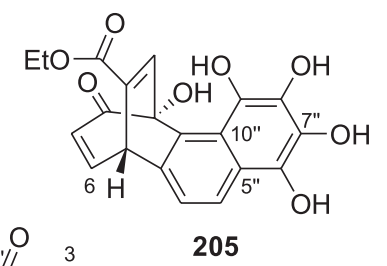

204

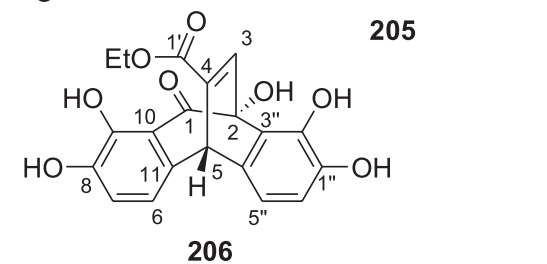

Figure 36. Proposed structures of goupiolones A and B (204 and 205, respectively), and revised structure of goupiolone B (206).

derivatives isolated by Rodríguez-Afonso and co-workers ${ }^{89}$ in 2003 from the aerial parts of Goupia glabra Aublet, a species distributed in the Peruvian Amazon. These natural products were biologically interesting as they were reported to show significant toxicity against a panel of DNA damage checkpoint defective yeast mutants and behaved as genotoxins. ${ }^{90}$

Goupiolone B was reported as the Diels-Alder adduct 205 between a tropolone and a naphthalene derivative. Its planar structure elucidation was heavily based in twodimensional NMR experiments, with the bridge bicyclic system, the $\alpha, \beta$-unsaturated carbonyl system and the substitution pattern in the naphthalene unit deduced by key correlations in the COSY, ROESY and HMBC spectra.

In 2017, Matsuo et al. ${ }^{91}$ pointed out that the proposed 1,2,3,4-naphthalenetetraol architecture was unknown in natural products and that the structure of goupiolone B could be in error. These authors also argued that the ${ }^{13} \mathrm{C}$ NMR chemical shifts for $\mathrm{C}-\beta$ in the $\alpha, \beta$-unsaturated 


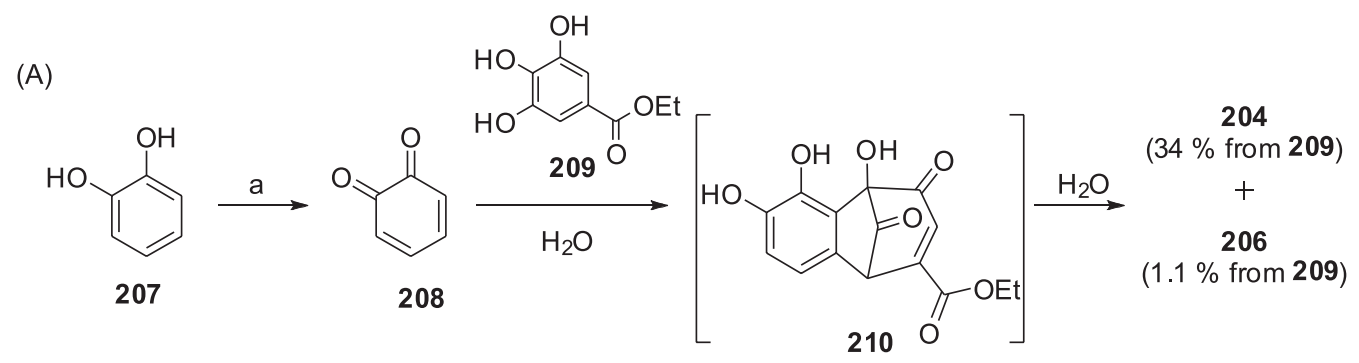

(B)

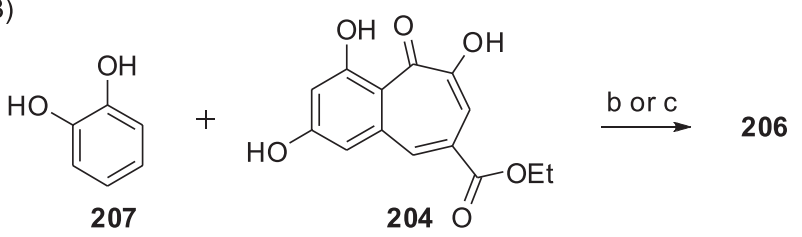

Scheme 30. Synthesis of the revised structure of goupiolone B (206). Selected reagents and conditions: (a) 2,2-diphenyl-1-picrylhydrazyl (DPPH), acetone, rt; (b) $\mathrm{K}_{3}\left[\mathrm{Fe}(\mathrm{CN})_{6}\right], \mathrm{NaHCO}_{3}, \mathrm{MeCH} / \mathrm{H}_{2} \mathrm{O}(4: 1)$, rt (11\%); (c) cerium ammonium nitrate (CAN), $\mathrm{MeCH} / \mathrm{H}_{2} \mathrm{O}(4: 1)$, rt (22\%).

carbonyl moiety and in the 1,2,3,4-tetrahydroxynaphtalene were inappropriate for such systems. Furthermore, Matsuo et al.$^{91}$ speculated that goupiolone B should present structure 206 as it may be biosynthetically derived from goupiolone A after its coupling with catechol quinone $\mathbf{2 0 8}$ (see Scheme 30), followed by reduction.

To validate compound $\mathbf{2 0 6}$ as the real structure of natural goupiolone B, DFT calculations of the ${ }^{13} \mathrm{C}$ chemical shifts of $\mathbf{2 0 5}$ and $\mathbf{2 0 6}$ were carried out at the mPW1PW91$\mathrm{SCRF} / 6-311+\mathrm{G}(2 \mathrm{~d}, \mathrm{p})$ level in $\mathrm{CHCl}_{3}(\mathrm{PCM})$, and these data were compared to the reported one, obtaining a low correlation for $\mathbf{2 0 5}$ and a high correlation for $\mathbf{2 0 6}$.

Taking into consideration this analysis, Matsuo et al. ${ }^{91}$ deftly applied a non-enzymatic biomimetic method for the preparation of 204 and 206. Starting with the oxidation of catechol (207) with 2,3-diphenyl-1-picrichydrazyl (DPPH) radical in acetone to afford 208, ethyl gallate (209) was then added to form the benzobicyclo[3.2.1]octane-type intermediate 210 (Scheme 30A). Addition of water finally formed 204 (34\% form 209) and 206 (1.1\% from 209) through ring cleavage, followed by spontaneous oxidation and decarboxylation steps.

The spectroscopic data of synthetic 204 and 206 were in full agreement with those of natural goupiolone A and $\mathrm{B}$, including COSY and HMBC spectra. To further confirm that goupiolone $\mathrm{B}$ (206) was produced by oxidative coupling between goupiolone A (204) and catechol 207, the authors found that treatment of these compounds with CAN or $\mathrm{K}_{3}\left[\mathrm{Fe}(\mathrm{CN})_{6}\right]$ afforded 206 (Scheme 30B).

\section{Spiroleucettadine}

This section is a nice example on how postulated structures can be questioned when they present challenging motifs that are unlikely to be found in nature.
Spiroleucettadine (211) was isolated in 2004 by Ralifo and Crews ${ }^{92}$ from the sponge Leucetta sp. found in the coral reefs of Fiji, being its structural assignment based on 2D NMR analysis (Figure 37).

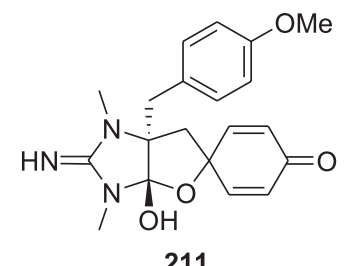

Figure 37. Originally proposed structure for spiroleucettadine.

The rare 5,5-trans-fused imidazolidine-oxolane core, along with the uncommon presence of an orthoamide functionality in the proposed structure of spiroleucettadine (structure 211), quickly called the attention of the scientific community and several synthetic approaches were reported. Danishefsky and co-workers, ${ }^{93}$ Ciufolini and co-workers, ${ }^{94}$ and Watson and co-workers ${ }^{95}$ courageously undertook the total synthesis of the reported structure of the natural product, but not surprisingly, none of these laboratories could reach the proposed structure. Whereas Danishefsky and co-workers ${ }^{93}$ and Ciufolini and coworkers ${ }^{94}$ independently reached similar ring-opened isomers of 211 (compounds 212 and 216, respectively), they were not able to finally form the orthoamide moiety and reach 211 (Scheme 31).

For their part, Watson and co-workers ${ }^{95}$ also advanced a similar conclusion about the stability of the orthoamide functionality. Considering their own results and those from Danishefsky and co-workers, ${ }^{93}$ and Ciufolini and co-workers, ${ }^{94}$ Watson and co-workers ${ }^{95}$ reanalyzed the HMBC correlations reported by Ralifo et al..$^{92}$ and disclosed a false correlation between H-8 and C-6. In 
Danishevsky approach

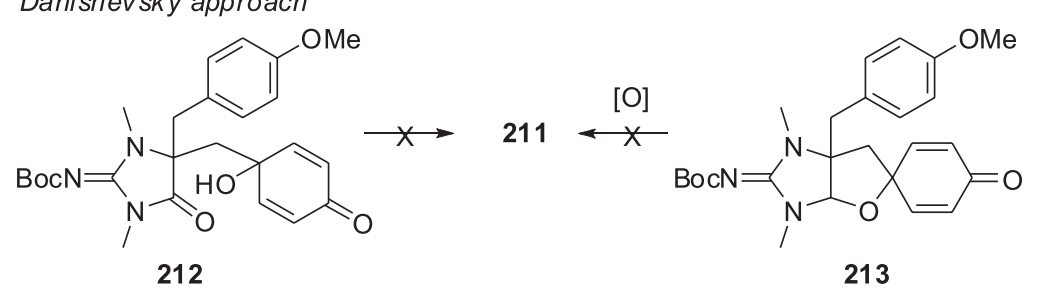

Ciufolini approach

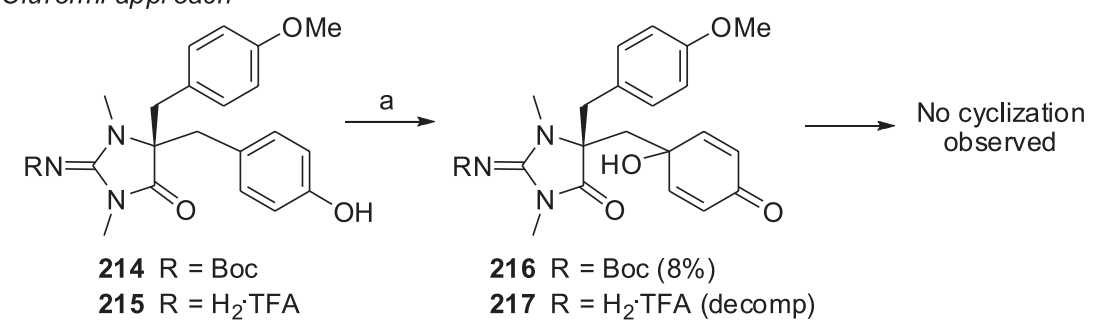

Watson approach

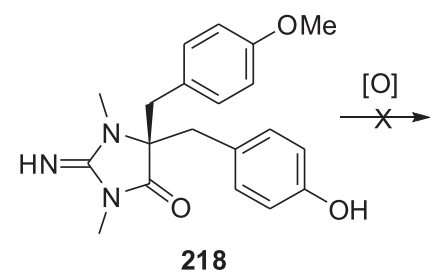<smiles>COc1ccc(C[C@@]2(CC3(O)C=CC(=O)C=C3)C(=O)N(C)C(=N)N2C)cc1</smiles>

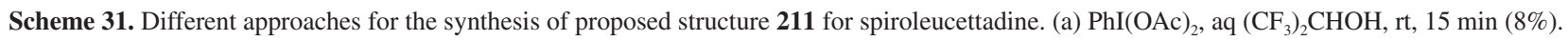

order to elucidate the structure of spiroleucettadine, they started a DFT calculation of ${ }^{13} \mathrm{C}$ chemical shifts at the mPW1PW91/6-311+G(2d,p)//B3LYP/6-31G(d) level of theory for several plausible isomers that came into consideration after reanalyzing the biosynthetic path and the spectrometric data of natural spiroleucettadine. After arbitrarily comparing the mean absolute error (MAE) of the considered molecules, Watson and co-workers ${ }^{95}$ concluded that either compound 220 (biosynthetically possible isomer) or compound 221 (DFT lowest MAE) could be the real structure of spiroleucettadine (Figure 38).

Crews and co-workers ${ }^{96}$ was surprised that three independent groups were not able to reach the originally proposed structure of spiroleucettadine, and decided to reinvestigate this issue. In a first approach, and inspired by the results of Watson and co-workers, ${ }^{95}$ they turned to DFT calculated NMR chemical shifts at the B3LYP/6-31G(d)<smiles>COc1ccc(C[C@@]23OC4(C=CC(=O)C=C4)C[C@]2(O)N(C)C(=N)N3C)cc1</smiles>

220

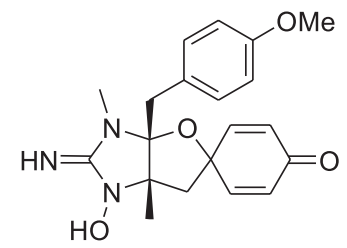

221
Figure 38. Structures of $\mathbf{2 2 0}$ and $\mathbf{2 2 1}$ considered as possible candidates for spiroleucettadine. level to evaluate structure 211, the proposed structures $\mathbf{2 2 0}$ and 221, as well as additional 13 structural possibilities. The originally reported structure $\mathbf{2 1 1}$ and structure $\mathbf{2 2 1}$ proposed by Watson and co-workers ${ }^{95}$ were ruled out because of the poor matching of rating parameters established by the authors. Structure ent-220 and 222, although with good relative matchings, were also ruled out based on observed HMBC correlations in the natural product spectra that were not possible in these structures, leaving structure $\mathbf{2 2 3}$ as the revised structure for spiroleucettadine (Figure 39).

In a second approach by Crews and co-workers, ${ }^{96}$ they were able to reisolate natural spiroleucettadine and perform additional analyses for structure determination, including X-ray analysis, confirming structure $\mathbf{2 2 3}$ as the real structure o spiroleucettadine.

Recently, Hawkings and co-workers ${ }^{97}$ reported the first stereoselective synthesis of (-)-spiroleucettadine (223), corroborating the revised structure proposed by Crews and co-workers ${ }^{96}$ (Scheme 32). In their synthetic proposal, commercially available $N$-Boc tyrosine methyl ester (224) was converted to bis-aryl ketone $\mathbf{2 2 5}$, which was transformed into trifluoroacetate $\mathbf{2 2 6}$ after removal of the protecting groups. Next, urea formation followed by hypervalent iodine mediated oxidation, gave the advanced intermediate 227. For the incorporation of the methylamine sidechain the authors again relayed in a hypervalent iodine 


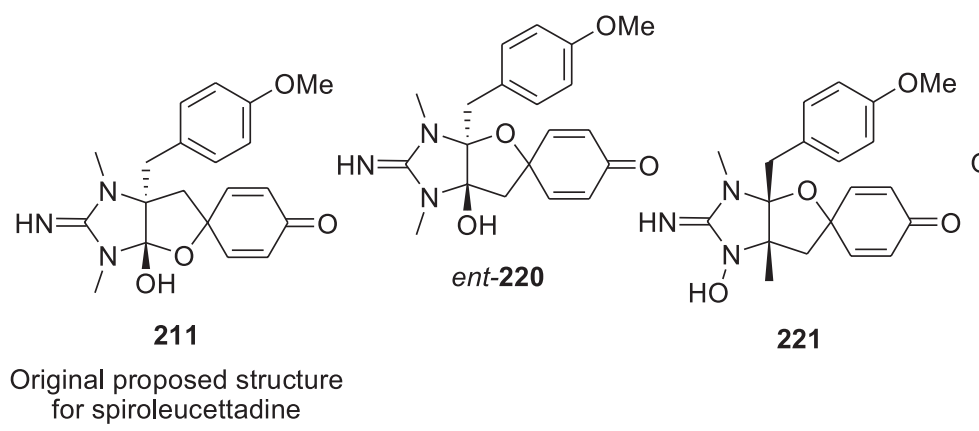<smiles>COc1ccc(C[C@]23OC4(C=CC(=O)C=C4)C[C@@](N)([C@@H]2O)N(C)C(=O)N3C)cc1</smiles>

222<smiles>CN[C@]12CC3(C=CC(=O)C=C3)O[C@]1(Cc1ccc(OC)cc1)NC(=O)N2C</smiles>

223

Revised structure for spiroleucettadine

Figure 39. Calculated possible structures for spiroleucettadine.

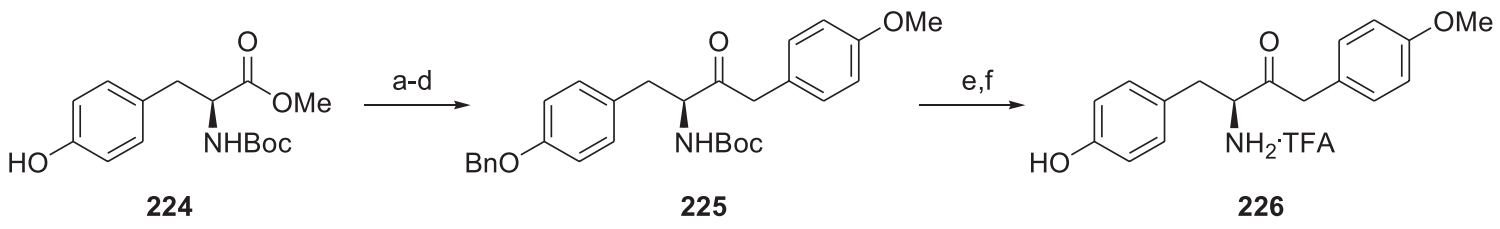<smiles>CCCOc1ccc(C2(Cc3ccc(OC)cc3)C[C@@H]3NC(=O)N(C)C32Cc2ccccc2)cc1</smiles><smiles>COc1ccc(CC2(OC3(c4ccc(OC)cc4)C=CC(=O)C=C3)CN(C)C(=O)N2)cc1</smiles>

Scheme 32. Total synthesis of the most likely structure of spiroleucettadine (223). Selected reagents and conditions: (a) $\mathrm{BnCl}_{2} \mathrm{~K}_{2} \mathrm{CO}_{3}$, tetrabutylammonium iodide (TBAI), acetone, $70{ }^{\circ} \mathrm{C}(87 \%)$; (b) $\mathrm{NaOH}, \mathrm{DCM} / \mathrm{MeOH}(82 \%)$; (c) $\mathrm{NH}(\mathrm{OMe}) \mathrm{Me} \cdot \mathrm{HCl}, \mathrm{EDCI}$, hydroxybenzotriazole (HOBT), Et $\mathrm{N}_{3} \mathrm{~N}(87 \%)$; (d) 4-MeOBnMgCl, THF, $0{ }^{\circ} \mathrm{C}$ (67\%); (e) $\mathrm{H}_{2}$, Pd/C 5\%, MeOH/EtOAc (84\%); (f) TFA, DCM, $0{ }^{\circ} \mathrm{C}$ (93\%); (g) $\mathrm{N}$-methyl carbamoylimidazole, THF; (h) PIDA, TFE, $0{ }^{\circ} \mathrm{C}\left(17 \%\right.$, two steps); (i) DMP, fluoroethanol, $60{ }^{\circ} \mathrm{C}(75 \%)$; (j) $\mathrm{NH}_{2} \mathrm{Me} \cdot \mathrm{HCl}, \mathrm{Et}_{3} \mathrm{~N}, \mathrm{THF}(91 \%)$.

mediated oxidation methodology $y^{98}$ to give acetate 228 in good yield. Finally, addition of methylamine afforded levorotatory spiroleucettadine (223) which displayed spectroscopic data identical to those recorded for the natural product. Due to divergences in the specific optical rotations reported for the natural product isolated from the sponge Leucetta sp. and the synthetic sample, the authors also prepared a racemic mixture of leucettadine in order to evaluate if any racemization had occurred along the synthetic studies. Comparison of the HPLC traces revealed that the synthetic spiroleucettadine (223) was indeed a single enantiomer as is probably the case for the natural product.

\section{Concluding Remarks}

Quantum chemical calculations of NMR shifts and coupling constants emerge as a powerful and valuable complement to experimental NMR spectroscopy. Among different applications, such theoretical approaches can be used to determine the most likely structure of complex natural products. This can be particularly helpful for synthetic groups before venturing towards a long- termed synthesis of natural products when a plausible misassignment is suspected. In understanding the evolution of the so-called "computer-guided total synthesis", it can be guessed that this merged experimental/computational strategies will be largely explored in years to come. In this regard, one final reflection should be brought up. Much research is currently being undertaken in the development of more accurate and reliable methods for the calculations of NMR properties, and coupled with the increasing power of computers, will surely improve the predictive capacity of the models. However, given the current state of the art of the discipline, the results of such calculations should not be taken as a final structural identity proof (such as those provided by X-ray). Instead, they must be considered as a complement to guide the synthetic work, still vital to confirm (or reject) the molecular architecture of natural products.

\section{Acknowledgments}

The authors are grateful to FAPESP (grants 2013/07607-8, 2014/25474-8 and 2016/12541-4) and CONICET, ANPCyT and UNR for financial support. 


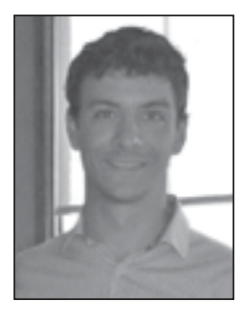

Franco Della-Felice obtained his BSc degree in Chemistry at the National University of Rosario (UNR, Argentina) under the guidance of Professors Edmundo A. Rúveda and María I. Colombo in 2013. Currently, he is a PhD student under the supervision of Professor Ronaldo A. Pilli at the University of Campinas (Brazil), focusing on synthesis and structural revision of natural products.

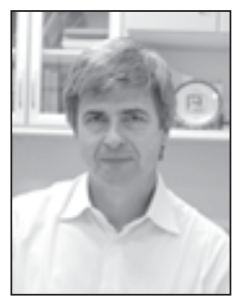

Ronaldo A. Pilli got his PhD degree from University of Campinas (Brazil) in 1981 and carried out his postdoctoral work under the supervision of Professor Clayton H. Heathcock, at the University of California, Berkeley. In 1985, he started his independent research on the total synthesis of natural products and medicinal chemistry.

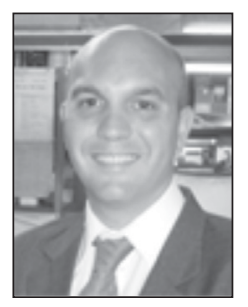

Ariel M. Sarotti received his $P h D$ from the National University of Rosario (UNR, Argentina) in 2007, under supervision of Prof Alejandra G. Suárez. After his postdoctoral research in computational chemistry at IQUIR, he became researcher of the Argentine National Council Research (CONICET). Currently, he is Associate Professsor of Organic Chemistry at UNR, and Independent Researcher at CONICET. His scientific interests include green and sustainable chemistry, asymmetric synthesis, computational chemistry, NMR spectroscopy and medicinal chemistry.

\section{References}

1. Newman, D. J.; Cragg, G. M.; Snader, K. M.; J. Nat. Prod. 2003, 66, 1022; Newman, D. J.; Cragg, G. M.; J. Nat. Prod. 2012, 75, 311; Newman, D. J.; Cragg, G. M.; J. Nat. Prod. 2007, 70, 461; Koehn, F. E.; Carter, G. T.; Nat. Rev. Drug Discovery 2005, 4, 206; Cragg, G. M.; Newman, D. J.; Snader, K. M.; J. Nat. Prod. 1997, 60, 52.

2. Gil, R. R.; Angew. Chem., Int. Ed. 2011, 50, 7222; Breton, R. C.; Reynolds, W. F.; Nat. Prod. Rep. 2013, 30, 501; Breitmaier, E.; Structure Elucidation by NMR in Organic Chemistry; John Wiley \& Sons: Chichester, England, 2002.

3. Saurí, J.; Bermel, W.; Buevich, A. V.; Sherer, E. C.; Joyce, L. A.; Sharaf, M. H. M.; Schiff, P. L.; Parella, T.; Williamson, R. T.; Martin, G. E.; Angew. Chem., Int. Ed. 2015, 54, 10160; Martin, G. E.; Annu. Rep. NMR Spectrosc. 2011, 74, 215.
4. Aguilar, J. A.; Nilsson, M.; Morris, G. A.; Angew. Chem., Int. Ed. 2011, 50, 9716; Aguilar, J. A.; Faulkner, S.; Nilsson, M.; Morris, G. A.; Angew. Chem., Int. Ed. 2010, 49, 3901; Zangger, K.; Prog. Nucl. Magn. Reson. Spectrosc. 2015, 86-87, 1.

5. Nath, N.; Schmidt, M.; Gil, R. R.; Williamson, R. T.; Martin, G. E.; Navarro-Vazquez, A.; Griesinger, C.; Liu, Y.; J. Am. Chem. Soc. 2016, 138, 9548, and references cited therein; Trigo-Mouriño, P.; Navarro-Vazquez, A.; Ying, J. F.; Gil, R. R.; Angew. Chem., Int. Ed. 2011, 50, 7576, and references cited therein.

6. Jaspars, M.; Nat. Prod. Rep. 1999, 16, 241; Elyashberg, M.; Blinov, K.; Molodtsov, S.; Smurnyy, Y.; Williams, A. J.; Churanova, T.; J. Cheminf. 2009, 1, 3; Elyashberg, M.; Williams, A.; Blinov, K.; Contemporary Computer-Assisted Approaches to Molecular Structure Elucidation; Royal Society of Chemistry: Cambridge, 2011; Masui, H.; Hong, H.; J. Chem. Inf. Model. 2006, 46, 775; Troche-Pesqueira, E.; Anklin, C.; Gil, R. R.; Navarro-Vázquez, A.; Angew. Chem., Int. Ed. 2017, 56, 3660.

7. For leading reviews, see: Nicolaou, K. C.; Snyder, S. A.; Angew. Chem., Int. Ed. 2005, 44, 1012; Suyama, T. L.; Gerwick, W. H.; McPhail, K. L.; Bioorg. Med. Chem. 2011, 19, 6675; Maier, M. E.; Nat. Prod. Rep. 2009, 26, 1105.

8. For recent references, see: Nicolaou, K. C.; Shah, A. A.; Korman, H.; Khan, T.; Shi, L.; Worawalai, W.; Theodorakis, E. A.; Angew. Chem., Int. Ed. 2015, 54, 9203; Zhu, L.; Liu, Y.; Ma, R.; Tong, R.; Angew. Chem., Int. Ed. 2015, 54, 627; Xiao, Q.; Young, K.; Zakarinan, K.; J. Am. Chem. Soc. 2015, 137, 5907; Willwacher, J.; Fürstner, A.; Angew. Chem., Int. Ed. 2014, 53, 4217; Nicolaou, K. C.; Hale, C. R. H.; Nilewski, C.; Ioannidou, H. A.; ElMarrouni, A.; Nilewski, L. G.; Beabout, K.; Wang, T. T.; Shamoo, Y.; J. Am. Chem. Soc. 2014, 136, 12137; Fuse, S.; Koinuma, H.; Kimbara, A.; Izumikawa, M.; Mifune, Y.; He, H.; Shin-ya, K.; Takahashi, T.; Doi, T.; J. Am. Chem. Soc. 2014, 136, 12011; Xu, T.; Dong, G.; Angew. Chem., Int. Ed. 2014, 53, 10733; Fuwa, H.; Muto, T.; Sekine, K.; Sasaki, M.; Chem.-Eur. J. 2014, 20, 1848; Botubol, J. M.; Durán-Peña, M. J.; Macías-Sánchez, A. J.; Hanson, J. R.; Collado, I. G.; Hernández-Galán, R.; J. Org. Chem. 2014, 79, 11349; Bian, Z.; Marvin, C. C.; Pettersson, M.; Martin, S. F.; J. Am. Chem. Soc. 2014, 136, 14184.

9. Yang, P.; Yao, M.; Li, J.; Li, Y.; Li, A.; Angew. Chem., Int. Ed. 2016, 55, 6964.

10. Nicolaou, K. C.; Vourloumis, D.; Winssinger, N.; Baran, P. S.; Angew. Chem., Int. Ed. 2000, 39, 44.

11. For leading reviews, see: Grimblat, N.; Sarotti, A. M.; Chem.-Eur. J. 2016, 22, 12246; Lodewyk, M. W.; Siebert, M. R.; Tantillo, D. J.; Chem. Rev. 2012, 112, 1839; Bagno, A.; Saielli, G.; Wiley Interdiscip. Rev.: Comput. Mol. Sci. 2015, 5, 228; Tantillo, D. J.; Nat. Prod. Rep. 2013, 30, 1079; Bifulco, G.; Dambruoso, P.; Gomez-Paloma, L.; Riccio, R.; Chem. Rev. 2007, 107, 3744; Navarro-Vázquez, A.; Magn. Reson. Chem. 2017, 55, 29. 
12. For seminal references, see: Bagno, A.; Rastrelli, F.; Saielli, G.; Chem.-Eur. J. 2006, 12, 5514; Bagno, A.; Rastrelli, F.; Saielli, G.; J. Phys. Chem. A 2003, 107, 9964; Bagno, A.; Chem.-Eur. J. 2001, 7, 1652; Barone, G.; Gomez-Paloma, L.; Duca, D.; Silvestri, A.; Riccio, R.; Bifulco, G.; Chem.-Eur. J. 2002, 8, 3233; Barone, G.; Duca, D.; Silvestri, A; Gomez-Paloma, L.; Riccio, R.; Bifulco, G.; Chem.-Eur. J. 2002, 8, 3240.

13. For leading references, see: Sarotti, A. M.; Pellegrinet, S. C.; J. Org. Chem. 2009, 74, 7254; Sarotti, A. M.; Pellegrinet, S. C.; J. Org. Chem. 2012, 77, 6059; Jain, R.; Bally, T.; Rablen, P. R.; J. Org. Chem. 2009, 74, 4017; Flaig, D.; Maurer, M.; Hanni, M.; Braunger, K.; Kick, L.; Thubauville, M.; Ochsenfeld, C.; J. Chem. Theory Comput. 2014, 10, 572; Elyashberg, M.; Blinov, K.; Smurnyy, Y.; Churanova, T.; Williams, A.; Magn. Reson. Chem. 2010, 48, 219; Andrews, K. G.; Spivey, A. C.; J. Org. Chem. 2013, 78, 11302; Cheeseman, J. R.; Trucks, G. W.; Keith, T. A.; Frish, M. J.; J. Chem. Phys. 1996, 104, 5497; Kutateladze, A. G.; Mukhina, O. A.; J. Org. Chem. 2014, 79, 8397; Kutateladze, A. G.; Mukhina, O. A.; J. Org. Chem. 2015, 80, 5218; Kutateladze, A. G.; Mukhina, O. A.; J. Org. Chem. 2015, 80, 10838.

14. Smith, S. G.; Goodman, J. M.; J. Org. Chem. 2009, 74, 4597.

15. Smith, S. G.; Goodman, J. M.; J. Am. Chem. Soc. 2010, 132, 12946; Ermanis, K.; Parkes, K. E. B.; Agback, T.; Goodman, J. M.; Org. Biomol. Chem. 2016, 14, 3943.

16. Grimblat, N.; Zanardi, M. M.; Sarotti, A. M.; J. Org. Chem. 2015, 80, 12526; Zanardi, M. M.; Suárez, A. G.; Sarotti, A. M.; J. Org. Chem. 2017, 82, 1873.

17. Sarotti, A. M.; Org. Biomol. Chem. 2013, 11, 4847; Zanardi, M. M.; Sarotti, A. M.; J. Org. Chem. 2015, 80, 9371.

18. For leading references, see: Cen-Pacheco, F.; Rodríguez, J.; Norte, M.; Fernández, J. J.; Hernández Daranas, A.; Chem. Eur. J. 2013, 19, 8525; Lodewyk, M. W.; Soldi, C.; Jones, P. B.; Olmstead, M. M.; Rita, J.; Shaw, J. T.; Tantillo, D. J.; J. Am. Chem. Soc. 2012, 134, 18550; Quasdorf, K. W.; Huters, A. D.; Lodewyk, M. W.; Tantillo, D. J.; Garg, N. K.; J. Am. Chem. Soc. 2012, 134, 1396; Saielli, G.; Nicolaou, K. C.; Ortiz, A.; Zhang, H.; Bagno, A.; J. Am. Chem. Soc. 2011, 133, 6072; Lodewyk, M. W.; Tantillo, D. J.; J. Nat. Prod. 2011, 74, 1339; Sarotti, A. M.; Suárez, A. G.; Spanevello, R. A.; Tetrahedron Lett. 2011, 52, 3116; Llompart, D. F.; Sarotti, A. M.; Corne, V.; Suárez, A. G.; Spanevello, R. A.; Echeverría, G. A.; Piro, O. E.; Castellano, E. E.; Tetrahedron Lett. 2014, 55, 2394; Zurita, M. A.; Avila, A.; Spanevello, R. A.; Suárez, A. G.; Sarotti, A. M.; Carbohydr. Res. 2015, 402, 67; Gerosa, G. G.; Spanevello, R. A.; Suárez, A. G.; Sarotti, A. M.; J. Org. Chem. 2015, 80, 7626; Karak, M.; Barbosa, L. C. A.; Acosta, J. A. M.; Sarotti, A. M.; Boukouvalas, J.; Org. Biomol. Chem. 2016, 14, 4897; Grimblat, N.; Kaufman, T. S.; Sarotti, A. M.; Org. Lett. 2016, 18, 6420; Huang, P.; Li, C.; Sarotti, A. M.; Turkson, J.; Cao, S.; Tetrahedron Lett. 2017, 58,
1330; Li, C.; Sarotti, A. M.; Turkson, J.; Cao, S.; Tetrahedron Lett. 2017, 58, 2290; Reddy, D. S.; Kutateladze, A. G.; Org. Lett. 2016, 18, 4860; Li, C.-S.; Sarotti, A. M.; Huang, P.; Dang, U. T.; Hurdle, J. G.; Kondratyuk, T. P.; Pezzuto, J. M.; Turkson, J.; Cao, S.; Sci. Rep. 2017, 7, 10424.

19. Dong, L.-B.; Wu, Y.-N.; Jiang, S.-Z.; Wu, X.-D.; He, J.; Yang, Y.-R.; Zhao, Q.-S.; Org. Lett. 2014, 16, 2700.

20. Ayer, W. A.; Fukazawa, Y.; Singer, P. P.; Altenkirk, B.; Tetrahedron Lett. 1973, 14, 5045.

21. Cavalheiro, A. J.; Yoshida, M.; Phytochemistry 2000, 53, 811.

22. Novaes, L. F. T.; Sarotti, A. M.; Pilli, R. A.; RSC Adv. 2015, 5 , 53471; Novaes, L. F. T.; Drekener, R. L.; Avila, C. M.; Pilli, R. A.; Tetrahedron 2014, 70, 6467; Carneiro, V. M. T.; Avila, C. M.; Balunas, M. J.; Gerwick, W. H.; Pilli, R. A.; J. Org. Chem. 2014, 79, 630 .

23. Novaes, L. F. T.; Sarotti, A. M.; Pilli, R. A.; J. Org. Chem. 2015 , 80, 12027.

24. Yang, B.-Y.; Kong, L.-Y.; Wang, X.-B.; Zhang, Y.-M.; Li, R.-J.; Yang, M.-H.; Luo, J.-G.; J. Nat. Prod. 2016, 79, 196.

25. Seco, J. M.; Quiñoá, E.; Riguera, R.; Chem. Rev. 2004, 104, 17.

26. Snatzke, G.; Angew. Chem., Int. Ed. 1968, 7, 14.

27. Della-Felice, F.; Sarotti, A. M.; Pilli, R. A.; J. Org. Chem. 2017, $82,9191$.

28. Kim, I. S.; Ngai, M.-Y.; Krische, M. J.; J. Am. Chem. Soc. 2008, 130, 14891; Dechert-Schmitt, A.-M. R.; Schmitt, D. C.; Krische, M. J.; Angew. Chem., Int. Ed. 2013, 52, 3195.

29. Hansen, E. C.; Lee, D.; Tetrahedron Lett. 2004, 45, 7151.

30. Carletti, I.; Massiot, G.; Debitus, C.; WO 2011/051380 Al, 2011.

31. Fleury, E.; Lannou, M.-I.; Bistri, O.; Sautel, F.; Massiot, G.; Pancrazi, A.; Ardisson, J.; J. Org. Chem. 2009, 74, 7034.

32. Fleury, E.; Sorin, G.; Prost, E.; Pancrazi, A.; Sautel, F.; Massiot, G.; Lannou, M.-I.; Ardisson, J.; J. Org. Chem. 2013, 78, 855.

33. Sorin, G.; Fleury, E.; Tran, C.; Prost, E.; Molinier, N.; Sautel, F.; Massiot, G.; Specklin, S.; Meyer, C.; Cossy, J.; Lannou, M.-I.; Ardisson, J.; Org. Lett. 2013, 15, 4734; Lecourt, C.; Boinapally, S.; Dhambri, S.; Boissonnat, G.; Meyer, C.; Cossy, J.; Sautel, F.; Massiot, G.; Ardisson, J.; Sorin, G.; Lannou, M.-I.; J. Org. Chem. 2016, 81, 12275.

34. Specklin, S.; Boissonnat, G.; Lecourt, C.; Sorin, G.; Lannou, M.-I.; Ardisson, J.; Sautel, F.; Massiot, G.; Meyer, C.; Cossy, J.; Org. Lett. 2015, 17, 2446.

35. MacGregor, C. I.; Han, B. Y.; Goodman, J. M.; Paterson, I.; Chem. Commun. 2016, 52, 4632.

36. Tran, T. D.; Pham, N. B.; Ekins, M.; Hooper, J. N. A.; Quinn, R. J.; Mar. Drugs 2015, 13, 4556.

37. Jayasuriya, H.; Zink, D.; Basilio, A.; Vicente, F.; Collado, J.; Bills, G.; Goldman, M. L.; Motyl, M.; Huber, J.; Dezeny, G.; Byrne, K.; Singh, S. B.; J. Antibiot. 2009, 62, 265.

38. Li, Y.; RSC Adv. 2015, 5, 36858. 
39. Chu, M.; Mierzwa, R.; Xu, L.; He, L.; Terracciano, J.; Patel, M.; Gullo, V.; Black, T.; Zhao, W.; Chan, T.-M.; McPhail, A. T.; J. Nat. Prod. 2003, 66, 1527.

40. Ishigami, K.; Katsuta, R.; Watanabe, H.; Tetrahedron 2006, 62, 2224; Snider, B. B.; Zhou, J.; Org. Lett. 2006, 8, 1283; Wilson, E. M.; Trauner, D.; Org. Lett. 2007, 9, 1327; Fujioka, H.; Ohba, Y.; Nakahara, K.; Takatsuji, M.; Murai, K.; Ito, M.; Kita, Y.; Org. Lett. 2007, 9, 5605; Dermenci, A.; Selig, P. S.; Domaoal, R. A.; Spasov, K. A.; Anderson, K. S.; Miller, S. J.; Chem. Sci. 2011, 2, 1568.

41. Ishigami, K.; Katsuta, R.; Watanabe, H.; Tetrahedron 2006, 62, 2224.

42. Ishigami, K.; Yamamoto, M.; Watanabe, H.; Tetrahedron Lett. 2015, 56, 6290; Yamamoto, M.; Ishigami, K.; Watanabe, H.; Tetrahedron 2017, 73, 3271.

43. Evidente, A.; Abou-Donia, A. H.; Darwish, F. A.; Amer, M. E.; Kassem, F. F.; Hammoda, H. A. M.; Motta, A.; Phytochemistry 1999, 51, 1151.

44. Schwartz, B. D.; Jones, M. T.; Banwell, M. G.; Cade, I. A.; Org. Lett. 2010, 12, 5210.

45. Lodewyk, M. W.; Tantillo, D. J.; J. Nat. Prod. 2011, 74, 1339.

46. Schwartz, B. D.; White, L. V.; Banwell, M. G.; Willis, A. C.; J. Org. Chem. 2011, 76, 8560.

47. Boivin, J.; Henriet, E.; Zard, S. Z.; J. Am. Chem. Soc. 1994, 116, 9739.

48. Winder, P. L.; Ph.D. Thesis, Florida Atlantic University, 2009. Available at http://purl.flvc.org/FAU/369392, accessed in February 2018.

49. Paterson, I.; Haslett, G. W.; Org. Lett. 2013, 15, 1338.

50. Hwang, S.; Baek, I.; Lee, C.; Org. Lett. 2016, 18, 2154; Watanabe, K.; Li, J.; Veerasamy, N.; Ghosh, A.; Carter, R. G.; Org. Lett. 2016, 18, 1744.

51. Paterson, I.; Dalby, S. M.; Roberts, J. C.; Naylor, G. J.; Guzmán, E. A.; Isbrucker, R.; Pitts, T. P.; Linley, P.; Divlianska, D.; Reed, J. K.; Wright, A. E.; Angew. Chem., Int. Ed. 2011, 50, 3219.

52. Rink, C.; Navickas, V.; Maier, M. E.; Org. Lett. 2011, 13, 2334.

53. Paterson, I.; Paquet, T.; Dalby, S. M.; Org. Lett. 2011, 13, 4 398.

54. Willwacher, J.; Kausch-Busies, N.; Fürstner, A.; Angew. Chem., Int. Ed. 2012, 51, 12041.

55. Paterson, I.; Ng, K. K.-H.; Williams, S.; Millican, D. C.; Dalby, S. M.; Angew. Chem., Int. Ed. 2014, 53, 2692.

56. Hall, J. G.; Reiss, J. A.; Aust. J. Chem. 1986, 39, 1401.

57. Sheldrake, H. M.; Jamieson, C.; Burton, J. W.; Angew. Chem., Int. Ed. 2006, 45, 7199.

58. Smith, S. G.; Paton, R. S.; Burton, J. W.; Goodman, J. M.; J. Org. Chem. 2008, 73, 4053.

59. Dyson, B. S.; Burton, J. W.; Sohn, T.; Kim, B.; Bae, H.; Kim, D.; J. Am. Chem. Soc. 2012, 134, 11781.

60. Fukuzawa, A.; Honma, T.; Takasugi, Y.; Murai, A.; Phytochemistry 1993, 32, 1435.
61. Abdel-Mageed, W. M.; Ebel, R.; Valeriote, F. A.; Jaspars, M.; Tetrahedron 2010, 66, 2855.

62. Shepherd, D. J.; Broadwith, P. A.; Dyson, B. S.; Paton, R. S.; Burton, J. W.; Chem. Eur. J. 2013, 19, 12644.

63. Schlegel, B.; Härtl, A.; Dahse, H.-M.; Gollmick, F. A.; Gräfe, U.; Dörfelt, H.; Kappes, B.; J. Antibiot. 2002, 55, 814.

64. La Clair, J. J.; Angew. Chem., Int. Ed. 2006, 45, 2769.

65. Rychnovsky, S. D.; Org. Lett. 2006, 8, 2895.

66. Sekizawa, R.; Ikeno, S.; Nakamura, H.; Naganawa, H.; Matsui, S.; Iinuma, H.; Takeuchi, T.; J. Nat. Prod. 2002, 65, 1491.

67. Moses, J. E.; Commeiras, L.; Baldwin, J. E.; Adlington, R. M.; Org. Lett. 2003, 5, 2987; Lei, X.; Johnson, R. P.; Porco Jr., J. A.; Angew. Chem., Int. Ed. 2003, 42, 3913; Mehta, G.; Islam, K.; Tetrahedron Lett. 2004, 45, 7683; Mehta, G.; Ramesh, S. S.; Tetrahedron Lett. 2004, 45, 1985.

68. Porco Jr., J. A.; Su, S.; Lei, X.; Bardhan, S.; Rychnovsky, S. D.; Angew. Chem., Int. Ed. 2006, 45, 5790.

69. Saielli, G.; Bagno, A.; Org. Lett. 2009, 11, 1409.

70. La Clair, J. J.; Angew. Chem., Int. Ed. 2012, 51, 11661.

71. Carvalho, L. R.; Fujii, M. T.; Roque, N. F.; Kato, M. J.; Lago, J. H. G.; Tetrahedron Lett. 2003, 44, 2637; Carvalho, L. R.; Fujii, M. T.; Roque, N. F.; Lago, J. H. G.; Phytochemicals 2006, 67, 1331.

72. Crimmins, M. T.; Hughes, C. O.; Org. Lett. 2012, 14, 2168.

73. Takahashi, S.; Yasuda, M.; Nakamura, T.; Hatano, K.; Matsuoka, K.; Koshino, H.; J. Org. Chem. 2014, 79, 9373.

74. Kutateladze, A. G.; Mukhina, O. A.; J. Org. Chem. 2014, 79, 8397.

75. Mukhina, O. A.; Koshino, H.; Crimmins, M. T.; Kutateladze, A. G.; Tetrahedron Lett. 2015, 56, 4900.

76. San Feliciano, A.; Medarde, M.; del Corral, J. M. M.; Aramburu, A.; Gordalira, M.; Barreroa, A. F.; Tetrahedron Lett. 1989, 30, 2851.

77. Lodewyk, M. W.; Soldi, C.; Jones, P. B.; Olmstead, M. M.; Rita, J.; Shaw, J. T.; Tantillo, D. J.; J. Am. Chem. Soc. 2012, 134, 18550; Liu, Y.; Saurí, J.; Mevers, E.; Peczuh, M.W.; Hiemstra, H.; Clardy, J.; Martin, G. E.; Williamson, R. T.; Science 2017, 356, 5349.

78. Pauli, G. F.; Niemtiz, M.; Bisson, J.; Lodewyk, M. W.; Soldi, C.; Shaw, J. T.; Tantillo, J. D.; Saya, J. M.; Vos, K.; Kleinnijenhuis, R. A.; Hiemstra, H.; Chen, S.-N.; McAline, J. B.; Lankin, D. C.; Friesen, J. B.; J. Org. Chem. 2016, 81, 878.

79. Saya, J. M.; Vos, K.; Kleinnijenhuis, R. A.; van Maarseveen, J. H.; Ingemann, S.; Hiemstra, H.; Org. Lett. 2015, 17, 3892.

80. Shiraiwa, K.; Yuan, S.; Fujiyama, A.; Matsuo, Y.; Tanaka, T.; Jiang, Z. H.; Kuono, I.; J. Nat. Prod. 2012, 75, 88.

81. González-Márquez, V.; Cruz-Gregorio, S.; Sandoval-Lira, J.; Quintero, L.; Sartillo-Piscil, F.; Tetrahedron Lett. 2015, 56, 5416.

82. Kutateladze, A. G.; J. Org. Chem. 2016, 81, 8659.

83. Zhu, S.; US20100087469 A1, 2010.

84. Zhu, S.; US20130023552 A1, 2013. 
85. Nikolayevskiy, H.; Tun, M. K. M.; Rablen, P. R.; Mamoun, C. B.; Herzon, S. B.; Chem. Sci. 2017, 8, 4867.

86. Tripathi, A.; Schofield, M. M.; Chlipala, G. E.; Schultz, P. J.; Yim, I.; Newmister, S. A.; Nusca, T. D.; Scaglione, J. B.; Hanna, P. C.; Tamayo-Castillo, G.; Sherman, D. H.; J. Am. Chem. Soc. 2014, 136, 1579 [erratum: J. Am. Chem. Soc. 2014, 136, 10541].

87. Guchhait, S.; Chatterjee, S.; Ampapathi, R. S.; Goswami, R. K.; J. Org. Chem. 2017, 82, 2414.

88. Wu, J.; Lorenzo, P.; Zhong, S.; Ali, M.; Butts, C. P.; Myers, E. L.; Aggarwal, V. K.; Nature 2017, 547, 436.

89. Mesa-Siverio, D.; Estévez-Braun, A.; Ravelo, A. G.; Murguia, J. R.; Rodríguez-Afonso, A.; Eur. J. Org. Chem. 2003, 4243.

90. The structure of goupiolone A was revised by Suzuki and coworkers by total synthesis. See: Fukui, N.; Ohmori, K.; Suzuki, K.; Helv. Chim. Acta 2012, 95, 2194.

91. Matsuo, Y.; Yoshida, A.; Saito, Y.; Tanaka. T.; Angew. Chem., Int. Ed. 2017, 5I6, 11855.
92. Ralifo, P.; Crews, P.; J. Org. Chem. 2004, 69, 9025.

93. Lia, C.; Danishefsky, S. J.; Tetrahedron Lett. 2006, 47, 385.

94. Chang, J. J.; Chan, B.; Ciufolini, M. A.; Tetrahedron Lett. 2006, 47,3599 .

95. Aberle, N.; Ovenden, S. P. B.; Lessene, G.; Watson, K. G.; Smith, B. J.; Tetrahedron Lett. 2007, 48, 2199.

96. White, K. N.; Amagata, T.; Oliver, A. G.; Tenney, K.; Wenzel, P. J.; Crews, P.; J. Org. Chem. 2008, 73, 8719.

97. Lamb, R. A.; Aberle, N. S.; Lucas, N. T.; Lessene, G.; Hawkins, B. C.; Angew. Chem., Int. Ed. 2017, 56, 14663.

98. Nicolaou, K. C.; Mathison, C. J. N.; Angew. Chem., Int. Ed. $\mathbf{2 0 0 5}, 44,5992$.

Submitted: October 30, 2017

Published online: February 20, 2018 